\title{
Continuous Synthesis of Doped Pyrochlore Materials by Spray Pyrolysis for Auto-thermal Reforming Applications
}

Jonathan Yancey

Follow this and additional works at: https://researchrepository.wvu.edu/etd

\section{Recommended Citation}

Yancey, Jonathan, "Continuous Synthesis of Doped Pyrochlore Materials by Spray Pyrolysis for Autothermal Reforming Applications" (2015). Graduate Theses, Dissertations, and Problem Reports. 6996. https://researchrepository.wvu.edu/etd/6996

This Thesis is protected by copyright and/or related rights. It has been brought to you by the The Research Repository @ WVU with permission from the rights-holder(s). You are free to use this Thesis in any way that is permitted by the copyright and related rights legislation that applies to your use. For other uses you must obtain permission from the rights-holder(s) directly, unless additional rights are indicated by a Creative Commons license in the record and/ or on the work itself. This Thesis has been accepted for inclusion in WVU Graduate Theses, Dissertations, and Problem Reports collection by an authorized administrator of The Research Repository @ WVU. For more information, please contact researchrepository@mail.wvu.edu. 


\title{
Continuous Synthesis of Doped Pyrochlore Materials by Spray Pyrolysis for Auto-thermal Reforming Applications
}

\author{
Jonathan Yancey
}

Thesis submitted to the Statler College of Engineering and Mineral Resources at West

Virginia University in partial fulfillment of the requirements for the degree of

\author{
Master of Science in \\ Mechanical Engineering
}

Edward M. Sabolsky, Ph.D, Chair

Kostas Sierros, Ph.D

Dushyant Shekhawat, Ph.D

John Zondlo, Ph.D

Department of Mechanical and Aerospace Engineering

Morgantown, West Virginia

2015

Keywords: Spray pyrolysis, pyrochlore, oxide, catalyst, reforming, synthesis

Copyright 2015 Jonathan Yancey 


\section{Abstract \\ Continuous Synthesis of Doped Pyrochlore Materials \\ by Spray Pyrolysis for Auto-thermal Reforming Applications}

Jonathan Yancey

The use of a spray-pyrolysis method is studied for the continuous synthesis of refractory oxide reforming catalyst for the conversion of hydrocarbon fuels to $\mathrm{H}_{2}$ and $\mathrm{CO}$ at $900^{\circ} \mathrm{C}$. Nickeland rhodium-doped zirconate pyrochlore materials with the formulas $\mathrm{La}_{1.89} \mathrm{Ni}_{2.81} \mathrm{Y}_{0.25} \mathrm{Ca}_{0.11} \mathrm{Zr}_{1.47}$ and $\mathrm{La}_{1.89} \mathrm{Rh}_{1.09} \mathrm{Y}_{0.25} \mathrm{Ca}_{0.11} \mathrm{Zr}_{1.641}$ were synthesized using the spray pyrolysis method. Both Pechini and glycine-nitrate precursor solutions were used in order to control the particle morphology, crystallinity, and surface area of the catalyst powder. Samples synthesized by the Pechini solution required post-synthesis heat treatment to $1000{ }^{\circ} \mathrm{C}$ for 2 hours to form the fullycrystalline pyrochlore phase. Both the $\mathrm{Ni}$ - and $\mathrm{Rh}$-doped compositions formed by the spraypyrolysis method performed as reported elsewhere for powder produced by solid-state and Pechini bulk methods. The use of the glycine-nitrate precursor solution in the spray-pyrolysis resulted in the formation of fully crystalline pyrochlore catalyst for the Ni-doped composition without any additional high temperature treatment. The Rh-doped catalysts synthesized from the glycine-nitrate precursor did not form a fully crystalline material directly from the spraypyrolysis process, but required a further thermal treatment to $800{ }^{\circ} \mathrm{C}$ for 8 hours to transform the powder and burn-off excess carbon remaining from the synthesis process. Rapid catalyst aging tests for the Rh-doped catalysts synthesized by spray-pyrolysis (using either the Pechini and glycine-nitrate precursor solutions) produced stable and active catalysts achieving equilibrium hydrogen yield of $90 \%$ for 15 hours. To conclude, the work showed that through proper chemical design of the precursor system, a high surface area, chemically active, and stable zirconate pyrochlore catalyst could be synthesized efficiently by the spray-pyrolysis method developed. 


\section{Acknowledgements}

This work would not have been possible without the support and guidance of my advisor Dr. Edward M. Sabolsky. The lab skills I have developed under his tutelage during the last 5 years are invaluable, and I thank him for his patience in completing this work. I would also like to thank Dr. Dushyant Shekhawat at NETL for his advice and making equipment available for my use, without which my thesis would not yet be complete. Kathy Sabolsky has been of great help for all my years spent as both an undergraduate and graduate researcher. I am grateful to Dr. Mark Smith for his time, help and friendship. Donald Floyd was of great help in characterization of my samples, and without his work with the reforming reactors I would not be able to complete this work. I would also like to thank Dave Berry, Dan Haynes, and Dr. Devendra Pakhare for their advice and time during the project. The support of my mother Terri Yancey is essential to any of my successes, and the encouragement from my brother Jeffrey Yancey has been important in all of my endeavors. Without the "unique" problem solving skills imparted in me by my father Brent Yancey and grandfather Gerald Yancey I would have never found interest in engineering. 


\section{Table of Contents}

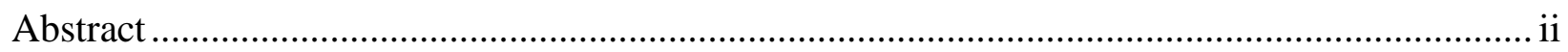

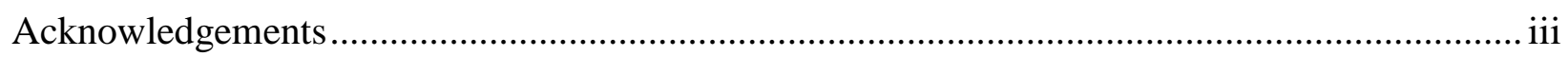

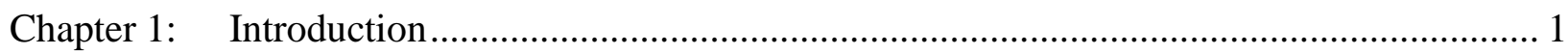

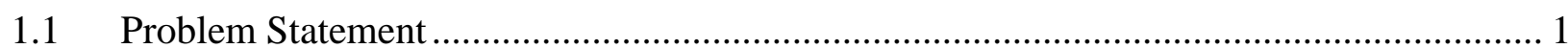

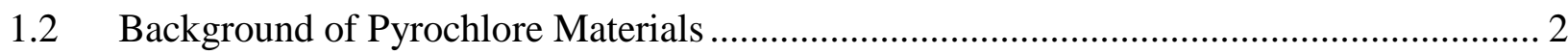

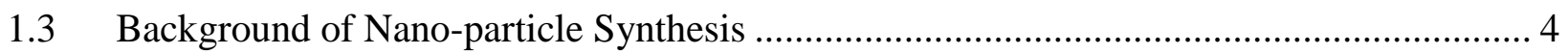

1.3.1 Solid-state Synthesis and Attrition milling .............................................................. 4

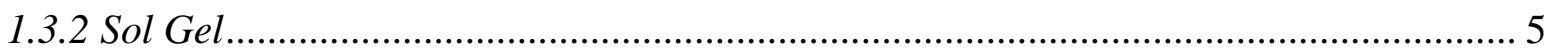

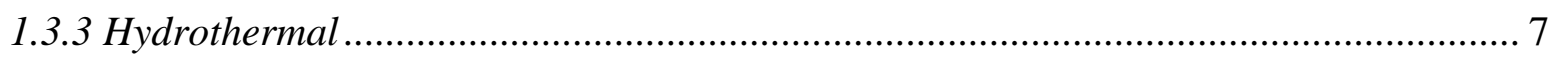

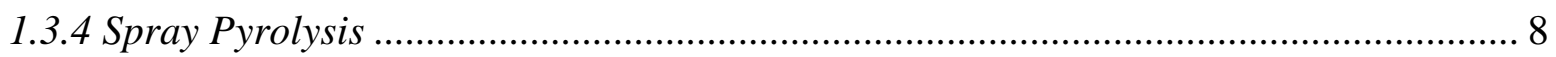

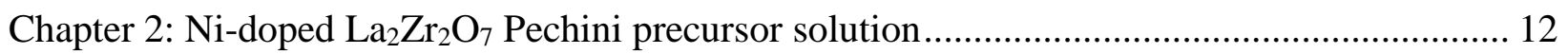

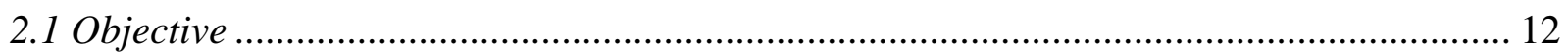

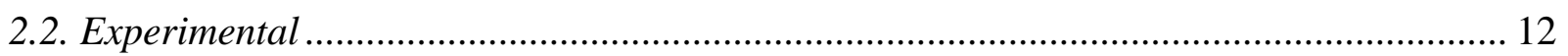

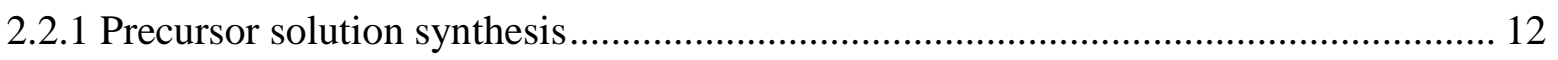

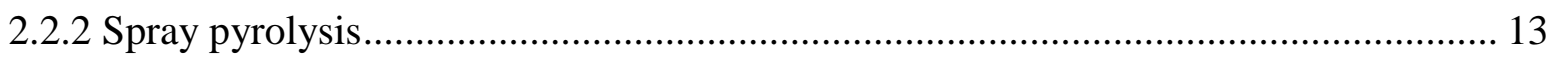

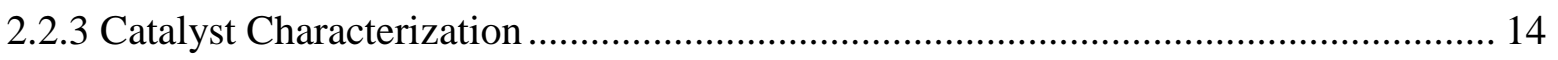

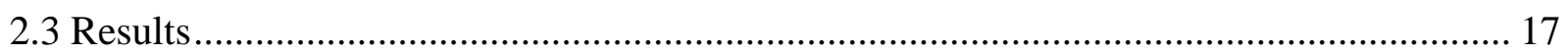

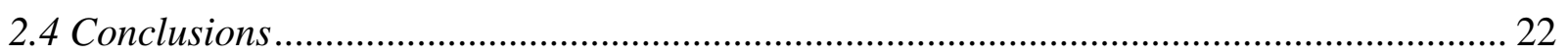

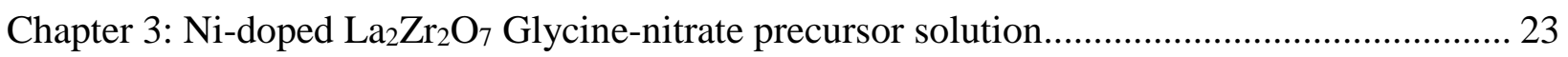

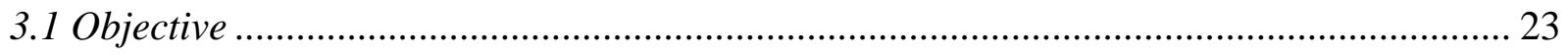

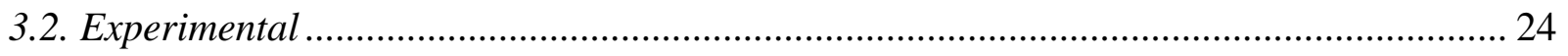

3.2.1 Precursor solution synthesis ................................................................................. 24

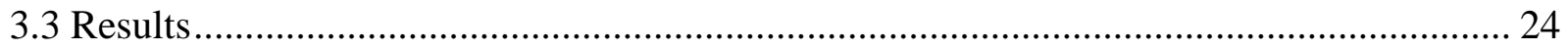

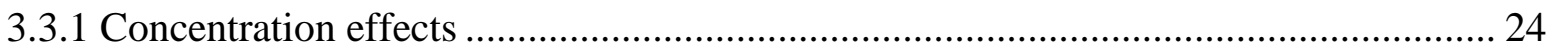

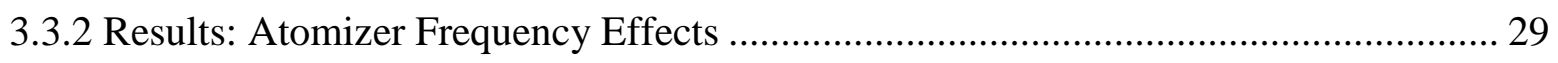

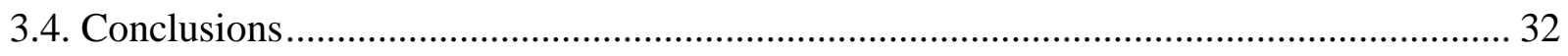

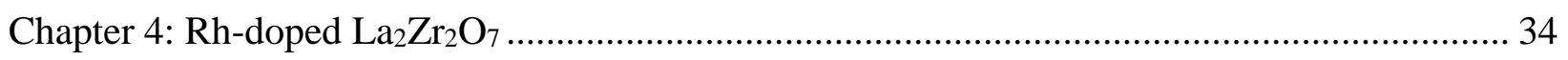

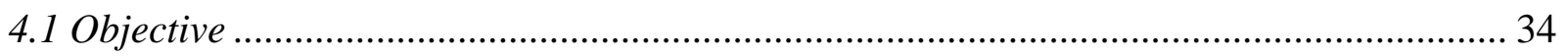

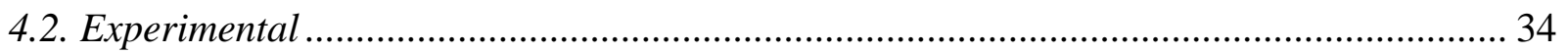

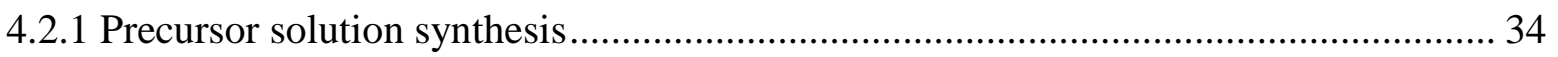

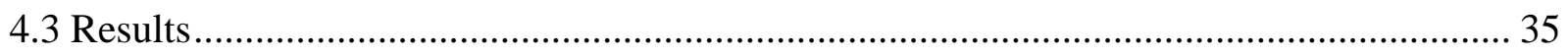

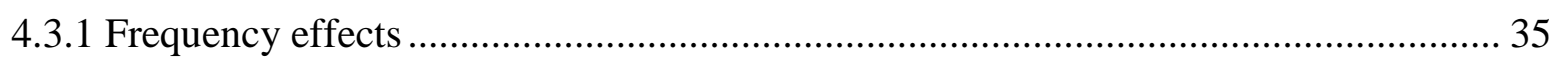

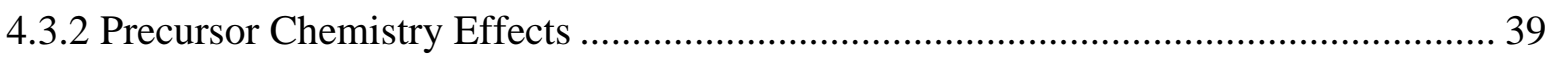




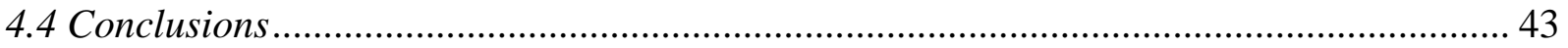

Chapter 5: High Frequency Atomization ......................................................................... 45

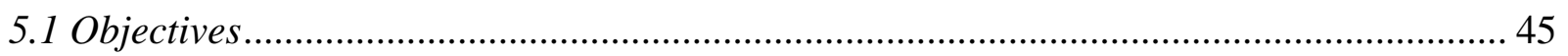

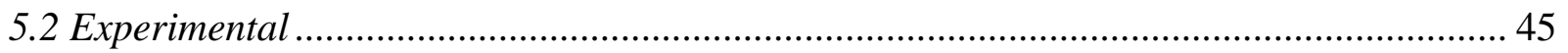

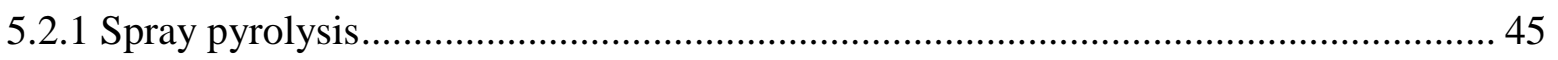

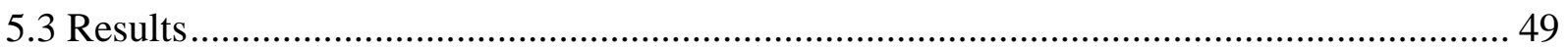

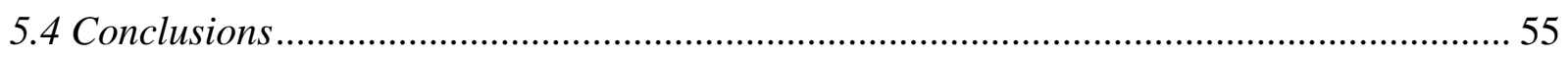

Chapter 6: Conclusions and Recommendations for Future Study ......................................... 57

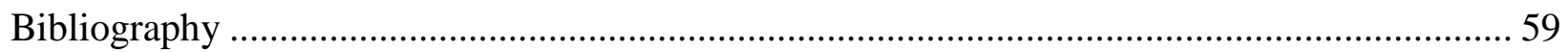

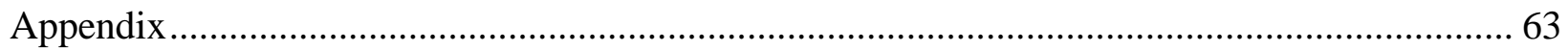




\section{Chapter 1: Introduction}

\subsection{Problem Statement}

The technology to produce a range of metal oxide powders has been developed over the past few decades, however most work primarily aims to make binary oxide powders. Spray pyrolysis is a method of forming materials that is widely used to economically produce relatively large quantities of macro- and nano-particles for use in research and industry. During spray pyrolysis a mist of precursor droplets are introduced to a heated reactor where they dry and combust to form a powder. Drying, gelation, nucleation, solid-state reactions, sintering, and grain growth all occur within the spray pyrolysis reactor. Each step is affected by processing and precursor parameters, such as reactor temperature and solution chemistry, which in turn affect the material properties. Spray pyrolysis has yet to be utilized to reliably synthesize compounds with complex structures and morphologies, and studies on producing multi-component oxides are just now beginning to emerge in the literature. Before this technology can be utilized industrially to produce said materials, the relationships among process variables, solution chemistry, and material properties need to be characterized. The current study aims to produce a highly active $\mathrm{La}_{2} \mathrm{Zr}_{2} \mathrm{O}_{7}$ pyrochlore catalyst. Rhodium-doped pyrochlore catalysts were extensively studied recently ${ }^{1-6}$ due to their favorable properties for auto-thermal reforming of hydrocarbon fuels such as proton conduction, thermal stability and chemical stability ${ }^{7,8}$. These materials were produced using a batch sol-gel method, but to produce catalysts on a commercial scale, a continuous and reproducible synthesis method is desired.

The objective of this study is to characterize spray pyrolysis processing variables and observe effects on the physical and chemical properties of the catalyst. Process variables will 
then be manipulated to control the morphology and characteristics of catalyst particles. At the same time the effect of catalyst morphology and chemistry upon performance will be analyzed. The results from the analysis will be used to synthesize catalysts with the highest performance possible given the limitations of the system and the reactivity of the catalyst chemistry. Once the physical characteristics of the catalyst and the system dynamics have been defined, the maximum production rate of the unit and recommendations for scale-up of the process will be determined.

\subsection{Background of Pyrochlore Materials}

The pyrochlore crystal structure, show in Figure 1.2.1, is closely related to the prominent perovskite and fluorite structures that are widely studied in the field of ceramic materials. The specific space group for this structure is $\mathrm{Fd} 3 \mathrm{~m}$. The general chemical formula for a pyrochlore oxide is abbreviated by $\mathrm{A}_{2} \mathrm{~B}_{2} \mathrm{O}_{7}$, where $\mathrm{A}$ and $\mathrm{B}$ typically represent rare-earth elements and transition metals, respectively. There is a broad range of trivalent and tetravalent cations that can form the pyrochlore structure to yield a variety of material properties including oxygen conduction $^{9-11}$, ion conduction ${ }^{12-14}$, and electronic conduction ${ }^{15-17}$. These properties can be further enhanced by doping the structure with other cations to manipulate the crystal lattice. However, to form a stable pyrochlore at atmospheric pressure with the cations $\mathrm{A}=3^{+}$and $\mathrm{B}=4^{+}$, the ionic radius ratio $r_{r}=r_{A} / r_{B}$ must be between the values of 1.4 and $1.8^{7-9}$. 


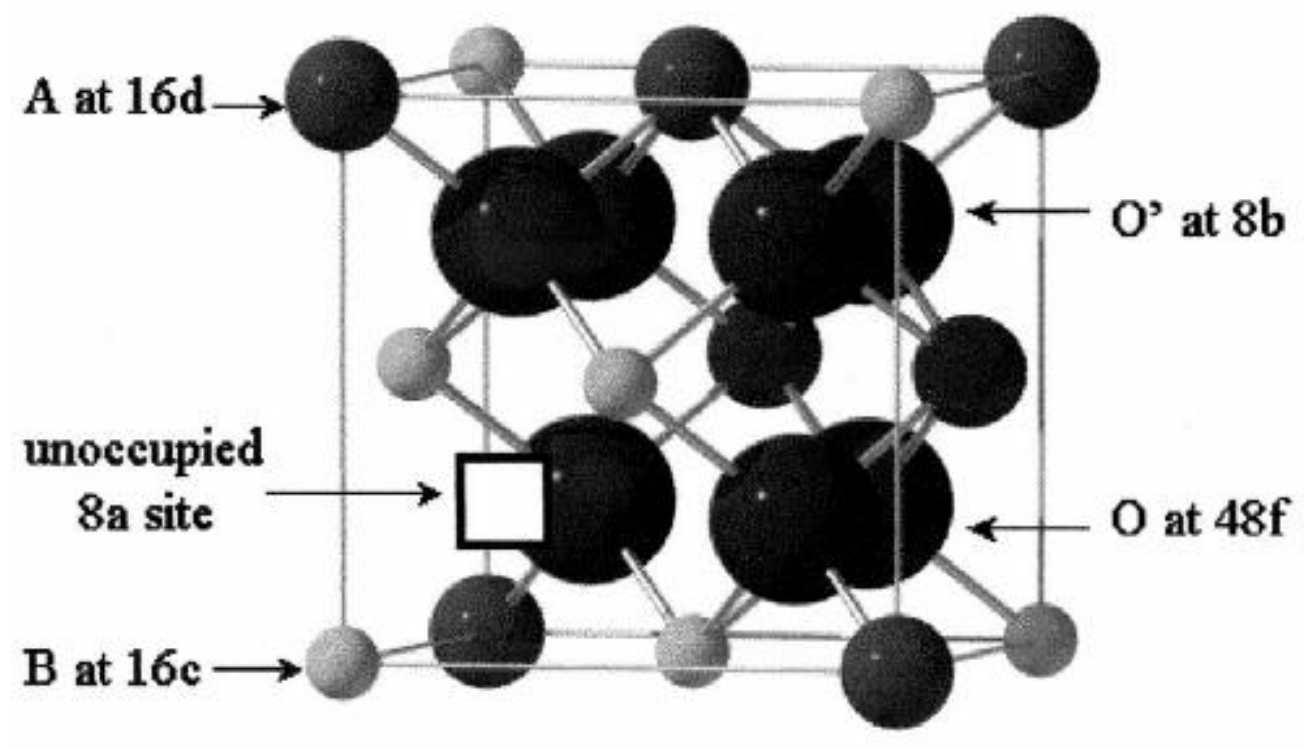

Figure 1.2.1: Partial unit cell of $\mathrm{A}_{2} \mathrm{~B}_{2} \mathrm{O}_{7}$ pyrochlore ${ }^{18}$

Among the properties inherent to the pyrochlore materials, proton conductance is crucial to high performing reforming catalysts. The pyrochlore structure is a suitable material for this application because the conductive properties can be manipulated readily, and it is both thermally and chemically stable at the conditions in which the reforming catalyst operates: typically 20 psig and $900{ }^{\circ} \mathrm{C}$. Among materials with the pyrochlore structure, lanthanum zirconate (LZ) is an apt candidate for high-temperature catalyst applications. LZ forms the facecentered cubic pyrochlore crystal structure, and is thermally stable up to its melting point of $2300^{\circ}$ C. $^{19}$ As is common among fluorite and pyrochlore structured materials, LZ exhibits mobility of oxygen vacancies at high temperatures, is commonly used as a thermal barrier coating due to its high thermal stability and low thermal conductivity. ${ }^{8}$ 


\subsection{Background of Nano-particle Synthesis}

\subsubsection{Solid-state Synthesis and Attrition milling}

One of the most common methods to synthesize refractory oxide materials is through solid-state synthesis process. In solid-state synthesis, the stoichiometric amounts of carbonates, hydroxide or oxide powders are milled until evenly mixed at the desired particle size. The resultant powder is dried and heated to very high temperatures for hours until the desired phase is formed through solid-state diffusion and reaction. The particle size yielded by this process is macroscopic, so attrition milling is commonly used to reduce particles to a desired size. Attrition milling of particles has been widely used in material science to reduce the size of particles for many years. In attrition milling, particle size is reduced by impact with an inert media over varied periods of time. Attrition milling can also change the shape of particles or even increase particle size. However reduction in particle size is the most common goal of a milling process. Attrition milling is effective in producing nano-powders when milled for long periods of time. Particle sizes of $<100 \mathrm{~nm}$ have been reported for $\mathrm{ZrO}_{2}$ and $\mathrm{TiO}_{2}$ milled for 24 hours. Kintaka et al. ${ }^{20}$ found that lanthanum zirconate produced by the solid-state method yield grain sizes of 10 $\mu \mathrm{m}$. However, Jarligo et al. $^{21}$ synthesized crystalline lanthanum zirconate by ball-milling precursor powders in ethanol for 9 hours and calcining to $1500{ }^{\circ} \mathrm{C}$ for $1 \mathrm{~h}$., but the long milling time resulted in larger particle sizes. When milled less than 9 hours, secondary phases were formed. Although solid-state synthesis is a relatively simple and economical method, there is little control over the physical and chemical structure of the particles, and long dwell times at elevated temperatures as high as $1700{ }^{\circ} \mathrm{C}^{22}$ are needed. Solid-state synthesis is not a suitable method for the production of homogenous complex oxide materials with a morphology tailored for high performance. 


\subsubsection{Sol Gel}

Sol gel synthesis is a prevalent method of producing inorganic nanoparticles, primarily metal oxides. A sol is a liquid dispersion of colloidal particles with diameters which range from 1 to $100 \mathrm{~nm}$. The sol is formed by mixing the constituent colloidal particles in water at modified $\mathrm{pH}$ which prevents precipitation. The sol is then transferred to a mold in a desired shape. The mold is typically made of a ceramic that inhibits gel adhesion, such as dense alumina. A rigid network of long polymer chains with pores and sub-micron dimensions is formed as solvent evaporates, and is the network is referred to as a gel. The physical characteristics are strongly dependent on the degree of cross-linking achieved before gelation and upon the particle size. As the solvent is removed from the system densification of the gel network occurs. Capillary stress can cause cracking if the gel was not aged sufficiently. The gel is then heated to high temperature, causing pore collapse and densification.

The sol-gel method forms very well mixed precursors and results in homogenous materials, even when introducing many dopants. The sol-gel method also does not require the very high reaction temperatures such as that used for the solid-state synthesis method. Sathyamurthy et al. ${ }^{23}$ produced LZ by a sol-gel process, and after heat treating to $1100^{\circ} \mathrm{C}$ a highly crystalline, dense material was formed. Crystalline LZ in the pyrochlore phase has been synthesized using a sol-gel method at temperatures as low as $800^{\circ} \mathrm{C}$ and a hold time of 1 hour. ${ }^{24}$ Although many groups ${ }^{7,19,25,26}$ have prepared dense thermal barrier coatings of LZ using the solgel method, catalyst materials benefit from less dense morphologies due to the higher surface

area and access to active sites. To that effect, Kitaoka et al. ${ }^{27}$ synthesized lanthanum zirconium titanate via the sol-gel method and found that rapid heating during the calcination step yields higher porosity. 
One synthesis method that rapidly increases the temperature resulting in increased porosity is the Pechini method. The Pechini method is a modified sol-gel method that utilizes carboxylic acids to form metal chelate compounds ${ }^{28}$. When the solution is heated in the presence of a poly-hydroxyl alcohol, such as ethylene glycol, the chelates undergo a poly-esterification that disperses the metal chelates evenly through the solution, as illustrated by Figure 1.3.2.1.

\section{Chelation}

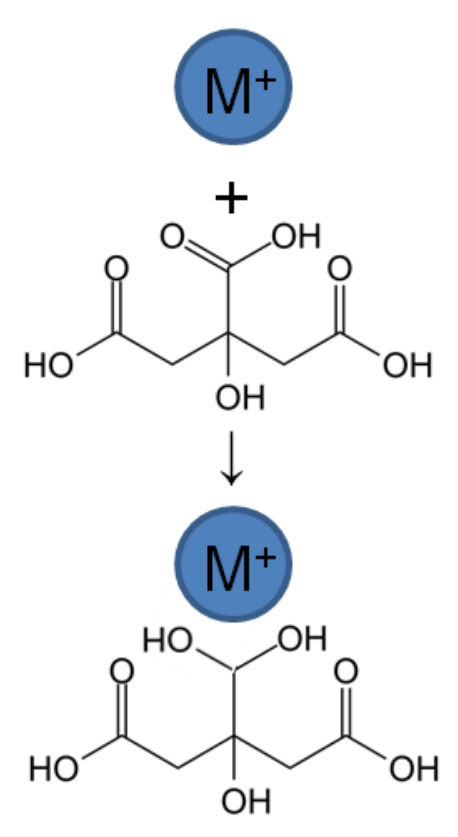

\section{Polymerization}

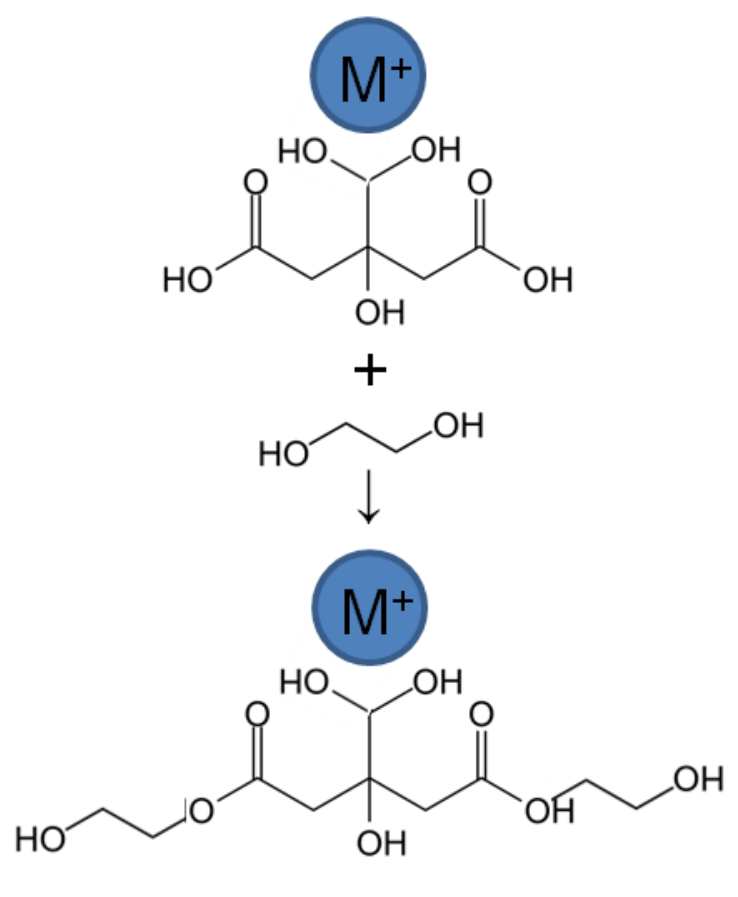

Figure 1.3.2.1: Pechini chelation and polymerization reaction paths

The polymeric gel is dried and then calcined similarly to the traditional sol-gel method and the resultant particles have small particle size with high chemical homogeneity ${ }^{29}$. Qiu et al. ${ }^{30}$ found that Pechini prepared powders displayed higher crystallinity than powders prepared by the standard sol-gel method. The Pechini method has been reported in the literature by Nair et al. ${ }^{31}$ to produce lanthanum zirconate particles with surface areas higher than that of particles produced by sol-gel and hydrolysis methods. The Pechini method provides several additional variables that 
can be manipulated to yield the desired particle morphology. Farhikhteh et al. ${ }^{8}$, and Thanguruju et $a .^{32}$ reported that the $\mathrm{pH}$ of the precursor solution can strongly effect the morphology and surface area of particles. Chen et al. ${ }^{33}$ found the shape of porous particles can be controlled by adjusting the ratio of solvents in the precursor solution. The sol-gel method provides extensive control over the stoichiometry and structure due to the even dispersion of precursor metals. However, the sol gel method requires several steps that would not scale easily or economically, such as sintering and casting processes. Thus a method which incorporates the even molecular dispersion of the sol-gel method but utilizes a more continuous heating process is desirable.

\subsubsection{Hydrothermal}

Hydrothermal synthesis refers to the synthesis of crystallites from aqueous solution at high temperature and pressure. Although several methods of producing material hydrothermally exist, the most frequently cited method utilizes a temperature gradient to supersaturate the solution and facilitate precipitation of crystals. Solvent is evaporated in the hot region of the vessel, causing convection currents that dissolve any solids remaining elsewhere ending in a fully saturated solution. As the super-saturated solution interacts with the cooler surface of the vessel, crystals form. The growth of the crystals depends primarily upon the solubility limit of the metal salts, but the temperature and pressure also have significant effects upon crystal characteristics. The product is usually calcined to high temperature to form the desired phase. zirconate pyrochlores have been synthesized hydrothermally by Wang et al. ${ }^{34}$. The solution was heated in the hydrothermal reactor for 24 hours, and post calcined at $1200{ }^{\circ} \mathrm{C}$ for 2 hours. Increasing the hydrothermal treatment temperature resulted in more crystalline zirconates with fewer defects in the material structure. Although the hydrothermal method can require more time 
than the solid-state synthesis, doping the crystal structure is much easier to achieve. Sardar et al. ${ }^{35}$ formed bismuth-doped nano-ceria, and found that the hydrothermal synthesis method incorporated more dopant into the lattice than other methods. Hydrothermal synthesis is favorable to a large-scale process due to the very limited number of steps required to form the product, however each step requires significant dwell time and the process is constrained to a batch method. Zeng et al. ${ }^{36}$ synthesized $\mathrm{La}_{2} \mathrm{Sn}_{2} \mathrm{O}_{7}$ pyrochlore using a hydrothermal method. They reported that 18 hours at $200{ }^{\circ} \mathrm{C}$ produced crystalline pyrochlore after calcination. Weng et al. ${ }^{37}$ synthesized nano-ceria using a continuous system. However, they found deviations in stoichiometry that were attributed to differences in precursor kinetics and varied residence time. Deviations in stoichiometry, long processing steps, and the difficulty in modifying an autoclave to incorporate a continuous process, detract from the viability of the hydrothermal method as a high-yield continuous synthesis process.

\subsubsection{Spray Pyrolysis}

Spray pyrolysis is a method that produces metal oxide powders from precursor liquid that is fed into a heated reactor in a gas or dispersion of droplets. The precursor can be composed of aqueous solutions, colloidal dispersions, emulsions, sols and aerosols. The precursor chemistry and characteristics strongly affect the particles characteristics and morphology. The steps in particle formation by spray pyrolysis are shown in Figure 1.3.4.1. The resonant frequency and precursor solution viscosity of the atomizer affect the droplet size and velocity. Higher frequency results in smaller particle size and longer residence time in the reactor. The fluid viscosity and surface tension can be adjusted by changing the amount of solvent which changes the morphology of the nanoparticles produced. After atomization, the droplets begin to undergo 
evaporation. During this phase, solvent evaporates and diffuses from the surface, the droplet shrinks, solutes diffuse throughout the droplet, and the temperature changes. Among these processes, vapor diffusion and temperature change occur the most rapidly ${ }^{38}$. A high droplet velocity can cause evaporation to occur more rapidly resulting in higher solute concentration at the surface. As the solute concentration increases precipitation occurs at the surface of the droplet. Slow evaporation steps can cause precipitation and chemical segregation leading to secondary phase formation as reported by Tohge et al. ${ }^{39}$. Therefore it is crucial to limit solute diffusion or accelerate evaporation when synthesizing multi-component materials. After precipitation the droplet enters the drying stage. The solvent evaporation rate is slowed due to the presence of solids and reduction in surface area available for diffusion. The process continues until particle reaches several hundred degrees, at which point organic compounds in the precursor undergo pyrolysis and the enthalpy of reaction further affects the particle temperature. The temperature reached during pyrolysis is typically insufficient to form the desired material, so particles are heated externally to high temperature. The particles calcined and sintered by the high temperatures and collected at the reactor exit, typically using an electrostatic precipitator or bag-house in larger-scale processes. Aqueous nitrate salts were used by Jang et al. ${ }^{40}$ to produce hollow spherical nano-ceria with thin walls. However the particles were amorphous and required calcination which caused growth of the grains to sizes of $10 \mu \mathrm{m}$. To fully calcine materials during SP, significant heated length or inclusion of highly combustible phases are required. One variation of SP that forms fully calcined powders by enhancing combustion is flame spray pyrolysis (FSP). 


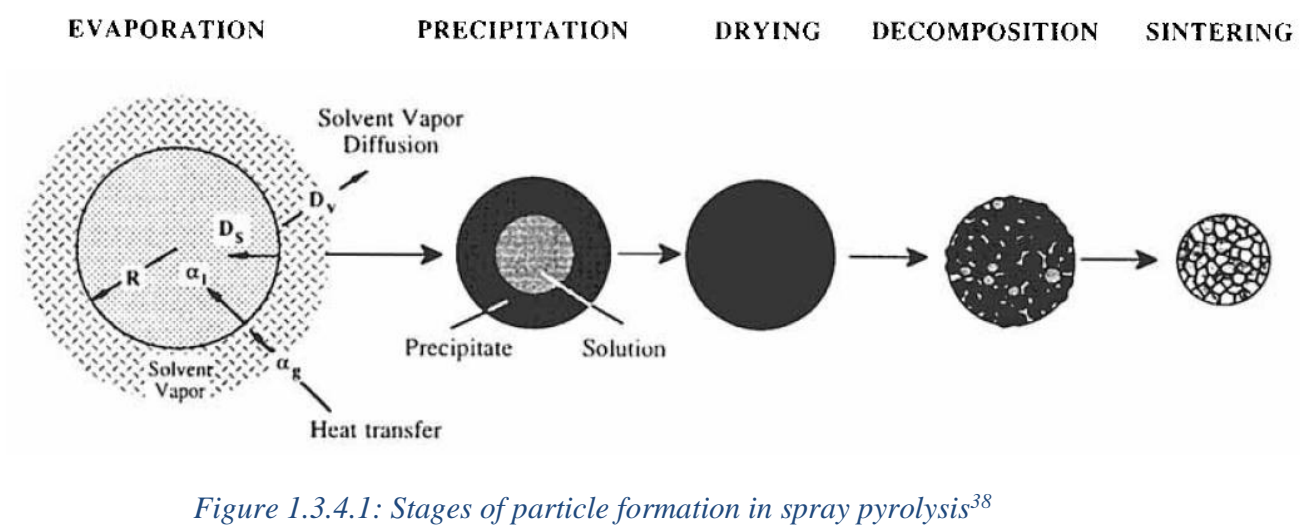

Flame spray pyrolysis is a variation of spray pyrolysis that adds fuel to the precursor and uses oxygen or another oxidizer as the carrier gas. The precursor is combined with the fuel in a 2-fluid atomizer, rather than using an ultrasonic nebulizer and ignited with the oxygen stream to produce an intense flame that calcines the droplets produced by the atomizer. FSP has been used extensively to produce simple oxide powders such as $\mathrm{SiO}_{2}{ }^{41}, \mathrm{ZnO}^{42}, \mathrm{Bi}_{2} \mathrm{O}_{3}{ }^{43}$, and $\mathrm{TiO}_{2}{ }^{44}$. More complex metal oxides such as Mn-doped zinc silicate ${ }^{45}$ have been produce as well, however significant fluctuation in particle morphology and chemistry was observed due to the variation of flame temperature seen by each particle. Although flame spray pyrolysis efficiently produces a highly-crystalline powder, conventional spray pyrolysis allows for more control of particle characteristics and is more suitable for multi-component oxides such as LZ.

Conventional spray pyrolysis provides several concurrent methods of controlling morphology and chemistry of the produced particles by manipulating the variables of the system. Since spray pyrolysis can utilize several precursor solutions, including sols, it offers the capability to alter many aspects of the solution chemistry and the physical atomization process to control the morphology and size of the particles, as well as influence the evaporation and pyrolysis steps. Lee et al. ${ }^{46}$ compared the properties of Mn-doped $\mathrm{ZnSiO}_{4}$ particles produced by aqueous and Pechini precursor solutions, and found that the particles produced by the Pechini 
precursor had higher crystallinity, surface area, and smaller grain size. By using a Pechini solution as a precursor, Jiang ${ }^{47}$ et al. produced crystalline $\mathrm{La}_{2} \mathrm{Zr}_{2} \mathrm{O}_{7}$ particles with grains as small as $10 \mathrm{~nm}$. The polymerization of the precursor solution that occurs during the Pechini method limits the diffusion of solutes through the particle during SP, which is highly beneficial for synthesis of multi-component oxides. However, very few materials with complex chemistries have been produced using this process. Spray pyrolysis is most frequently used in the production of transition metal-oxides with little or no dopants ${ }^{48,49,50}$, however recent work has started synthesizing doped $\mathrm{ZnSiO}_{4}, \mathrm{ZnO}, \mathrm{SnO}_{2}$, and $\mathrm{CeO}_{2}$ materials using this process ${ }^{45,51-53}$. Because the process is continuous and occurs entirely within the reactor, spray pyrolysis is a very scalable process and allows control over the product materials properties. Spray pyrolysis was chosen as the method of particle production in this work because it is the most promising method of producing homogenous, multi-component oxides with the desired material properties. 


\section{Chapter 2: Ni-doped $\mathrm{La}_{2} \mathrm{Zr}_{2} \mathrm{O}_{7}$ Pechini precursor solution}

\subsection{Objective}

The objective of the initial work was to prepare Ni-doped LZ using the Pechini precursor and spray pyrolysis exhibiting properties consistent with compositions prepared by the batch process. Although characterization of $\mathrm{Rh}$ - and $\mathrm{Ni}$ - doped $\mathrm{LZ}$ prepared by the Pechini method has been reported previously in the literature ${ }^{1,5,6,54,55}$, catalysts were also prepared by the batch method in this work to minimize extraneous variables.

\subsection{Experimental}

All experiments were conducted using the following procedures unless otherwise noted.

\subsubsection{Precursor solution synthesis}

Nitrate hydrates $\mathrm{La}\left(\mathrm{NO}_{3}\right)_{3} \bullet 6 \mathrm{H}_{2} \mathrm{O}, \mathrm{ZrO}\left(\mathrm{NO}_{3}\right)_{2} \bullet \mathrm{xH}_{2} \mathrm{O}, \mathrm{Ni}\left(\mathrm{NO}_{3}\right)_{2} \bullet \times \mathrm{H}_{2} \mathrm{O}, \mathrm{Y}\left(\mathrm{NO}_{3}\right)_{3} \bullet 6 \mathrm{H}_{2} \mathrm{O}$, and $\mathrm{Ca}\left(\mathrm{NO}_{3}\right)_{2} \bullet 4 \mathrm{H}_{2} \mathrm{O}$ (Alfa Aesar) along with $\mathrm{RhCl}_{3}$ were used as precursors for the Pechini and glycine-nitrate solutions. The metal salts were weighed to achieve the desired atomic ratio for the catalyst compositions $\left(\mathrm{La}_{1.89} \mathrm{Ni}_{2.81} \mathrm{Y}_{0.25} \mathrm{Ca}_{0.11} \mathrm{Zr}_{1.47}\right)$, and dissolved in deionized water (DI). In the case of the Pechini precursor solution, citric acid (CA) was added to chelate the dissolved salts in a 1:1.2 molar ratio of metal salts to CA. The solution was stirred and heated to $60^{\circ} \mathrm{C}$ for several hours before adding ethylene glycol (EG) at a 1:1 ratio of CA:EG to distribute the metal complexes into solution. The solution was stirred on a hot plate to evaporate excess water from solution until the solution concentrations reached the desired molarities of $0.18,0.36,0.72$, and 1.44 molar. For comparison, some catalyst was prepared by a batch method. The desired volume of precursor solution was placed into an alumina crucible and heated to $600{ }^{\circ} \mathrm{C}$ for 8 hours, and 
then calcined at $1000{ }^{\circ} \mathrm{C}$ for 2 hours. The ramp rate for all heating operations was set to $3{ }^{\circ} \mathrm{C} / \mathrm{min}$ on ramp-up and $5^{\circ} \mathrm{C} / \mathrm{min}$ on ramp-down.

\subsubsection{Spray pyrolysis}

A schematic of the vertical spray pyrolysis reactor system for this work is presented in Figure 2.2.2.1. The precursor solution was loaded into the syringe pump (1), and fed at $200 \mathrm{~mL} / \mathrm{h}$ to the atomizing nozzle (2: Sonaer, WS60K50S316 and WS130K50S316) that produces a mist of particles. A laminar flow of compressed air (60 SCFH) was formed using a disc of porous alumina fit around the tip of the nozzle to carry the particles down the reactor. Stoke's law and space velocity calculations estimate a residence time of 10 seconds inside the reactor. The reactor is comprised of a quartz tube 1.5 meters in length and an inner diameter of $72 \mathrm{~mm}$. The particles flow through three heating zones $1 \mathrm{ft}$ in length (5) set to $600{ }^{\circ} \mathrm{C}, 800{ }^{\circ} \mathrm{C}$, and $900{ }^{\circ} \mathrm{C}$ respectively. The resultant powder was collected by a filter (3) and a DI water bubbler (4). Samples synthesized by the Pechini method were calcined to $1000{ }^{\circ} \mathrm{C}$ for 2 hours prior to temperature programmed reduction (TPR) and rapid aging testing (RAT). 


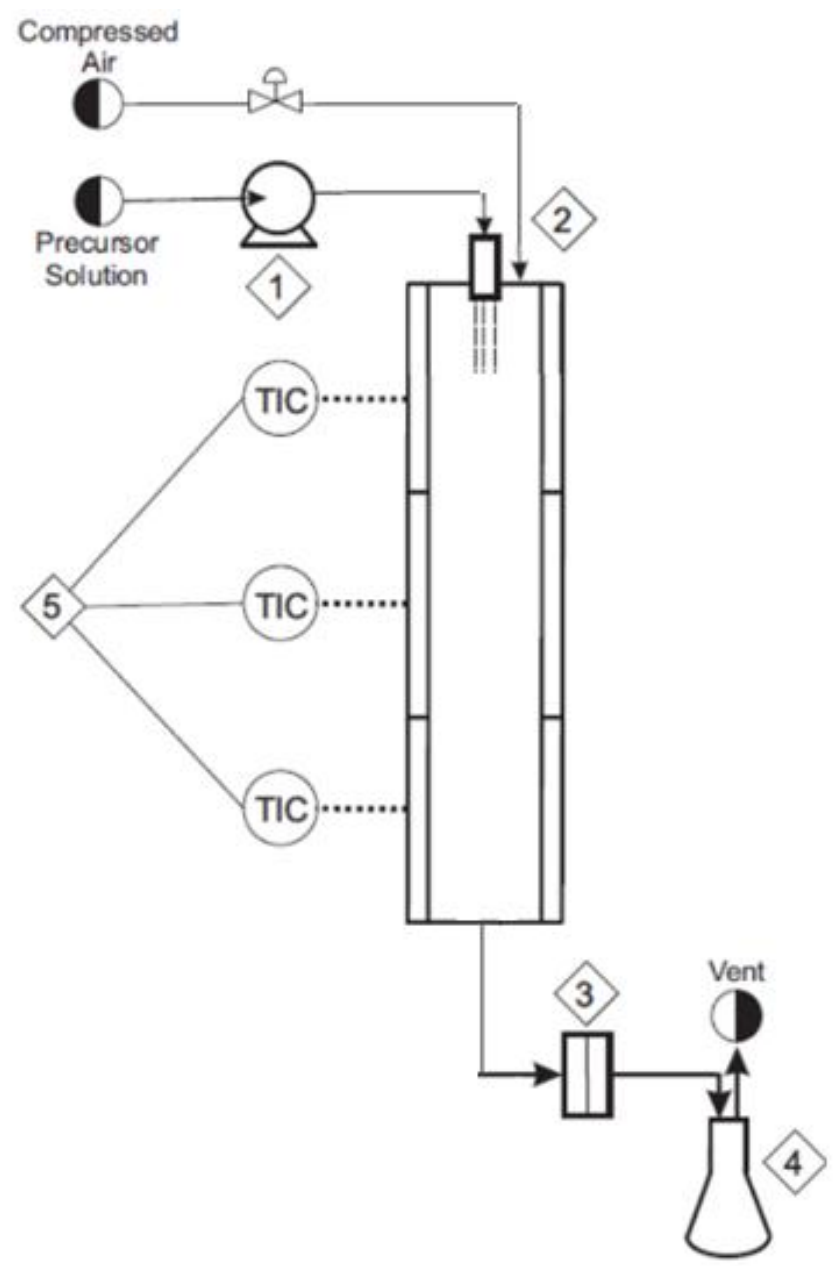

Figure 2.2.2.1: Spray pyrolysis experimental configuration.

\subsubsection{Catalyst Characterization}

\section{X-ray Diffraction}

Phase characterization of the prepared powder samples was performed using a PANalytical X'Pert Pro X-ray Diffractometer. The device used $\mathrm{Cu} \mathrm{K} \alpha$ radiation at a wavelength of $(\AA)$ 1.54184. Operation of the diffractometer was performed using $45 \mathrm{kV}$ and $40 \mathrm{~mA}$. Divergence slit angle was set to 1 . The $2 \Theta$ scanning range was $20^{\circ}$ to $80^{\circ}$ with a step size of 0.05 ${ }^{\circ}$. The same scan program was used for each sample, and a silicon standard was analyzed before each scanning in order to correct for any possible position error. Peak identification and full- 
width-half-maximum (FWHM) calculations were performed using Origin 8.0 software by the $2^{\text {nd }}$ derivative method.

\section{BET Surface Area}

Before BET analysis, all spray pyrolysis powders were loaded into quartz tubes and heated to $300^{\circ} \mathrm{C}$ at $5 \mathrm{mTorr}$ using a Micromeritics VacPrep 061 to remove adsorbed species from the surface of the particles. The sample surface area was measured using a Micromeritics ASAP 2020 Surface Area Analyzer. The unit contains two dewar flasks filled with liquid nitrogen in which the sample is immersed during measurement and a single sample port. A 5-point analysis

of $\left(\frac{\mathrm{P}}{\mathrm{P}_{\mathrm{o}}}\right)$ versus the volume of nitrogen adsorbed by the sample was conducted for each sample, and the unit was periodically calibrated using fine $\mathrm{Al}_{2} \mathrm{O}_{3}$ powder with a known surface area of $8.6 \mathrm{~m}^{2} / \mathrm{g}$.

\section{Temperature Programmed Reduction (TPR)}

Temperature programmed reduction was conducted using a Micromeritics Autochem 2910 unit. Approximately $0.2 \mathrm{~g}$ of each sample was loaded in a quartz tube, loosely packed on a bed of quartz wool. Concentration changes in the gas stream were determined using the gas conductivity data, which provided two thermal conductivity detectors exposed to the inlet and effluent gas streams. The sample was first heated in inert atmosphere to vaporize any contaminants remaining from the synthesis process, and then heated to $900^{\circ} \mathrm{C}$ at $10^{\circ} \mathrm{C} / \mathrm{min}$ in 30 SCCM of $5 \% \mathrm{H}_{2} / \mathrm{Ar}$. The sample was then cooled under argon to $50^{\circ} \mathrm{C}$ at $10{ }^{\circ} \mathrm{C} / \mathrm{min}$, and then 
heated to $600{ }^{\circ} \mathrm{C}$ under $30 \mathrm{SCCM}$ of $21 \% \mathrm{O}_{2} / \mathrm{N}_{2}$ at a ramp rate of $10{ }^{\circ} \mathrm{C} / \mathrm{min}$. The reduction and oxidation steps were repeated for the desired number of cycles, and the sample was returned to ambient temperature in argon. Peak identification was conducted using Originpro 8.0 software by the $2^{\text {nd }}$ derivative method.

\section{Scanning Electron Microscopy}

Scanning electron microscopy (SEM) microstructure analysis was performed in a JEOL JSM-7600F Scanning Electron Microscope. Powder samples were prepared by adhering to carbon tape secured to a sample stage. A $30 \mathrm{~nm}$ coating of $\mathrm{Au} / \mathrm{Pd}$ was applied to the samples using a Denton Desk V Sputter station to prevent charging and edge effects during analysis. The sample holder was then placed in a vacuum chamber overnight prior to the SEM session to degas the samples in order to reduce the time required to evacuate the main chamber. The electron beam accelerating voltage used in analysis was $5.0 \mathrm{kV}$, the detection mode was $\mathrm{SEI}$, and the working distance was in the range of 6-7 $\mathrm{mm}$. Size estimation of objects observed by SEM was conducted using the ruler tool in the software provided with the JSM-7600F.

\section{Rapid Aging Testing}

To simulate extended reaction during a reforming reaction, a reforming experiment with conditions known to deactivate the catalyst was performed. The rapid aging test was performed using commercial diesel fuel in a packed stainless steel reactor at $900{ }^{\circ} \mathrm{C}$ and a pressure of 20 PSIG. The layout of the system used is illustrated in Figure 2.2.3.1. Samples were pressed into fine pellets and sieved using a $-20 /+60$ mesh to prevent pressure buildup in the reactor, and loaded in the center of the reactor between two layers of inert quartz particles to ensure consistent temperature between experiments. The oxygen-to-carbon ratio was maintained at 1.15 
for all rapid aging testing experiments to simulate highly deactivating reaction conditions. Experiments were conducted for 16 hours. Results were plotted with $\% \mathrm{H}_{2}$ yield on the y-axis and reaction time on the x-axis. Equilibrium hydrogen yield was calculated by Equation 2.2.3.1.

$$
\% H_{2}=\frac{\text { Moles of } \mathrm{H}_{2} \text { produced }}{N * \text { Moles fuel fed to reactor } * E}(\text { Eq. 2.2.3.1) }
$$

Where $\mathrm{N}$ represents the moles of $\mathrm{H}_{2}$ per mole of fuel and $\mathrm{E}$ represents the maximum possible yield of the reaction $(90 \%)$.

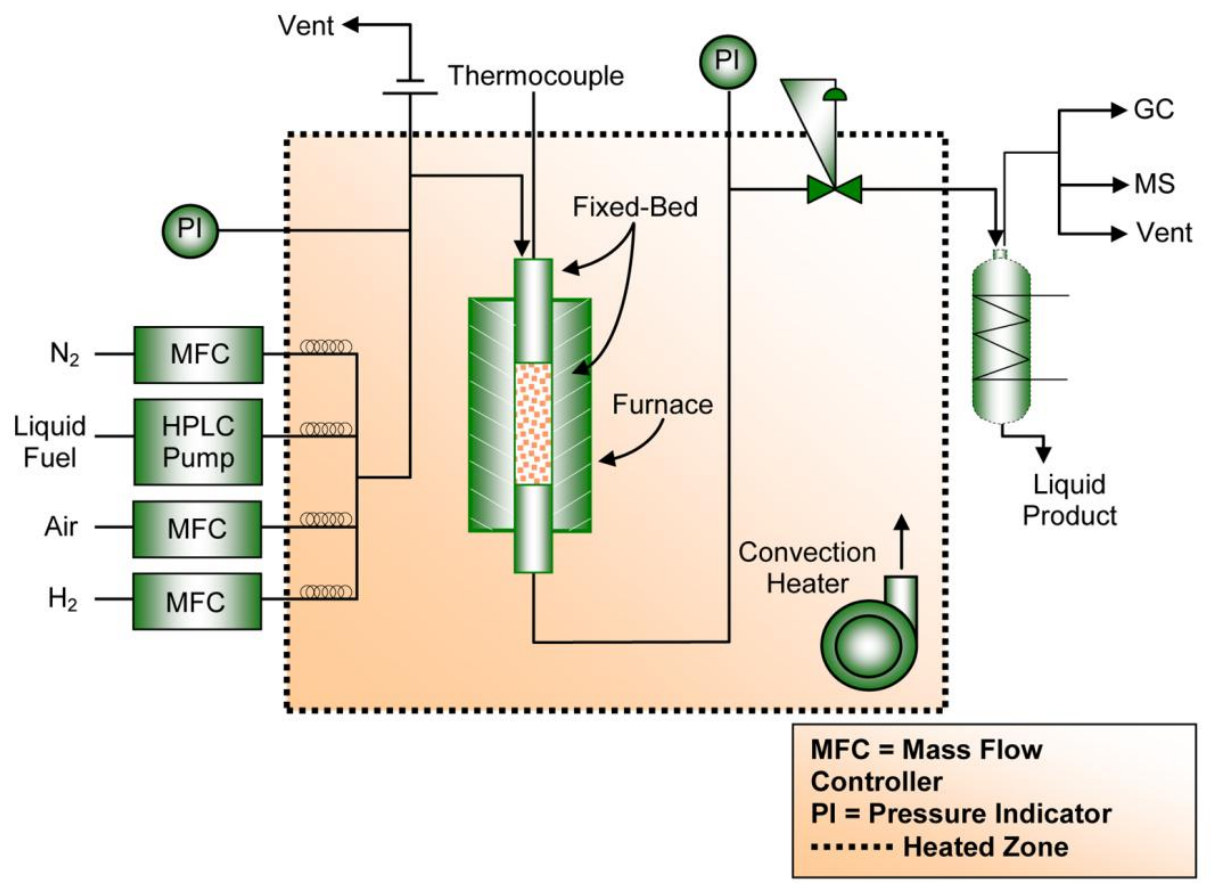

Figure 2.2.3.1: Rapid aging testing system schematic

\subsection{Results}

The initial work focused upon using a Pechini precursor solution which was reported by Gaur et al. ${ }^{5}$ to effectively substitute metals into both the A and B site of the pyrochlore crystal lattice. Precursor solutions were prepared as described above, however dilute solutions with viscosities $<30 \mathrm{cp}$ were required to be run through the 60 and $130 \mathrm{kHz}$ nozzles. Higher viscosity 
solutions required excessive pressure to pump, and resulted in excessive buildup of material on the reactor tube wall. Solutions with a metal-salt concentration of $0.72 \mathrm{M}$ were initially evaluated. Figure 2.3.1 represents SEM images of the particles obtained from spray pyrolysis (SP) using a $0.72 \mathrm{M}$ Pechini precursor atomized at 60 and $130 \mathrm{kHz}$. The particles are spherical and hollow, with most particles exhibiting at least one pore caused by gas expansion during drying. The average particle size varies between five and twenty microns, with the $130 \mathrm{kHz}$ particles having a smaller particle size as observed by SEM.

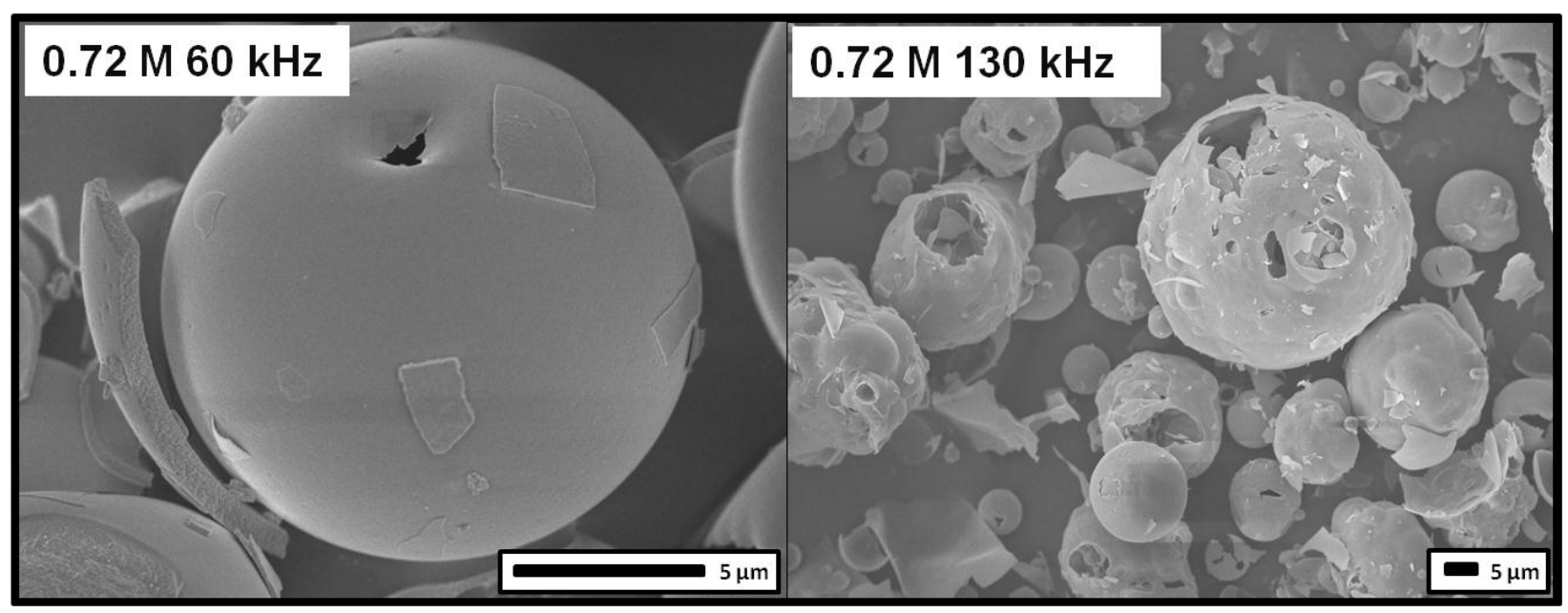

Figure 2.3.1: SEM images of particles obtained by spray pyrolysis of Pechini precursor solution at 60 and $130 \mathrm{kHz}$.

Figure 2.3.21 displays the XRD spectra for the material synthesized using the Pechini precursor solutions as synthesized, and post calcination at $1000{ }^{\circ} \mathrm{C}$ for 2 hours. The XRD spectra for each of the catalysts synthesized from the Pechini solution match a face-centered cubic unit cell crystal structure, and peaks corresponding to pyrochlore $\mathrm{La}_{2} \mathrm{Zr}_{2} \mathrm{O}_{7}\left(\mathrm{LZ}^{\mathrm{a}}\right)$ were measured in all the samples indicating that spray pyrolysis of the Pechini precursor results in a crystalline pyrochlore structure after heat treatment. At a solution concentration of $0.72 \mathrm{M}$, there is a shift of $-0.22{ }^{\circ}$ in peak position from that of pure LZ, however samples prepared at varied concentrations result in varied peak shifts between 0.05 and $-0.25^{\circ}$. No consistent trend between solution

a JCPDS\#:01-071-2363 
concentration and peak shift was found for samples prepared by SP, and the shift was attributed to an accumulated error in precursor preparation, XRD sample surface offset, and low XRD step resolution. The Pechini samples as synthesized present very broad peaks due to the low amount of crystallinity achieved during the pyrolysis step. Comparison between the amorphous batch and SP samples indicates that the SP samples do undergo the polymerization step of the Pechini method. The $130 \mathrm{kHz}$ sample is significantly more amorphous than the $60 \mathrm{kHz}$ sample, however after calcination both samples display comparable particle size and achieve similar levels of crystallinity. A secondary perovskite phase was shown to be present, where the largest two peaks being identified at 31.275 , and $31.575^{\circ}$. These peaks were previously identified by Gaur et al. ${ }^{5}$ as being associated with the formation of the perovskite $\mathrm{CaZrO}_{3}\left(\mathrm{CZ}^{\mathrm{b}}\right)$. Due to the small metal loading ( $2 \mathrm{wt} \%)$ in the crystal lattice, peaks corresponding to the active metal were below the diffractomer's limit of detection and may be partially present in the perovskite phase identified as CZ.

b JCPDS\#:76-2401 


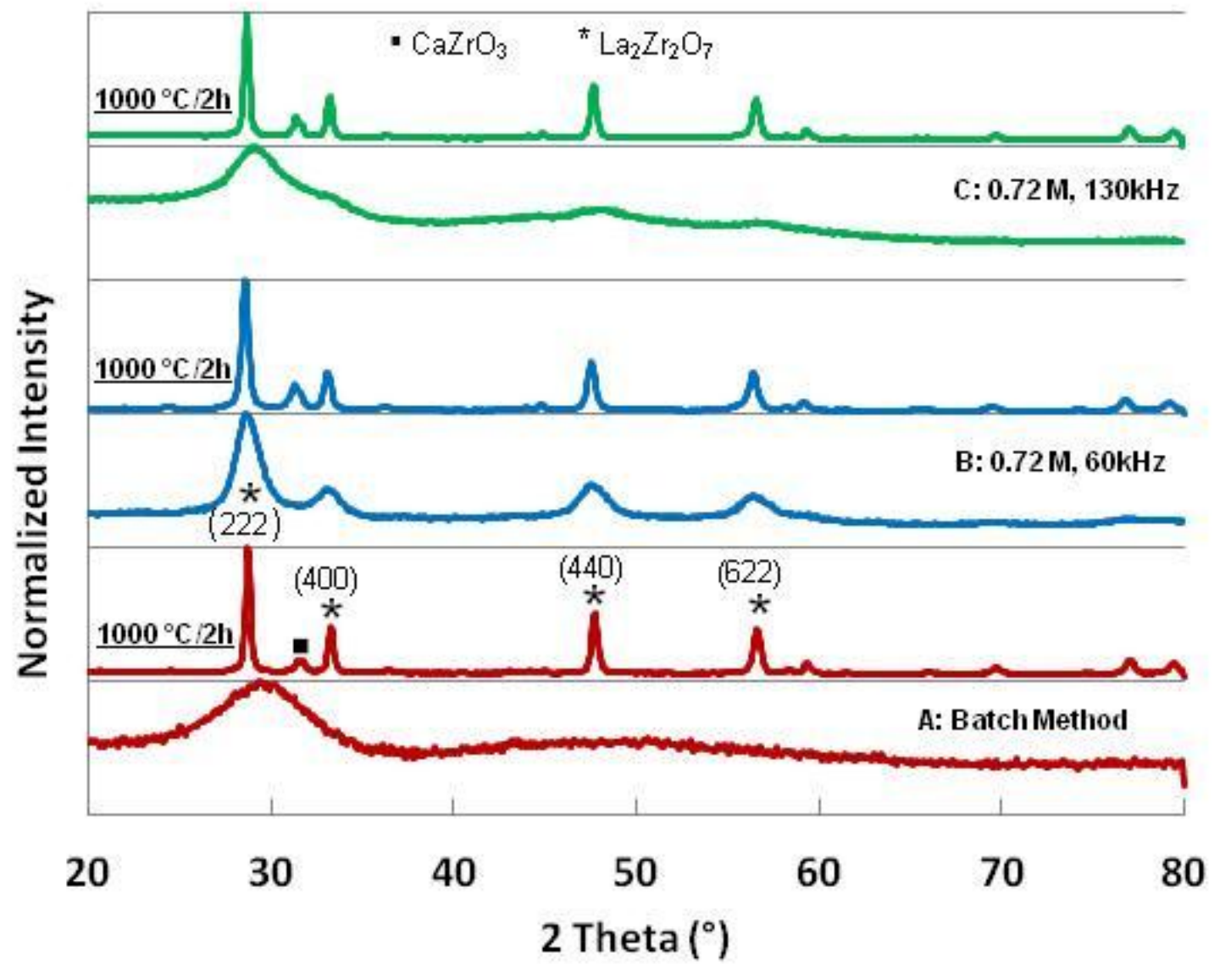

Figure 2.3.2: XRD spectra of catalysts synthesized from the Pechini precursor solution. (A: Batch method, B: $0.72 \mathrm{M} 60 \mathrm{kHz}, \mathrm{C}$ : $0.72 \mathrm{M} 130 \mathrm{kHz}$ )

To better determine in what phase the active metal is present, the samples were analyzed by TPR. Figure 2.3.3 is the TPR performance data for the catalysts prepared from the Pechini precursor solution and calcined to $1000{ }^{\circ} \mathrm{C}$ for 2 hours. Inflection points are present near 280 , 400, 480, and $625^{\circ} \mathrm{C}$ in the batch and SP samples. The lower temperature and more easily reducible peak at $280{ }^{\circ} \mathrm{C}$ was attributed to $\mathrm{NiO}$ by Gaur et al. ${ }^{5}$. The reduction peaks identified at 400 and $480{ }^{\circ} \mathrm{C}$ were attributed to the compound reduction of $\mathrm{Ni}_{2} \mathrm{O}_{3}$ from $\mathrm{Ni}^{3+}$ to $\mathrm{Ni}^{+, 56}$. The less reducible, higher temperature reduction peak at $625{ }^{\circ} \mathrm{C}$ is out of the nominal nickel phase range, and was attributed by Haynes et al. to reduction of surface zirconia. As evidenced from XRD and TPR analysis, catalysts with comparable phase purity and activity to the batch method were 
successfully synthesized by SP with a Pechini solution concentration of $0.72 \mathrm{M}$. However for this study it was desired to synthesize a fully crystalline catalyst using the available reactor with minimal heat treatment after synthesis. The three heating zone temperatures were set to the maximum of $900{ }^{\circ} \mathrm{C}$, but the resultant material was not significantly more crystalline than with the initial configuration, and continued operation at those conditions would quickly reduce the lifespan of the quartz tube and supporting hardware. Improving the crystallinity of the material as synthesized could be achieved by making significant modifications to the test stand, including increasing the height/length of the reactor and improving heat transfer to the carrier gas. To increase the temperature encountered by the particles, samples were synthesized using a glycinenitrate precursor solution which has been reported elsewhere ${ }^{22,31,34}$ to produce a high combustion temperature greater than that of the Pechini method, and has previously been used to produce crystalline ceria particles by SP. ${ }^{57}$ 


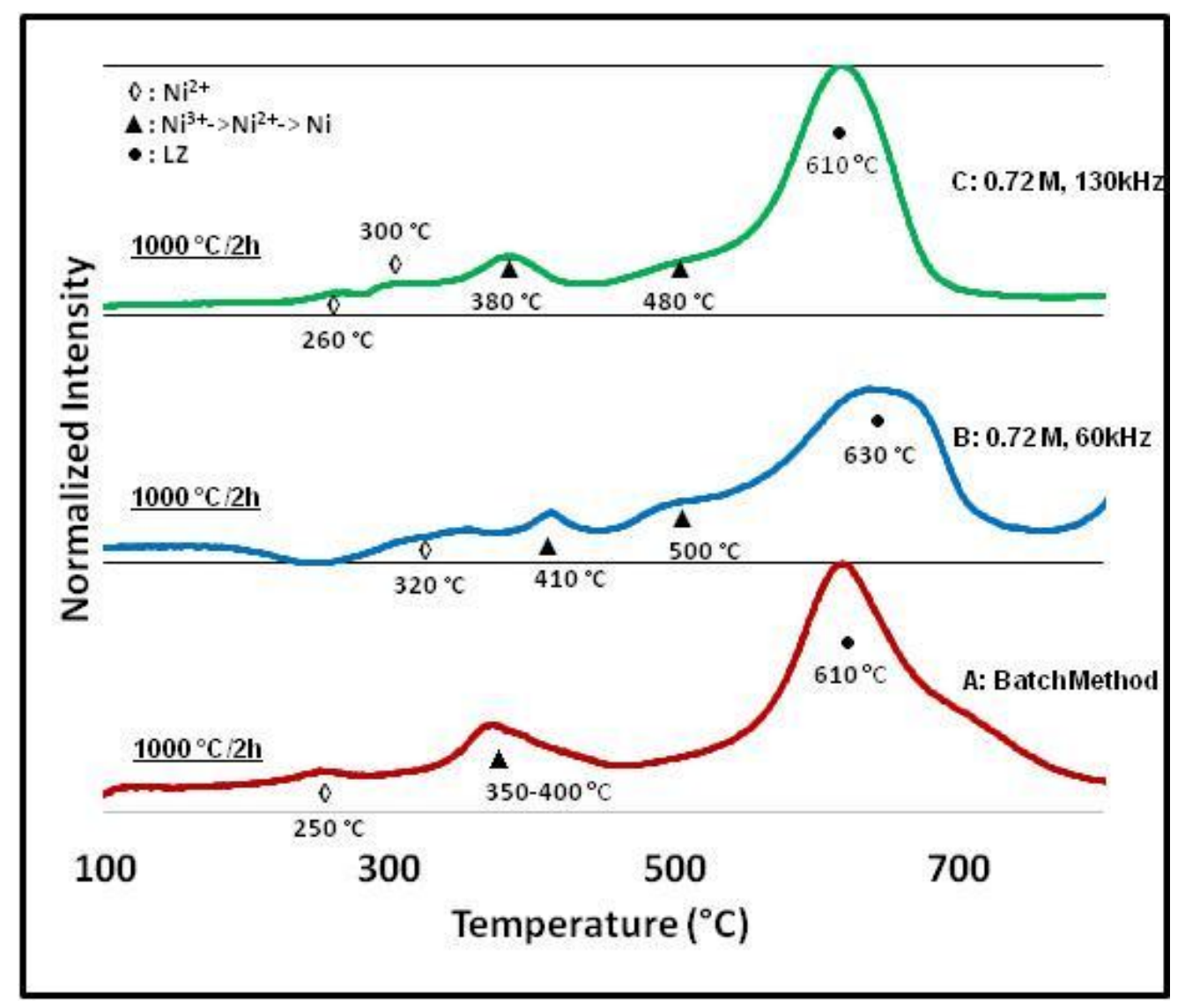

Figure 2.3.3: TPR of catalysts synthesized by SP from Pechini precursor solution. (A: Batch method, B: $0.72 \mathrm{M} 60 \mathrm{kHz}, \mathrm{C}: 0.72$ M $130 \mathrm{kHz}$ ) “*” denotes heat treatment to $1000{ }^{\circ} \mathrm{C}$ for 2 hours.

\subsection{Conclusions}

Ni-doped LZ was successfully synthesized from the Pechini precursor by spray pyrolysis. XRD spectra of the catalysts prepared by SP had the same peak position and broadness as the batch sample, indicating a comparable degree of crystallinity. More stable Ni-phases were formed in the SP, as evidenced by TPR peaks at 300 and $400{ }^{\circ} \mathrm{C}$ compared to 280 and $380{ }^{\circ} \mathrm{C}$ for the batch-prepared catalyst. However, heat treatment to $1000{ }^{\circ} \mathrm{C}$ for two hours was required to form the desired phase in the SP samples. 


\section{Chapter 3: Ni-doped $\mathrm{La}_{2} \mathrm{Zr}_{2} \mathrm{O}_{7}$ Glycine-nitrate precursor solution}

\subsection{Objective}

Glycine-nitrate based precursor solutions were prepared with the intent to raise particle temperatures sufficiently to form a crystalline material. Glycine is an amino acid with the chemical formula $\mathrm{C}_{2} \mathrm{H}_{5} \mathrm{O}_{2} \mathrm{~N}$ that acts as a chelating agent for metal complexes. The combustion of glycine is highly exothermic due to the strong nitrogen bonding in the $\mathrm{NH}_{2}$ group, and when combined with an oxidizer provides very rapid combustion. Previously Shih et al ${ }^{57}$ prepared crystalline $\mathrm{CeO}_{2}$ particles using a glycine-nitrate precursor and spray pyrolysis process. $\mathrm{CeO}_{2}$ is reported to require calcinations from 800 to $1200{ }^{\circ} \mathrm{C}^{40}$ to form crystalline material, indicating that use of GN precursors for spray pyrolysis yields combustion temperatures within that range. Hwang et al. ${ }^{58}$ synthesized $\mathrm{Ni}_{0.5} \mathrm{Zn}_{0.5} \mathrm{Fe}_{2} \mathrm{O}_{4}$ using a glycine-nitrate precursor and reported that the sample temperature reached $1285{ }^{\circ} \mathrm{C}$ during combustion. In a separate work, Hwang et al. ${ }^{59}$ identified three modes of glycine-nitrate combustion that can occur depending upon the molar ratio of glycine to metal nitrates. When the ratio, denoted by $Y$, is less than 1.05 a "smoldering" combustion occurs with a maximum combustion temperature $\left(\mathrm{T}_{\mathrm{c}}\right)$ of $650{ }^{\circ} \mathrm{C}$. When $\mathrm{Y}$ is between the values of 1.05 and $1.9 \mathrm{~T}_{\mathrm{c}}$ falls between 1000 and $1250{ }^{\circ} \mathrm{C}$ and is called volume combustion synthesis (VCS). Y values greater than 1.9 result in self-propagating hightemperature synthesis (SHS), with a maximum $\mathrm{T}_{\mathrm{c}}$ of $850-1000^{\circ} \mathrm{C}$. In order to reach the maximum possible temperature by this method it is desirable to operate in the VCS region. The Y values of the glycine-nitrate precursors prepared in this study were held at 1.2 for all experiments to achieve VCS combustion properties and maintain consistency with the precursors prepared by the Pechini method. 


\subsection{Experimental}

\subsubsection{Precursor solution synthesis}

Nitrate hydrates $\mathrm{La}\left(\mathrm{NO}_{3}\right)_{3} \bullet 6 \mathrm{H}_{2} \mathrm{O}, \mathrm{ZrO}\left(\mathrm{NO}_{3}\right)_{2} \bullet \mathrm{xH}_{2} \mathrm{O}, \mathrm{Ni}\left(\mathrm{NO}_{3}\right)_{2} \bullet \mathrm{xH}_{2} \mathrm{O}, \mathrm{Y}\left(\mathrm{NO}_{3}\right)_{3} \bullet 6 \mathrm{H}_{2} \mathrm{O}$, and $\mathrm{Ca}\left(\mathrm{NO}_{3}\right)_{2} \bullet 4 \mathrm{H}_{2} \mathrm{O}$ (Alfa Aesar) were used as precursors for the Pechini and glycine-nitrate solutions. The metal salts were weighed to achieve the desired atomic ratio for the catalyst compositions ( $\left.\mathrm{La}_{1.89} \mathrm{Ni}_{2.81} \mathrm{Y}_{0.25} \mathrm{Ca}_{0.11} \mathrm{Zr}_{1.47}\right)$, and dissolved in deionized water (DI). Glycine was added in a 1:1.2 molar ratio of metal ions to glycine. The solution was stirred on a hot plate at 60 ${ }^{\circ} \mathrm{C}$ to evaporate excess water from solution until the concentration reached the desired molarities of $0.18,0.36,0.72$, and 1.44 molar. All other experimental methods followed the procedures discussed in Chapter 2.

\subsection{Results}

\subsubsection{Concentration effects}

The glycine-nitrate precursor solution was used to prepare nickel-doped LZ with the objective of synthesizing crystalline doped LZ without additional heat treatment. Figure 3.3.1.1 shows the XRD spectra for $0.18,0.36,0.72$, and 1.44 molar concentrations atomized at $60 \mathrm{kHz}$. Peaks corresponding to the FCC LZ pyrochlore structure are identified in all the samples prepared with a minor shift of the $100 \%$ peak located at $28.425^{\circ}$ by -0.02 . Shift in the XRD peak locations were not consistent with concentration variation, in agreement with the result observed in the Pechini SP samples. As the concentration of the GN solution is increased, the FWHM decreases from 1.63 to 0.368 for the 0.18 and $1.44 \mathrm{M}$ solutions respectively. This is due to the combined effects of less evaporation required and greater heat concentration for each particle resulting in higher temperature experienced by each particle. 


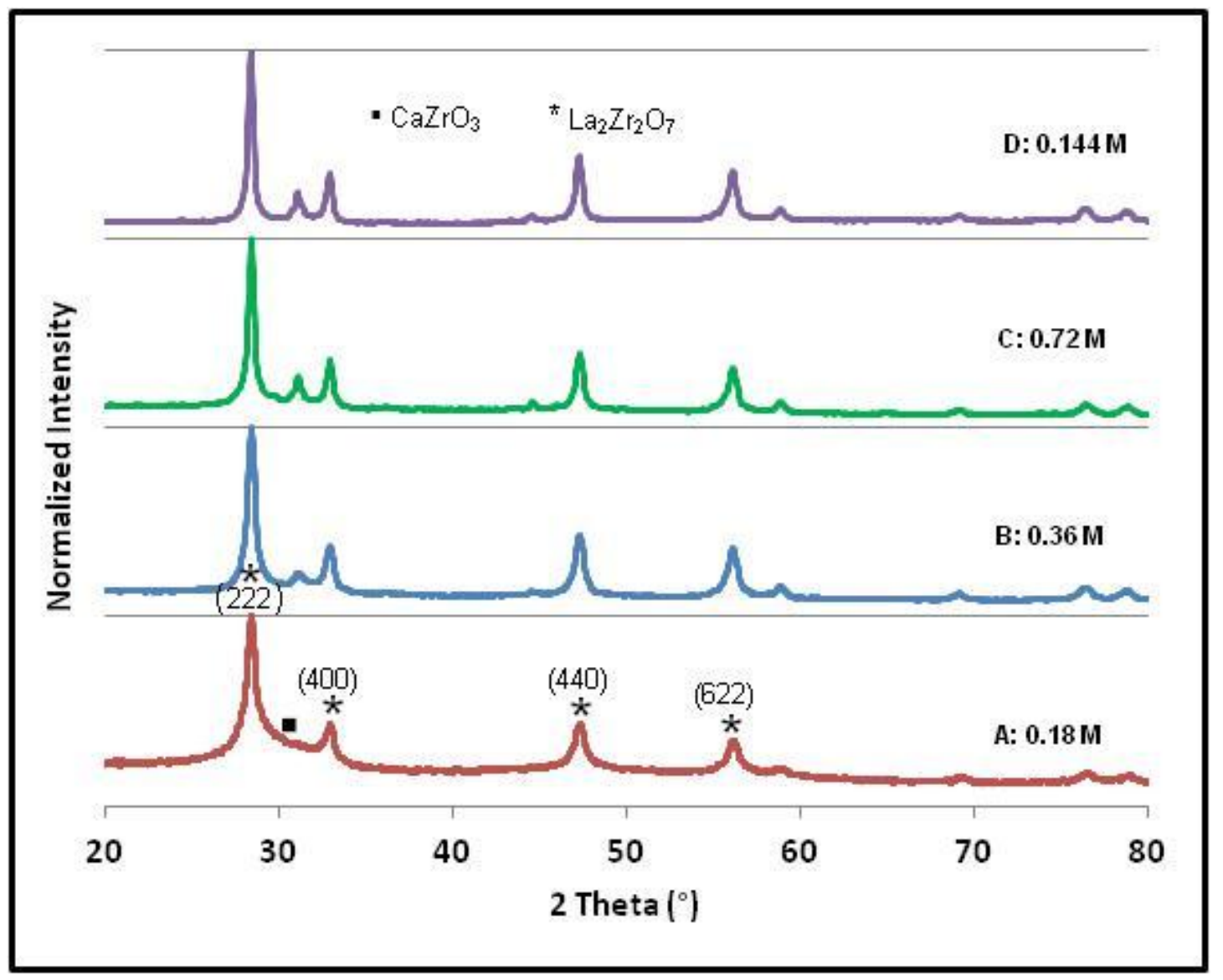

Figure 3.3.1.1: XRD spectra of catalysts synthesized from the glycine-nitrate precursor solution. (A: $0.18 \mathrm{M} 60 \mathrm{kHz}, \mathrm{B:}: 0.36 \mathrm{M}$ $60 \mathrm{kHz}, \mathrm{C}: 0.72 \mathrm{M} 60 \mathrm{kHz}, \mathrm{D}: 1.44 \mathrm{M} 60 \mathrm{kHz})$

In contrast to the samples prepared by the Pechini precursor, the GN samples have much more defined peaks for the as-synthesized powder. Increased peak broadness in XRD analysis can be attributed to smaller crystallite size (Debeye-Scherrer relation) or decreased crystallinity. To determine approximate crystallite size, SEM images of samples prepared from $0.72 \mathrm{M}$ Pechini and GN precursors atomized at $60 \mathrm{kHz}$ were collected in Figure 3.3.1.2. The Pechini sample shows a cross-section of a particle with visible grains. The GN micrograph shows the surface and cross-section of a particle showing grains and what appear to be void hollow regions. The Debeye-Scherrer equation estimates a grain-size of 20 and $80 \mathrm{~nm}$ for the Pechini and GN samples respectively. However grains visible in Figure 3.3.1.2 indicate that the primary particle size of the two samples is similar, with the GN sample having an observed grain size between 10 
and $30 \mathrm{~nm}$ rather than the $80 \mathrm{~nm}$ predicted by Debeye-Scherrer. This implies that the increased FWHM observed for the GN samples is due to increased crystallinity rather than grain growth.

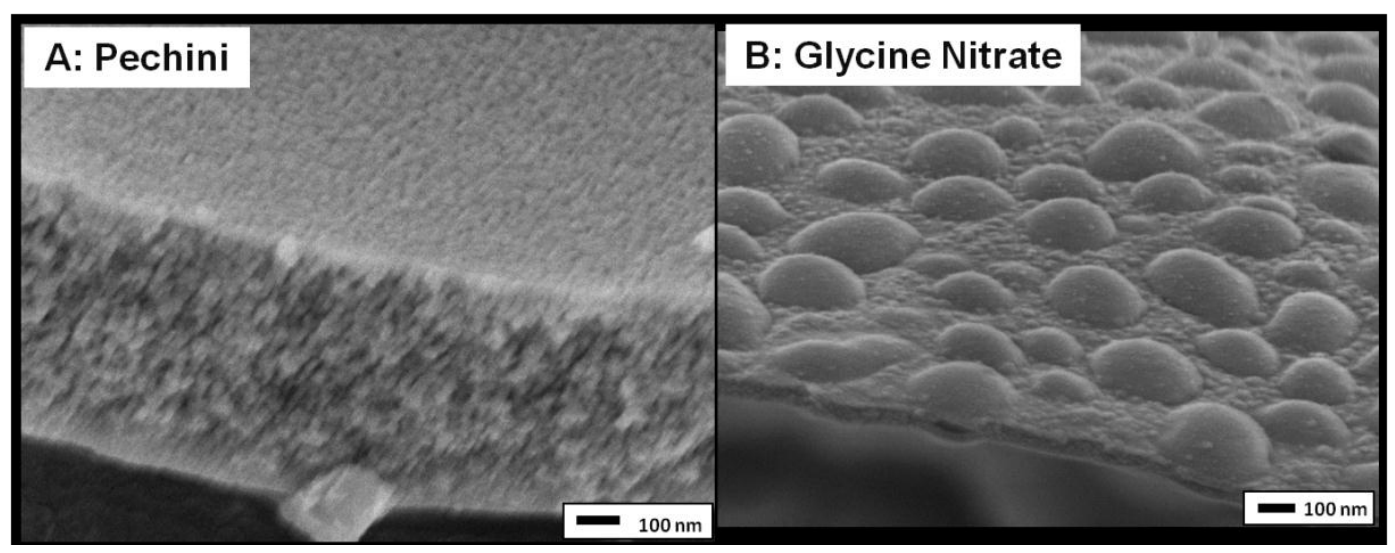

Figure 3.3.1.2: SEM images of Pechini and GN samples prepared at $60 \mathrm{kHz}$.(A: Pechini $0.72 \mathrm{M}$; B:Glycine-Nitrate $0.72 \mathrm{M}$ )

To determine the phase composition of the nickel in the material, TPR studies were performed. The TPR results for the samples prepared from the $0.18,0.36,0.72$, and $1.44 \mathrm{M}$ solution are plotted in Figure 3.3.1.3. Samples synthesized from the most dilute solution have no detectable nickel reduction peaks due to excess carbon from the synthesis process overwhelming the signal generated by nickel reduction. At higher concentrations, which underwent more complete combustion of the glycine during synthesis, TPR nickel peaks were observed at 330 380, and $475^{\circ} \mathrm{C}$. Non-nickel peaks corresponding to LZ were identified at 600 and $775^{\circ} \mathrm{C}$. 


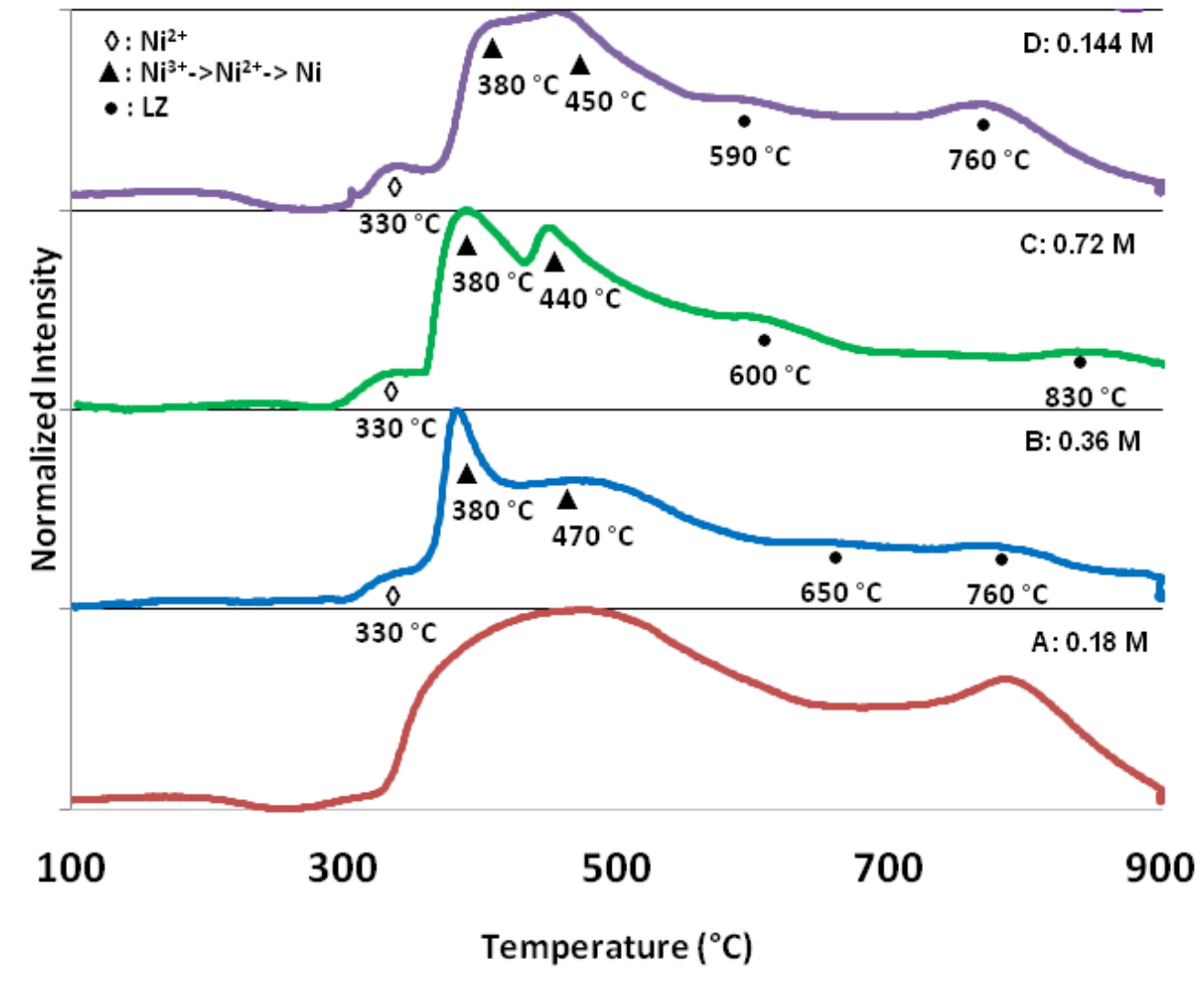

Figure 3.3.1.3: TPR of catalysts synthesized by SP from GN precursor solution. (A: $0.18 \mathrm{M} 60 \mathrm{kHz}, \mathrm{B}: 0.36 \mathrm{M} 60 \mathrm{kHz}, \mathrm{C}: 0.72 \mathrm{M}$ $60 \mathrm{kHz}, \mathrm{D}: 1.44 \mathrm{M} 60 \mathrm{kHz}$ )

Most peaks are attributed to the same phases discussed in the previous chapter, with peaks from 200 to $500{ }^{\circ} \mathrm{C}$ representing reduction of varied nickel-oxide phases and the peaks near $600{ }^{\circ} \mathrm{C}$ representing yttrium phases. In contrast to the Pechini samples, the majority of the peak area in the TPR curves is associated with nickel phases. As the concentration increases, the relative contribution of the high temperature Ni-phases increases. The increased contribution from more stable Ni-phases implies higher long-term performance for the catalysts prepared by GN. The peak at $775{ }^{\circ} \mathrm{C}$ was not observed in the Pechini TPR curves. To confirm that the peak is associated with inactive phases, LZ without nickel was synthesized from glycine-nitrate precursor. A broad peak that spans from 725 to $825{ }^{\circ} \mathrm{C}$, with its maximum at $775{ }^{\circ} \mathrm{C}$ is clearly observed in the nickel-free LZ sample shown in Figure 3.3.1.4. 


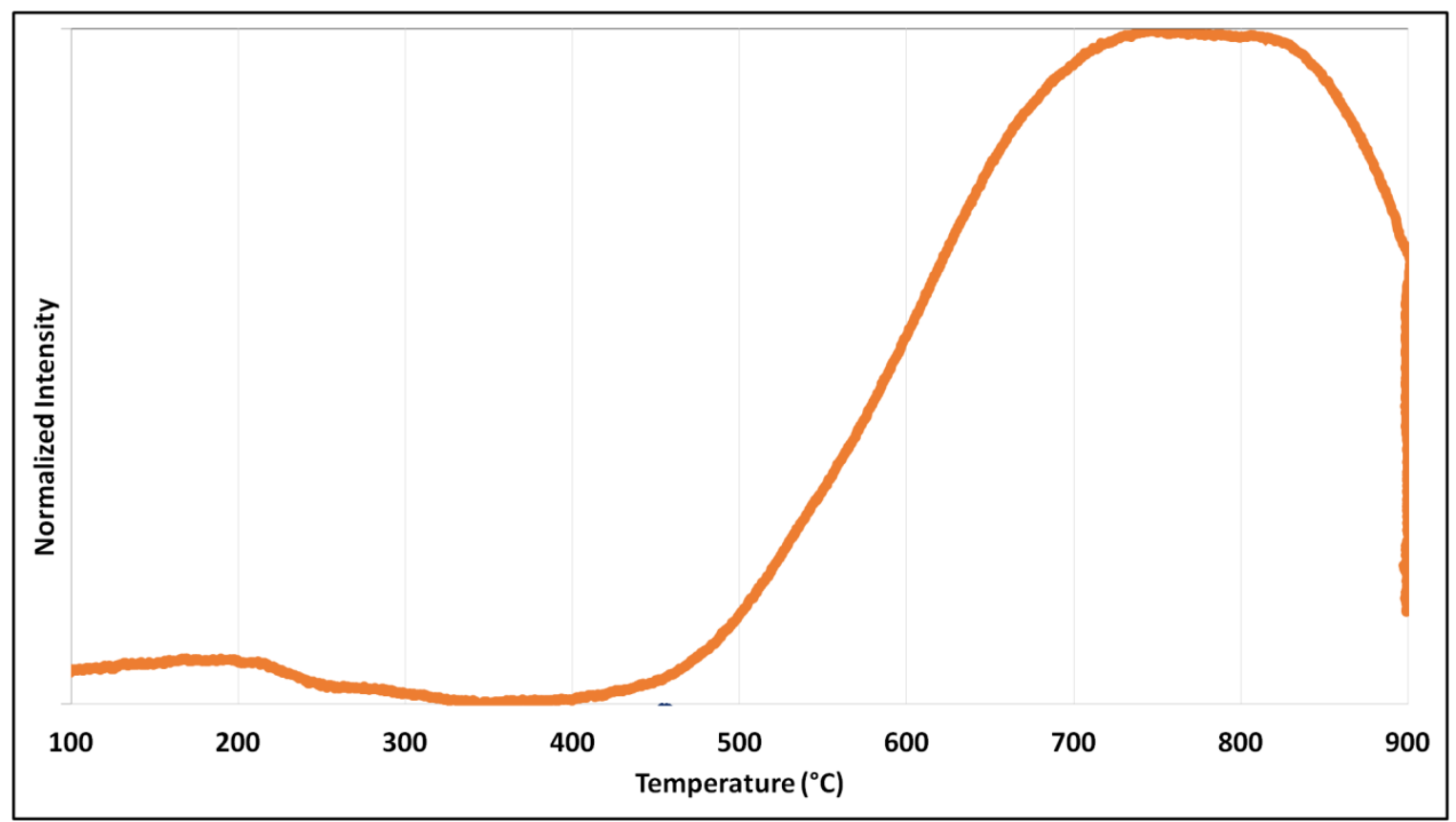

Figure 3.3.1.4: TPR of Nickel-free LZ sample prepared from glycine-nitrate precursor sollution

Therefore the peak near $775{ }^{\circ} \mathrm{C}$ is attributed to inactive $\mathrm{LZ}$ phases. Another factor that is expected to affect performance is the surface area of the samples. Samples prepared by GN have more surface area and available active sites than the Pechini samples with an average value of $11.5 \mathrm{~m}^{2} / \mathrm{g}$ compared to $1.9 \mathrm{~m}^{2} / \mathrm{g}$ respectively. No strong trend was discovered between concentration and surface area; the surface area fluctuated between 9 and $12 \mathrm{~m}^{2} / \mathrm{g}$ independent of solution concentration. 


\subsubsection{Results: Atomizer Frequency Effects}

In addition to the effect of the solution concentration, the effect of the atomizer frequency upon the particles was also of interest. Glycine-nitrate solutions at identical concentrations to the solutions used in the $60 \mathrm{kHz}$ experiments were used in spray pyrolysis experiments utilizing the $130 \mathrm{kHz}$ atomizing nozzle. Figure 3.3.2.1 shows XRD spectra of the samples atomized at 130 and $60 \mathrm{kHz}$ from the $0.72 \mathrm{M}$ solution. Increasing the atomizer frequency from $60 \mathrm{kHz}$ to 130 $\mathrm{kHz}$ resulted in a smaller FWHM value for all samples. The FWHM of the 222 peak in $130 \mathrm{kHz}$ sample prepared from the $0.72 \mathrm{M}$ solution is 0.426 , as opposed to 0.397 for its $60 \mathrm{kHz}$ counterpart.

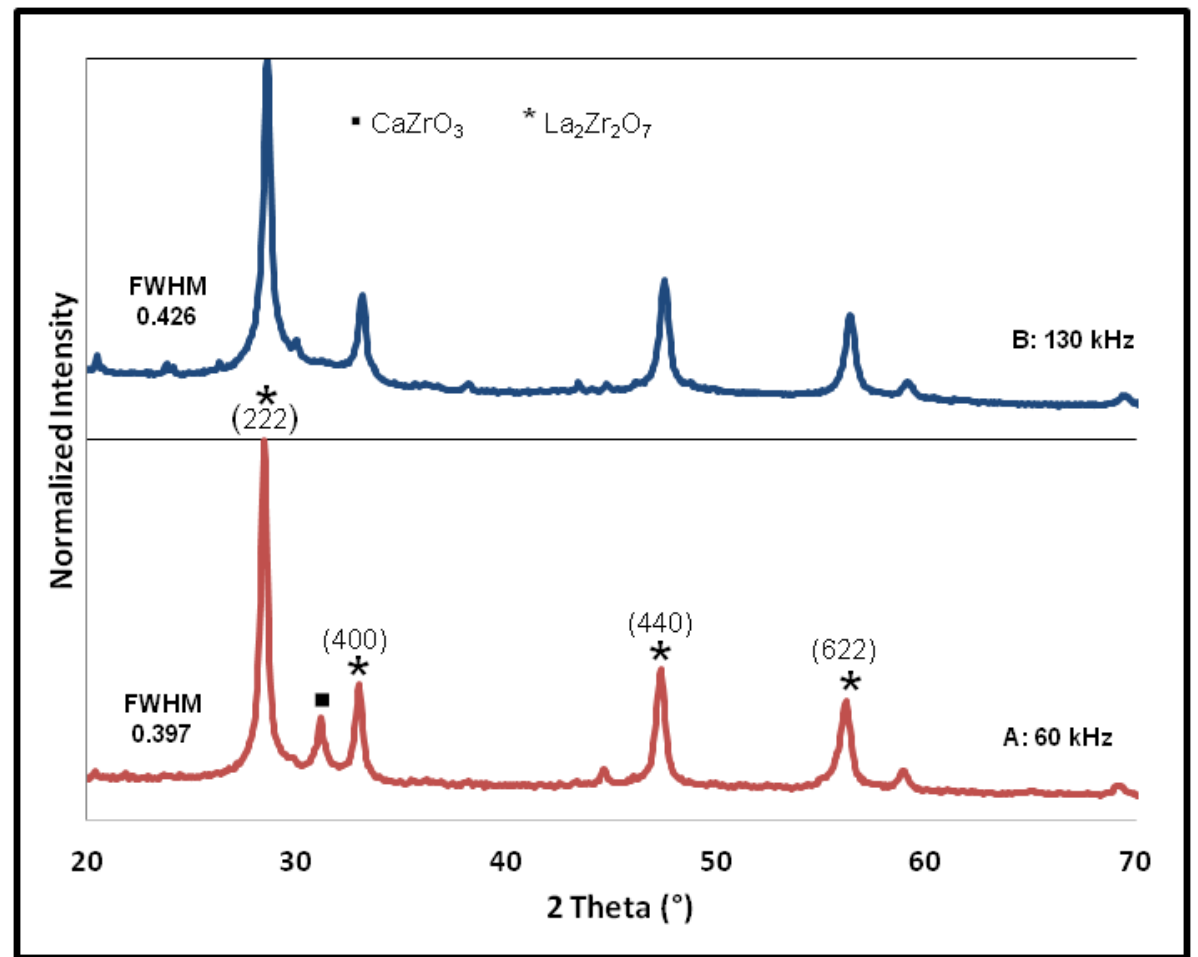

Figure 3.3.2.1: XRD spectra of catalysts synthesized from the glycine-nitrate precursor solution. (A: $0.72 \mathrm{M} 60 \mathrm{kHz}, \mathrm{B}: 0.72 \mathrm{M}$ $130 \mathrm{kHz})$

As discussed previously, primary particle size and crystallinity both affect the FWHM of an XRD peak. The crystallite size estimated by the Debeye-Scherrer equation for the 60 and 130 
$\mathrm{kHz}$ samples prepared from $0.72 \mathrm{M}$ solution is 80 and $73 \mathrm{~nm}$ respectively. SEM images of these samples are represented in Figure 3.3.2.2, where it was observed that the grain size difference between the samples is very slight, and neither sample's observed grain size is close to the size predicted by the Debeye-Scherrer relation.

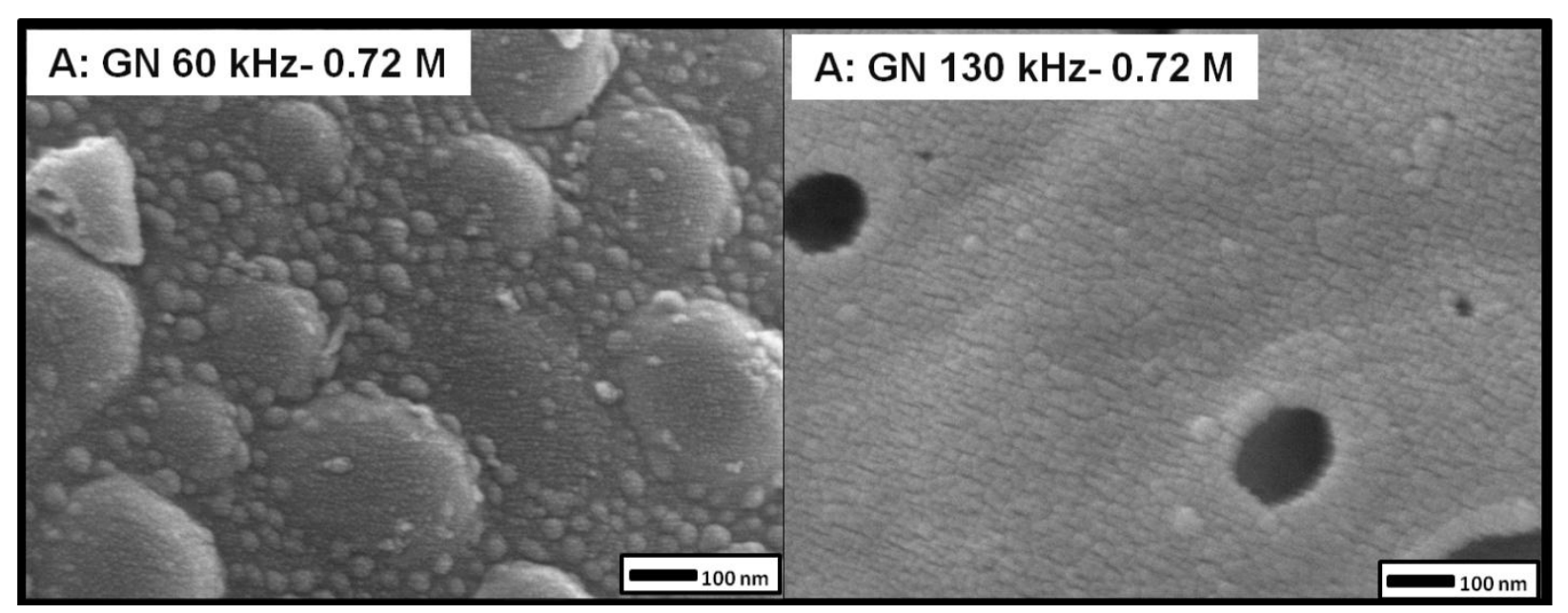

Figure 3.3.2.2: SEM images of GN samples prepared from $0.72 \mathrm{M}$ precursor solution.

Therefore it was concluded that the broader peaks present in the $130 \mathrm{kHz}$ samples are due to lower crystallinity. Lower crystallinity was attributed to the smaller particle size produced by the $130 \mathrm{kHz}$ nozzle, which reduces the maximum combustion temperature of each particle. The morphologies of the samples as observed by SEM, as shown in Figure 3.3.2.3, have hollowspherical morphology with significant porosity. The $130 \mathrm{kHz}$ has very few pores, but most particles are still hollow with thin walls. This can be explained by the increased surface tension of the smaller droplets, which causes more of the combustion gas to collect inside the droplet rather than diffuse from the surface. BET analysis of the samples shows a slightly higher surface area for the samples prepared at $130 \mathrm{kHz}$, likely due to a smaller particle diameter and more amorphous structure. 


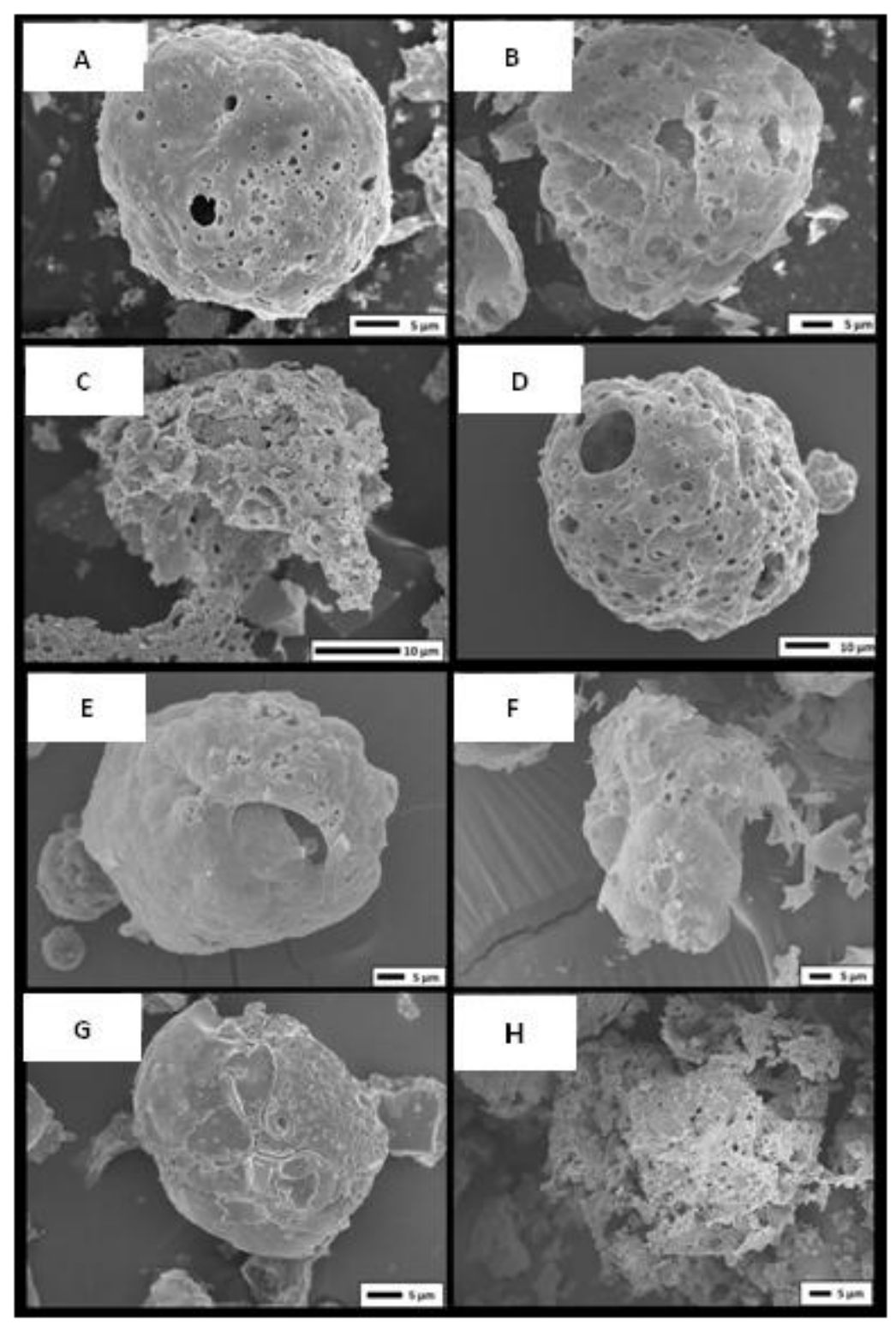

Figure 3.3.2.3: SEM of catalysts synthesized by SP from glycine-nitrate precursor solution.(A: $60 \mathrm{kHz} 0.18 \mathrm{M}, \mathrm{B:} 60 \mathrm{kHz} 0.36 \mathrm{M}$, C: $60 \mathrm{kHz} 0.72 \mathrm{M}, \mathrm{D}: 60 \mathrm{kHz} 1.44 \mathrm{M}, \mathrm{E}: 130 \mathrm{kHz} 0.18 \mathrm{M}, \mathrm{F}: 130 \mathrm{kHz} 0.36 \mathrm{M}, \mathrm{G}: 130 \mathrm{kHz} 0.72 \mathrm{M}, \mathrm{H}: 130 \mathrm{kHz} 1.44 \mathrm{M})$

If the $130 \mathrm{kHz}$ samples are in fact less crystalline than the $60 \mathrm{kHz}$ samples, it would be expected that the nickel phases present would be more easily reducible than the $60 \mathrm{kHz}$ samples. Figure 3.3.2.4 compares the TPR results for 60 and $130 \mathrm{kHz}$ glycine samples synthesized from a precursor concentration of $0.72 \mathrm{M}$. As hypothesized, $130 \mathrm{kHz}$ sample is composed of phases that are quite reducible at lower temperatures than the $60 \mathrm{kHz}$ sample, with a collection of peaks from 300 to $500{ }^{\circ} \mathrm{C}$ attributed to nickel oxide phases, as well as the $\mathrm{LZ}$ peaks identified 
previously. When compared to the TPR of the $130 \mathrm{kHz}$ sample, it was observed that the $60 \mathrm{kHz}$ samples had greater peak contribution from higher temperature Ni-peaks. The majority of 60 $\mathrm{kHz}$ sample peak contribution originates from Ni-peaks corresponding to more stable Ni-phases. The XRD and TPR results indicate that higher concentration and lower frequency will result in a more stable catalyst.

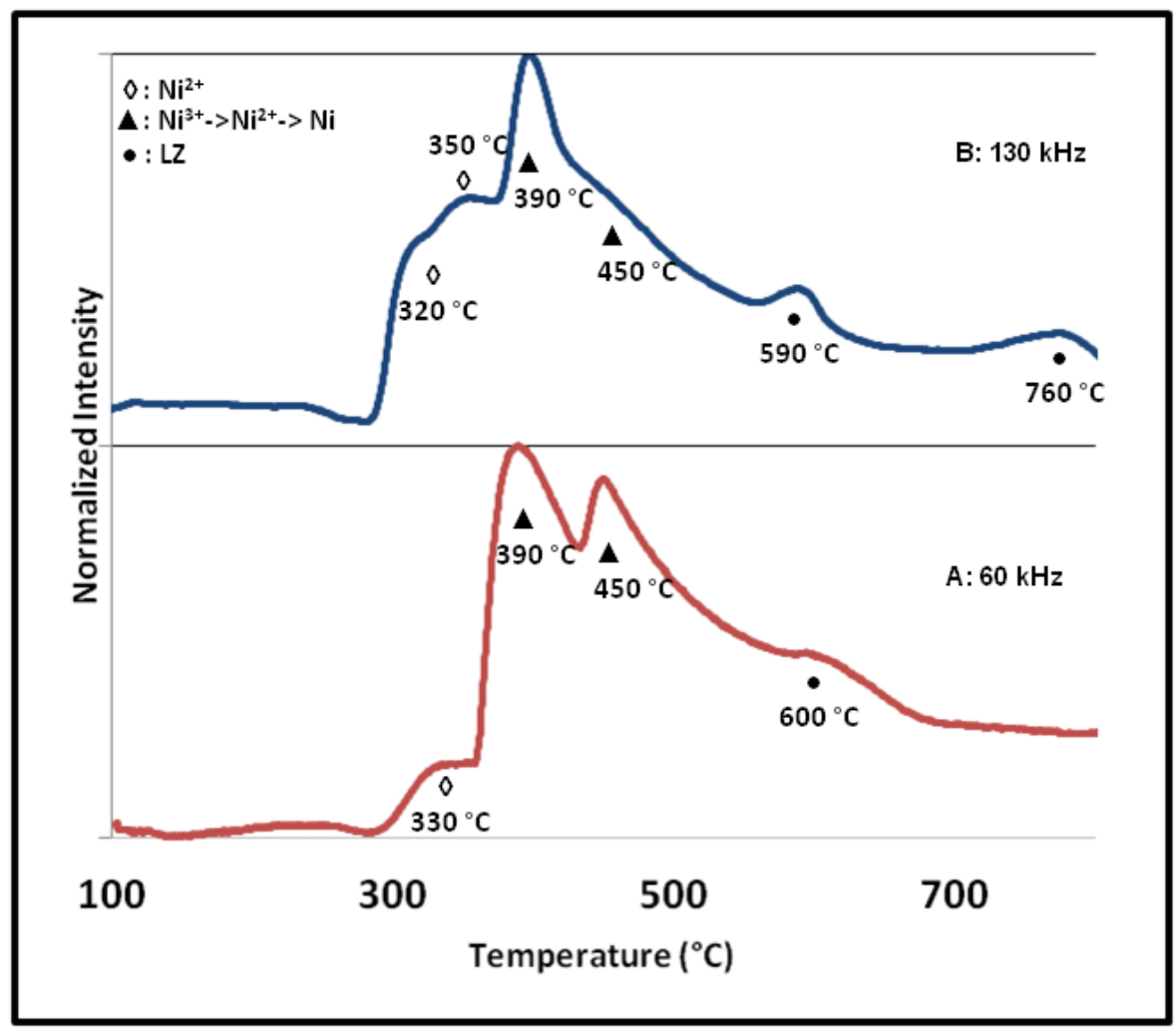

Figure 3.3.2.4: TPR of catalysts synthesized by SP from Pechini precursor solution. (A: $0.18 \mathrm{M} 60 \mathrm{kHz}, \mathrm{B:}: 0.36 \mathrm{M} 60 \mathrm{kHz}$, C: $0.72 \mathrm{M} 60 \mathrm{kHz}, \mathrm{D}: 1.44 \mathrm{M} 60 \mathrm{kHz}$ )

\subsection{Conclusions}

Spray pyrolysis of a glycine-nitrate precursor solution resulted in crystalline Ni-doped LZ with FWHM values ranging from 1.630 to 0.368 . Solution concentration was found to be directly proportional to crystallinity and stability of the catalyst. It was determined that atomizer frequency, and by relation droplet size, is indirectly proportional to cystallinity and reducibility of Ni-phases present in the catalyst. The relations found in this study provide evidence that low 
frequency atomization and high solution concentrations should be used when preparing LZ by spray pyrolysis. Use of the glycine-nitrate solution allowed for the elimination of the heat treatment to $1000{ }^{\circ} \mathrm{C}$ for 2 hours, and reduced the effective catalyst synthesis time from 36 hours to 30 minutes. 


\section{Chapter 4: Rh-doped $\operatorname{La}_{2} \mathrm{Zr}_{2} \mathrm{O}_{7}$}

\subsection{Objective}

Ni-doped $\mathrm{La}_{2} \mathrm{Zr}_{2} \mathrm{O}_{7}$ does actively participate in the auto-thermal reforming reaction, but Gaur et al.. ${ }^{5}$ reported $40 \%$ fuel conversion and rapid deactivation of the catalyst. Rh-doped LZ provided $95 \%$ of equilibrium conversion with no observable deactivation after 7 hours, indicating it is a great candidate for auto-thermal reaction applications. The objective of this section was to compare the performance Rh-doped LZ prepared from Pechini and glycine-nitrate precursors.

\subsection{Experimental}

\subsubsection{Precursor solution synthesis}

Nitrate hydrates $\mathrm{La}\left(\mathrm{NO}_{3}\right)_{3} \cdot 6 \mathrm{H}_{2} \mathrm{O}, \quad \mathrm{ZrO}\left(\mathrm{NO}_{3}\right)_{2} \cdot \mathrm{xH}_{2} \mathrm{O}, \quad \mathrm{Y}\left(\mathrm{NO}_{3}\right)_{3} \cdot 6 \mathrm{H}_{2} \mathrm{O}, \quad$ and $\mathrm{Ca}\left(\mathrm{NO}_{3}\right)_{2} \bullet 4 \mathrm{H}_{2} \mathrm{O}$ (Alfa Aesar) as well as $\mathrm{RhCl}_{3}$ were used as precursors for the Pechini and glycine-nitrate solutions. The metal salts were weighed to achieve the desired atomic ratio for the catalyst compositions $\left(\mathrm{La}_{1.89} \mathrm{Rh}_{1.09} \mathrm{Y}_{0.25} \mathrm{Ca}_{0.11} \mathrm{Zr}_{1.641}\right)$, and dissolved in de-ionized water (DI). In the case of the Pechini precursor solution, citric acid (CA) was added to chelate the dissolved salts in a 1:1.2 molar ratio of metal salts to CA. The solution was stirred and heated to $60^{\circ} \mathrm{C}$ for several hours before adding ethylene glycol (EG) at a 1:1 ratio of CA:EG to distribute the metal complexes into solution. The solution was stirred on a hot plate to evaporate excess water from solution until the solution concentrations reached the desired molarities of $0.18,0.36,0.72$, and 1.44 molar. For glycine-nitrate precursor solutions, glycine was substituted for CA at the same molar ratio, and no EG was added to the solution. For comparison, some catalyst was prepared by a batch method. The desired volume of precursor solution was placed into an alumina crucible 
and heated to $600{ }^{\circ} \mathrm{C}$ for 8 hours, and then calcined at $1000{ }^{\circ} \mathrm{C}$ for 2 hours. The ramp rate for all heating operations was set to $3{ }^{\circ} \mathrm{C} / \mathrm{min}$ on ramp-up and $5{ }^{\circ} \mathrm{C} / \mathrm{min}$ on ramp-down. All other experimental methods follow the procedures discussed in Chapter 2.

\subsection{Results}

\subsubsection{Frequency effects}

Although significant conclusions were drawn from experiments with the Ni-doped LZ, Rh-doped LZ has been shown to be more chemically stable at lower metal loading by Guar et al. ${ }^{5}$. Rh-doped $\mathrm{La}_{2} \mathrm{Zr}_{2} \mathrm{O}_{7}$ was synthesized by both Pechini and GN methods using the 60 and 130 $\mathrm{kHz}$ atomizers. The concentration of all precursor solutions was held constant at $0.72 \mathrm{M}$ for consistency and to allow for comparisons between frequencies and chemistries. The XRD spectra for the Rh-samples are presented in Figure 4.3.1.1. The spectra for each of the rhodium catalysts synthesized correspond to the FCC LZ pyrochlore structure as expected. The Pechini XRD patterns show no significant differences between frequencies; however the GN samples have significantly broader peaks than that of the nickel compositions synthesized at the same conditions. 


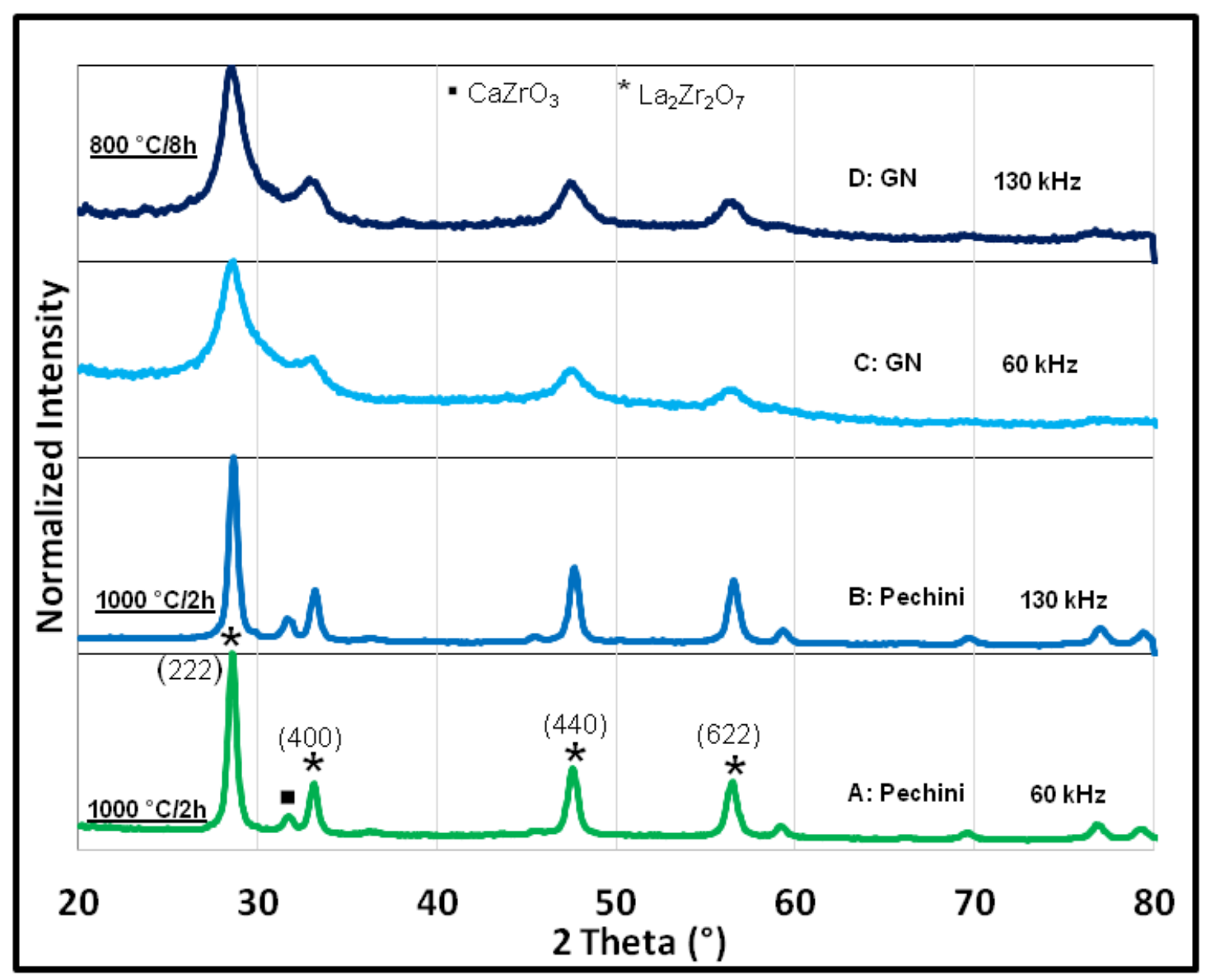

Figure 4.3.1.1: XRD spectra of catalysts synthesized from varied rhodium precursor solution. (A: Pechini $0.72 \mathrm{M} 60 \mathrm{kHz}, 1000$ ${ }^{\circ} \mathrm{C} / 2 \mathrm{~h}, \mathrm{~B}$ : Pechini $0.72 \mathrm{M} 130 \mathrm{kHz}, 1000{ }^{\circ} \mathrm{C} / 2 \mathrm{~h}$, C: Glycine $0.72 \mathrm{M} 60 \mathrm{kHz}, \mathrm{D}$ : Glycine $0.72 \mathrm{M} 130 \mathrm{kHz}$ )

The peak broadness was attributed to the reduced quantity of nitrates in solution due to the substitution of the $\mathrm{Ni}\left(\mathrm{NO}_{3}\right)_{2}$ precursor with $\mathrm{RhCl}_{3}$. The reduced availability of nitrates that act as local oxidants slowed combustion speed of particles during pyrolysis and resulted in a lower combustion temperature. Little difference in TPR peak location was observed between the frequencies for the Pechini and GN precursors as shown in Figure 4.3.1.2. Peaks at 350, 480, and $625{ }^{\circ} \mathrm{C}$ were identified in the Pechini samples. The peak at $480{ }^{\circ} \mathrm{C}$ as attributed to $\mathrm{Rh}^{3+}$ within the pyrochlore by Gaur et al. ${ }^{5}$ and Abdelsayad et al. ${ }^{60}$. The lower temperature peak at $350{ }^{\circ} \mathrm{C}$ was attributed to Rh species substituted into both the pyrochlore lattice and the secondary perovskite 
phase. Peaks near $240{ }^{\circ} \mathrm{C}$ were attributed to $\mathrm{Rh}^{2+}$, and peaks below $200{ }^{\circ} \mathrm{C}$ represent $\mathrm{Rh}$ species supported on the catalyst surface ${ }^{60}$. The relative contribution of the $\mathrm{Rh}^{3+}$ is greater in the $60 \mathrm{kHz}$ Pechini sample, and indicated the presence of more $\mathrm{Rh}^{3+}$ sites that were found by Gaur et al. to be the more stable phase.

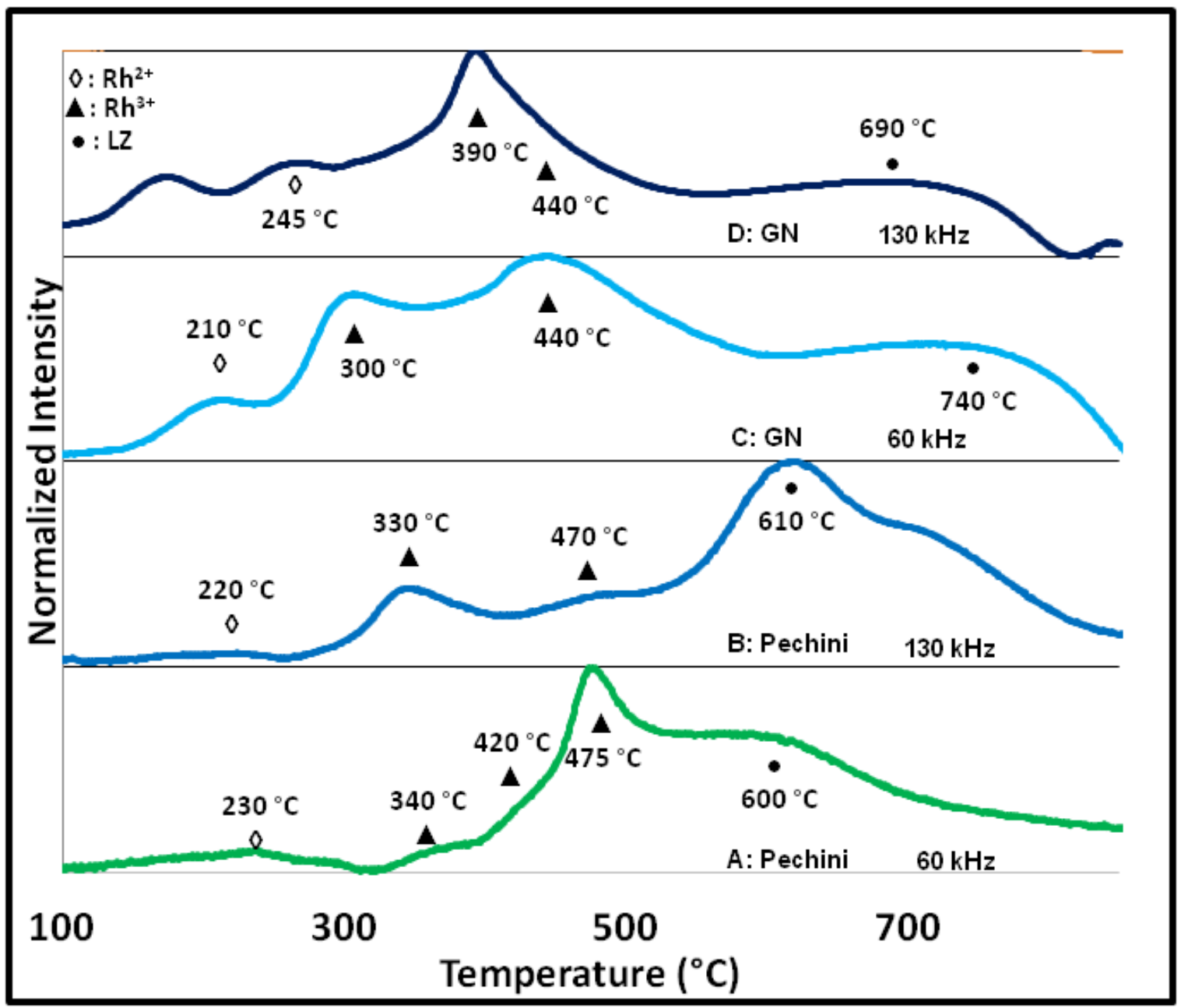

Figure 4.3.1.2: TPR of catalysts synthesized by SP from varied rhodium precursor solutions. (A: Pechini $0.72 \mathrm{M} 60 \mathrm{kHz}, 1000$ ${ }^{\circ} \mathrm{C} / 2 \mathrm{~h}, \mathrm{~B}$ : Pechini $0.72 \mathrm{M} 130 \mathrm{kHz}, 1000{ }^{\circ} \mathrm{C} / 2 \mathrm{~h}, \mathrm{C}$ : Glycine $0.72 \mathrm{M} 60 \mathrm{kHz}, \mathrm{D}$ : Glycine $0.72 \mathrm{M} 130 \mathrm{kHz}$ )

Figure 4.3.1.3 shows the \%yield of $\mathrm{H}_{2}$ for the Rh-catalysts during 16 hours of rapid aging testing. The RAT data show that the $60 \mathrm{kHz}$ Pechini catalyst remains highly active with the maximum equilibrium yield of $\mathrm{H}_{2}$ for the duration for the test. The $130 \mathrm{kHz}$ Pechini catalyst 
performs poorly, with the $\mathrm{H}_{2}$ yield dropping to $70 \%$ of equilibrium after 15 hours. This result supports the assertion that more $\mathrm{Rh}^{3+}$ present in the $60 \mathrm{kHz}$ than the $130 \mathrm{kHz}$ Pechini samples.

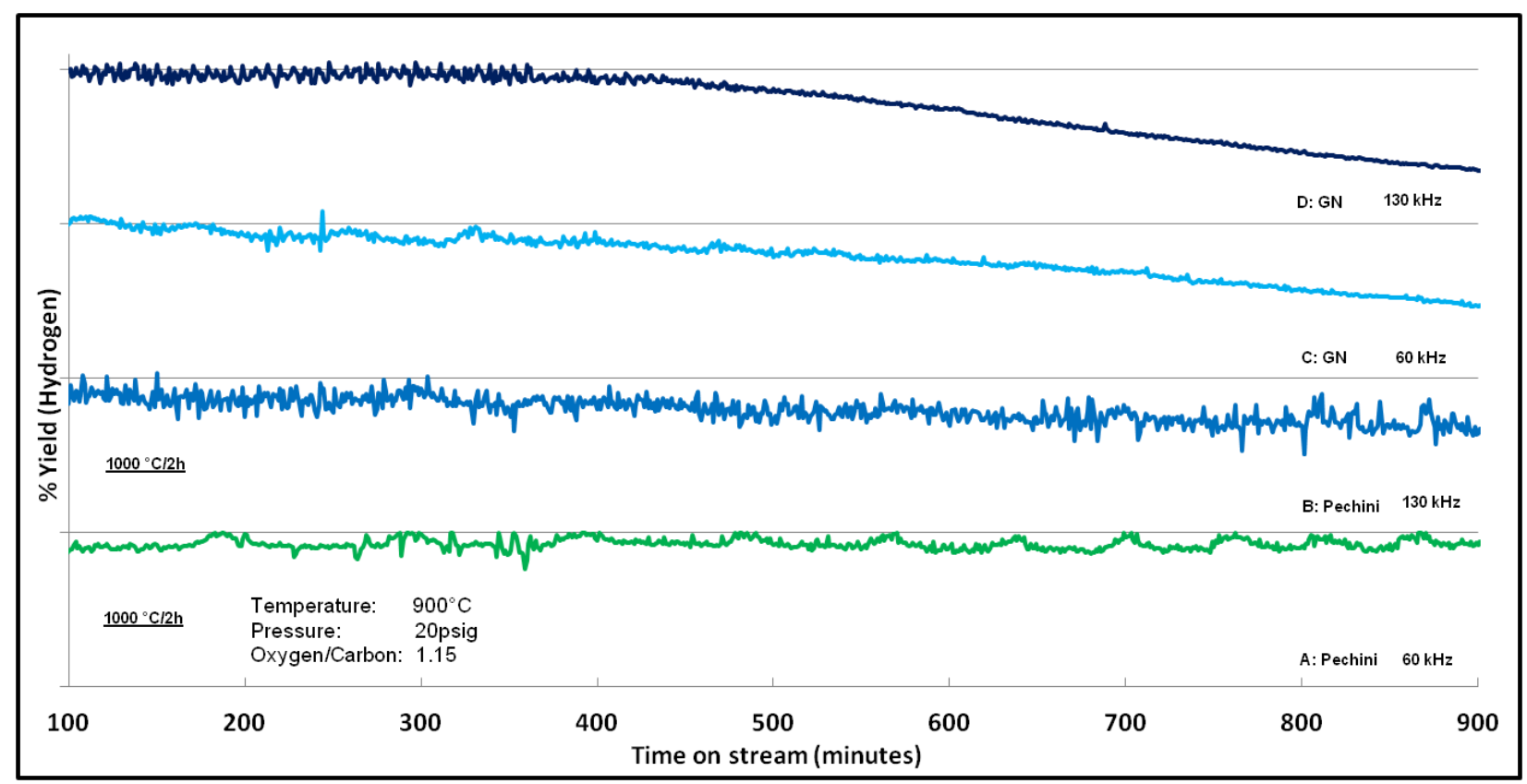

Figure 4.3.1.3: Rapid aging testing of catalysts synthesized by SP from varied rhodium precursor solutions. (A: Pechini 0.72 M $60 \mathrm{kHz}, 1000{ }^{\circ} \mathrm{C} / 2 \mathrm{~h}, \mathrm{~B}$ : Pechini $0.72 \mathrm{M} 130 \mathrm{kHz}, 1000{ }^{\circ} \mathrm{C} / 2 \mathrm{~h}, \mathrm{C}$ : Glycine $0.72 \mathrm{M} 60 \mathrm{kHz}, \mathrm{D}$ : Glycine $0.72 \mathrm{M} 130 \mathrm{kHz}$ )

The same trend between frequencies is observed in the Rh-GN catalysts. Both 60 and 130 $\mathrm{kHz}$ Rh-GN catalysts display TPR peaks near 230 , and $320^{\circ} \mathrm{C}$, but the $60 \mathrm{kHz}$ sample has a higher temperature peak at $450{ }^{\circ} \mathrm{C}$ which is associated with $\mathrm{Rh}^{3+}$. The lack of a $\mathrm{Rh}^{3+}$ peak indicates that the $130 \mathrm{kHz}$ GN catalyst is comprised of $\mathrm{Rh}^{2+}$ and $\mathrm{Rh}^{3+}$ interacting with secondary phases. The RAT results show that the 60 and $130 \mathrm{kHz}$ GN samples yield equilibrium $\mathrm{H}_{2}$ for the first 8 hours, but then begin deactivating and end with 40 and $30 \%$ of equilibrium yield respectively. 


\subsubsection{Precursor Chemistry Effects}

In addition to the effect of frequency upon catalyst properties, the differences caused by precursor chemistry were also of interest. The XRD spectra for the samples presented in Figure 4.3.1.1 indicate that the Pechini samples calcined to $1000{ }^{\circ} \mathrm{C}$ for 2 hours were more crystalline than the GN samples prepared at the same conditions. The TPR data in Figure 4.3.1.2 show more stable Rh-phases appearing in the Pechini samples, supporting the assertion that they are more crystalline. Comparing TPR results between sample A and C, Pechini and GN samples prepared at the same conditions, it would be expected that sample $\mathrm{C}$ would deactivate more quickly than sample A due to the greater relative peak area of the Rh-pyrochlore present in sample $\mathrm{A}$. This is reflected in the RAT data presented in Figure 4.3.1.3. Sample C deactivates rapidly after 8 hours, while the sample A is stable for the entire test. The same result is found for the catalysts prepared at $130 \mathrm{kHz}$, samples B and D. It was hypothesized that carbon leftover from the synthesis process was coating the surface of the particles and accelerating deactivation of the catalysts prepared by the GN precursor. Figure 4.3.2.1 shows surface and $200 \mathrm{~nm}$ depth XPS spectra of the GN sample prepared from the $0.72 \mathrm{M}$ solution. The results show that carbon is present of the surface of the catalyst particles, but not at a depth of $200 \mathrm{~nm}$. 


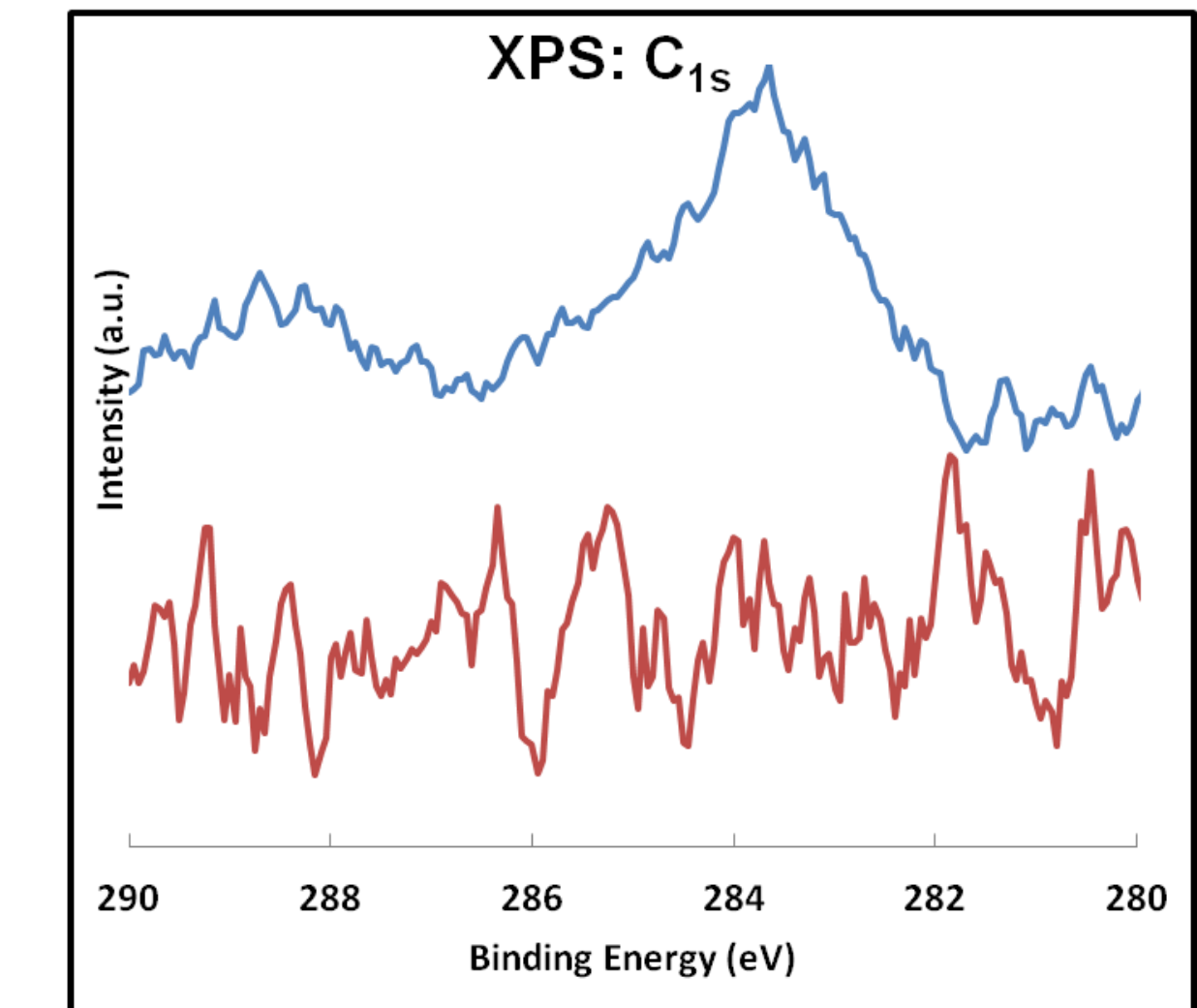

Figure 4.3.2.1: XPS spectra of 0.72 M GN sample prepared by SP.(Blue:Surface, Red: 200nm Depth)

To confirm surface carbon was contributing to catalyst deactivation, the $130 \mathrm{kHz} 0.72 \mathrm{M}$ GN sample was heated to $800{ }^{\circ} \mathrm{C}$ for 8 hours in a muffle furnace to burn-off any residual carbon. Figure 4.3.2.2 shows the XRD spectra of rhodium GN samples. Samples B and D represent the GN sample before and after heat treatment, respectively. No significant change was observed in the diffraction pattern after heat treatment sample B and D in Figure 4.3.2.2. The TPR data for the GN samples is presented in Figure 4.3.2.3. The broad Rh-peaks at 300 and $450{ }^{\circ} \mathrm{C}$ in sample B shift to 330 and $370{ }^{\circ} \mathrm{C}$ respectively in sample D. The shifting in TPR peak temperature is due to carbon masking of the signal, where the carbon coating the sample reacts with $\mathrm{H}_{2}$ to form $\mathrm{CH}_{4}$. The carbon at the surface is the reduced prior to the $\mathrm{Rh}$-species, causing the $\mathrm{Rh}$-peaks to appear at higher temperatures. 


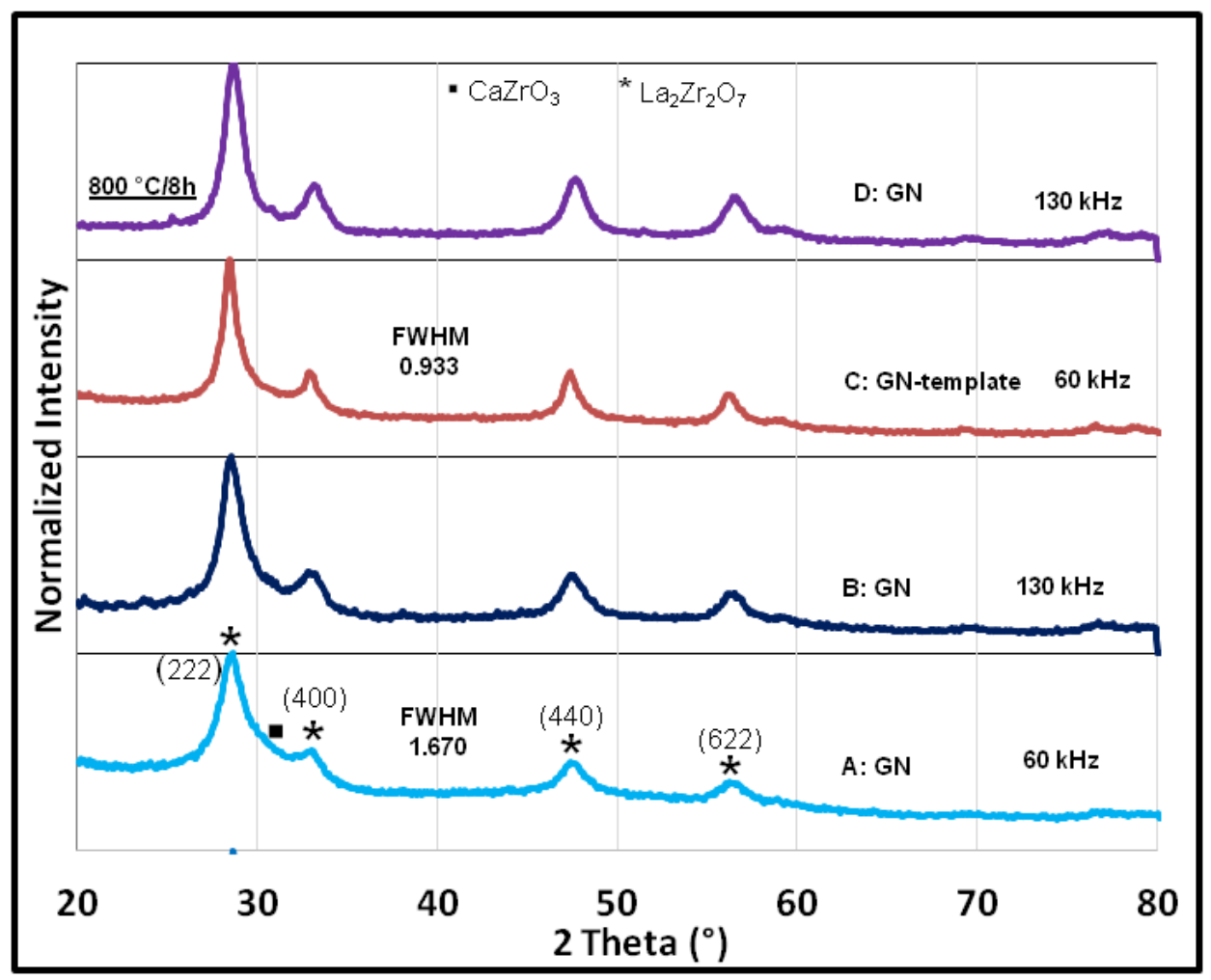

Figure 4.3.2.2: XRD spectra of catalysts synthesized from varied rhodium precursor solution. (A: Glycine $0.72 \mathrm{M} 60 \mathrm{kHz}, \mathrm{B}$ : Glycine $0.72 \mathrm{M} 130 \mathrm{kHz}, \mathrm{C}$ : Glycine $0.72 \mathrm{M} 60 \mathrm{kHz}, 20 \%$ seeded, D: Glycine $0.72 \mathrm{M} 130 \mathrm{kHz} 800{ }^{\circ} \mathrm{C} / 8 \mathrm{~h}$,)

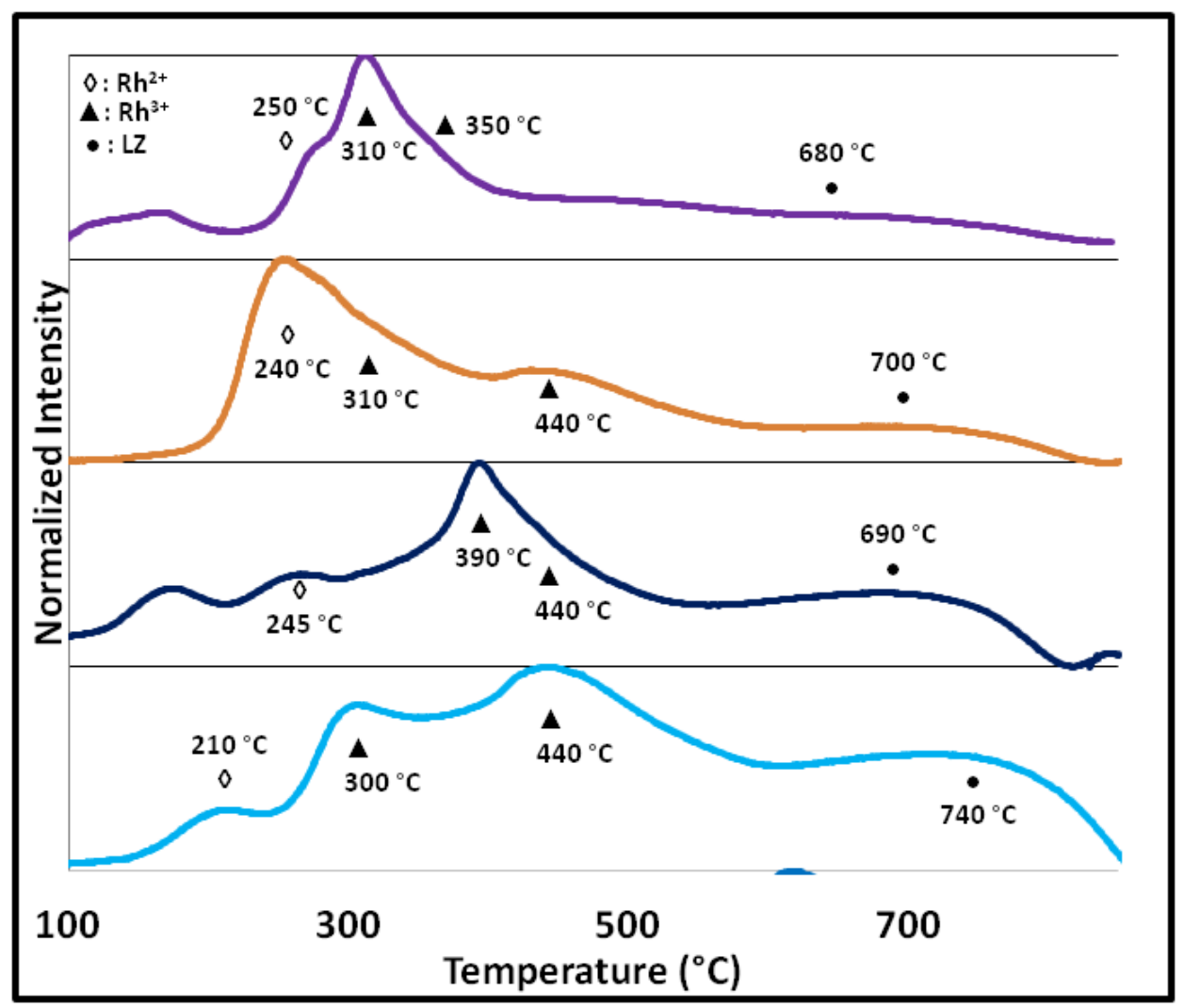

Figure 4.3.2.3: TPR of catalysts synthesized from varied rhodium precursor solution. (A: Glycine 0.72 M $60 \mathrm{kHz}, \mathrm{B}:$ Glycine 0.72 M $130 \mathrm{kHz}, \mathrm{C}$ : Glycine $0.72 \mathrm{M} 60 \mathrm{kHz}, 20 \%$ seeded, D: Glycine $0.72 \mathrm{M} 130 \mathrm{kHz} 800{ }^{\circ} \mathrm{C} / 8 \mathrm{~h}$,) 
The rapid aging testing results of the GN samples is presented in Figure 4.3.2.4. RAT results for the sample show the heat treated sample quickly reaches equilibrium yield of $\mathrm{H}_{2}$ and remains stable with little fluctuation 16 hours. This is a significant improvement from the as synthesized $130 \mathrm{kHz}$ GN sample, which deactivates to $30 \%$ of equilibrium $\mathrm{H}_{2}$ yield after 16 hours.

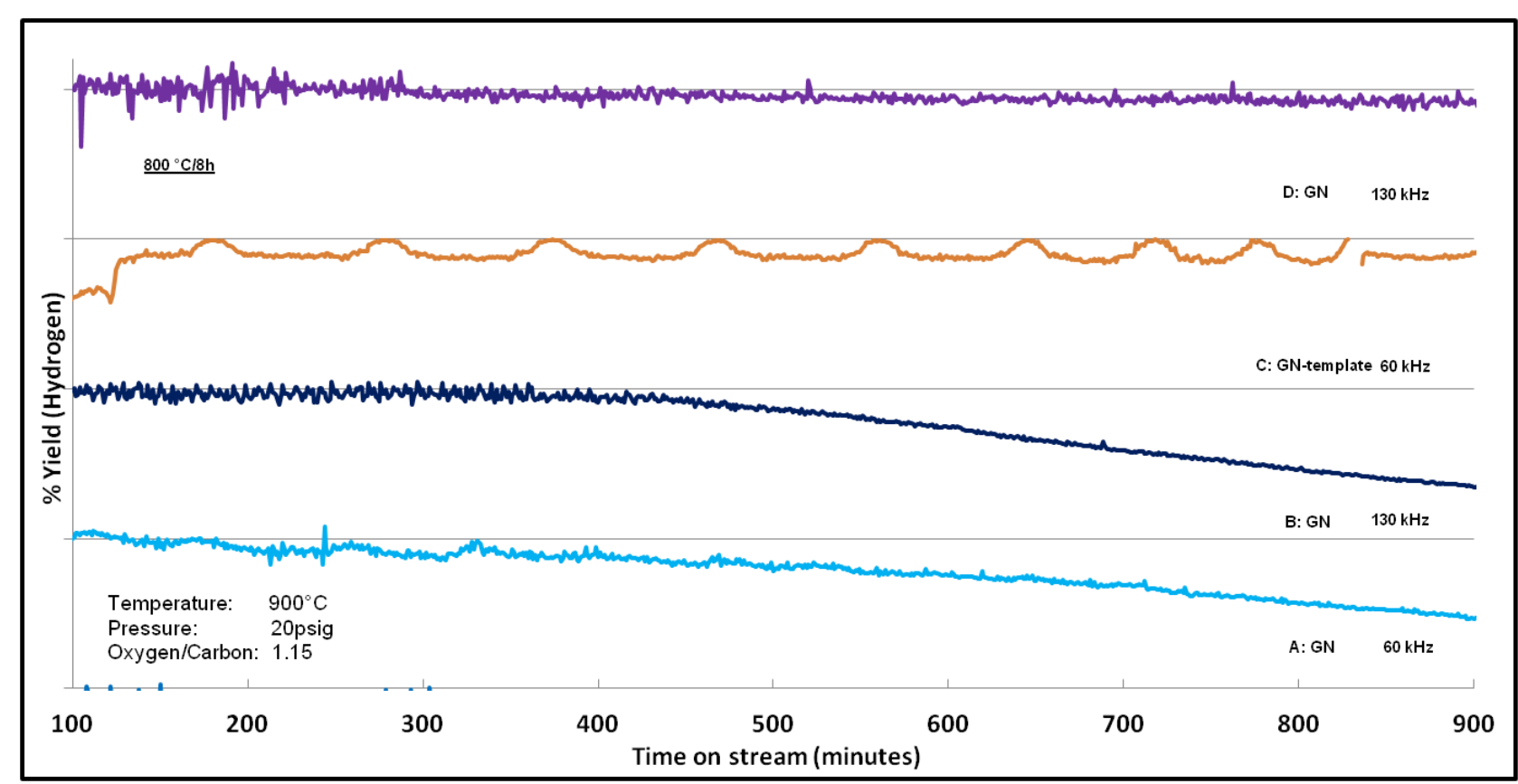

Figure 4.3.2.4: TPR of catalysts synthesized from varied rhodium precursor solution. (A: Glycine $0.72 \mathrm{M} 60 \mathrm{kHz}, \mathrm{B}: \mathrm{Glycine} 0.72$ M $130 \mathrm{kHz}, \mathrm{C}$ : Glycine $0.72 \mathrm{M} 60 \mathrm{kHz}, 20 \%$ seeded, D: Glycine $0.72 \mathrm{M} 130 \mathrm{kHz} 800{ }^{\circ} \mathrm{C} / 8 \mathrm{~h}$,)

Although the GN sample performed favorably after heat treatment, the purpose of the glycine-nitrate precursor solution experiments was to allow for single-step synthesis without heat treatment using the current SP test stand. To burn-off the excess carbon present in the samples, it was determined that the evaporation and nucleation steps needed to be accelerated. One method commonly used to accelerate crystallization in material synthesis is introducing a template material $^{61-63}$, but to the knowledge of the author this method has yet to be applied to a spray pyrolysis process. The precursor solution coats the template resulting in more surface area for vapor diffusion and defect sites that lower the energy required to begin crystallization. To prepare the template GN precursor, $50 \mathrm{~mL}$ of $0.72 \mathrm{M}$ Rh-GN solution was loaded with $1 \mathrm{~g}(20 \%$ 
of solution's theoretical yield) of particles prepared from the same solution at $60 \mathrm{kHz}$. The XRD spectra for the template and non-template solutions are presented as samples $\mathrm{A}$ and $\mathrm{C}$ in Figure 4.3.2.1. The spectrum displayed the expected 222 peak for pyrochlore at 28.475 in both samples and FWHM was calculated to be 1.670 and 0.933 respectively. This indicates a higher degree of crystallinity in the template sample. The normalized TPR results of the template and nontemplated samples prepared from the $0.72 \mathrm{M} \mathrm{GN}$ solution are presented as samples $\mathrm{A}$ and $\mathrm{C}$ in Figure 4.3.2.2. The TPR curve for the template sample shows broad peaks that span from 250 to $350{ }^{\circ} \mathrm{C}$ and a peak at $450{ }^{\circ} \mathrm{C}$. As discussed earlier, these peaks can be attributed to $\mathrm{Rh}^{2+,} \mathrm{Rh}^{3+}$ interacting with multiple phases, and $\mathrm{Rh}^{3+}$ in the pyrochlore phase, respectively. The same TPR peaks are identified in the non-template sample, however the $\mathrm{Rh}^{2+}$ peak is significantly less intense. Although the lower temperature peak areas contribute more than the $\mathrm{Rh}^{3+}$ peak in the template sample, the area of the $\mathrm{Rh}^{3+}$ peak relative to the $\mathrm{LZ}$ background is comparable to that of the non-template sample. This suggests that more Rh-sites are available in the template sample, which could be due to less surface carbon coating the sites. The RAT data of the samples are presented in Figure 4.3.2.3, where samples $\mathrm{A}$ and $\mathrm{C}$ represent the non-template and template samples respectively. The template sample remains stable with $\mathrm{H}_{2}$ yield near equilibrium for the duration of the test. As discussed previously, the non-template sample began deactivation after 8 hours and had a final $\mathrm{H}_{2}$ yield of $40 \%$.

\subsection{Conclusions}

As evidenced by the RAT results, both Pechini and Glycine-Nitrate precursor solutions can result in stable Rh-doped LZ catalysts suitable for auto-thermal applications. As concluded from the results in Chapter 3, catalysts prepared from the $60 \mathrm{kHz}$ atomizer were proven more 
stable. Increasing the frequency results in formation of less stable Rh-phases in the material that reduce at lower temperature during TPR analysis. GN samples show rapid deactivation after 8 hours during RAT, but removal surface carbon by heat treatment or the template method result in stable performance for the duration of the 16 rapid aging tests. 


\section{Chapter 5: High Frequency Atomization}

\subsection{Objectives}

The objective of this work is to synthesize and determine the properties of Ni-doped LZ nano-particles produced by spray pyrolysis. The previous work utilized atomizers operating in the kilo-hertz range that produce particles with diameters $>5 \mu \mathrm{m}$. To achieve particle sizes $<1$ $\mu \mathrm{m}$ an atomizer with a frequency in the mega-hertz range is required. Particles prepared from Pechini and glycine-nitrate methods atomized at $2.4 \mathrm{MHz}$ will be compared.

\subsection{Experimental}

\subsubsection{Spray pyrolysis}

A schematic of the vertical spray pyrolysis reactor system in this work is presented in Figure 5.2.1.1. The precursor solution was loaded into the syringe pump (1), and fed to the atomizing nozzle (2: Sonaer,) that produces a mist of particles. A laminar flow of compressed air was formed using a disc of porous alumina fit around the tip of the nozzle to carry the particles up the height of the reactor. The reactor is comprised of a quartz tube 1.5 meters in length and an inner diameter of $72 \mathrm{~mm}$. The particles flow through three heating zones $1 \mathrm{ft}$ in length (5) set to $600{ }^{\circ} \mathrm{C}, 800{ }^{\circ} \mathrm{C}$, and $900{ }^{\circ} \mathrm{C}$ respectively. The resultant powder was collected by a filter (3) and a DI water bubbler (4). Samples synthesized by the Pechini method were calcined to $1000{ }^{\circ} \mathrm{C}$ for 2 hours prior to TPR and rapid aging testing. 


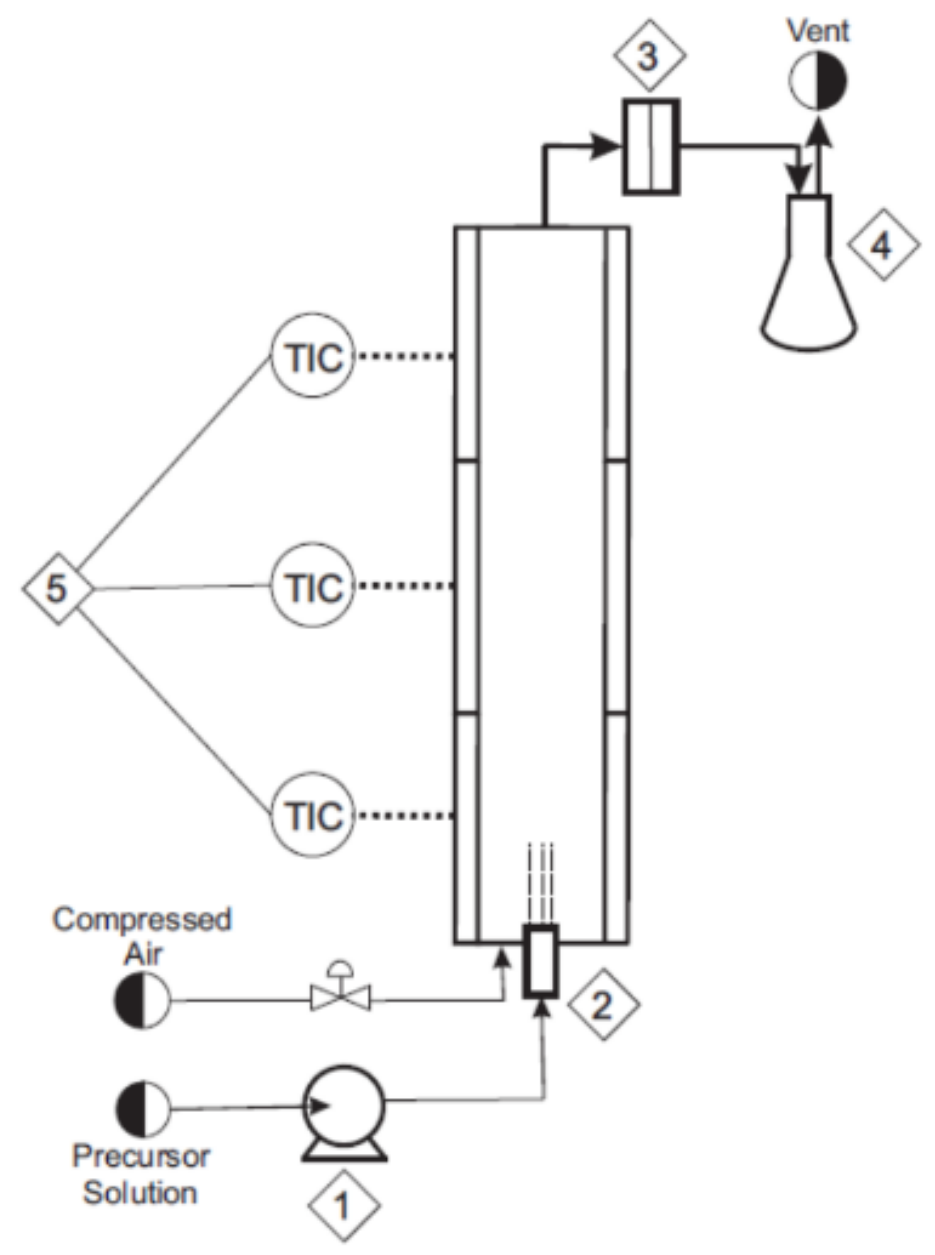

Figure 5.2.1.1: Spray pyrolysis experimental configuration.

Although the manufacturer of the nebulizing device (Sonaer.Inc) recommends circulating solution using the two ports on the nebulizer housing, early experiments indicated that the suction effect on the collection port was disrupting the air flow in the reactor, and preventing the particles from entering the reactor. In order to introduce sufficient precursor solution for the operation of the atomizer without encountering overflow or failure of the unit due to atomizer overheating, a liquid level control system was assembled, as illustrated by Figure 5.2.1.2. A positive DC current at 12 volts was supplied to 12 gauge copper wire positioned 1 inch from the nebulizer surface. A second wire was positioned approximately $1 / 8$ inch from the live wire and 
routed to a series of solid-state relay switches. The configuration of the relays was designed in order to supply AC current to GFCI receptacles powering a pump and the atomizer. The pump received power only when the fluid level dropped below the copper wires, opening the circuit, and turning on the atomizer when the fluid level covered the wires creating a closed circuit. This allowed for the nebulizer to be operated continuously near optimum fluid level.

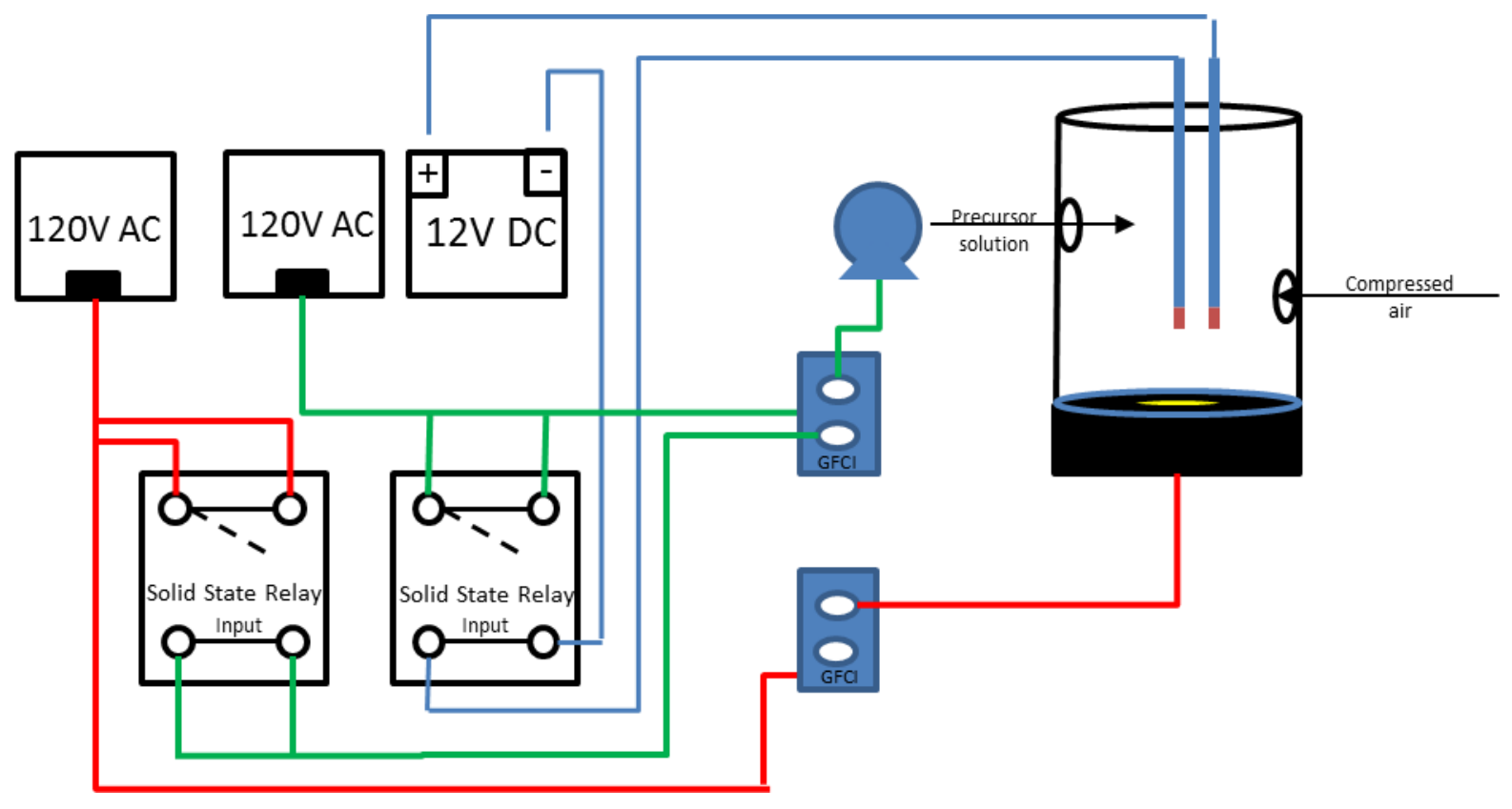

Figure 5.2.1.2: Liquid Level Control Diagram

The nebulizer configuration for initial experiments in this study is illustrated by Figure 5.2.1.3. The nebulizer generates a cloud of particles that are carried by compressed air into the reactor. At the reactor inlet, additional gas is added to assist in transporting the droplets up through the length of the reactor tube. This configuration did not successfully yield a sufficient amount of catalyst for characterization. The low yield was attributed to mist produced by the nebulizer that was not able to flow around the $90^{\circ}$ angle, causing observed accumulation of precursor gel in the tubing at that point. To confirm this hypothesis, the compressed air flow rate to the nebulizer was varied from 5 to 40 SCFM in a fume hood while atomizing distilled water to observe the flow characteristics. A significant quantity of particles were not observed to exit the 
tubing at any of the flow rates, and it was concluded that this configuration is not suitable for a vertical tubular reactor system.

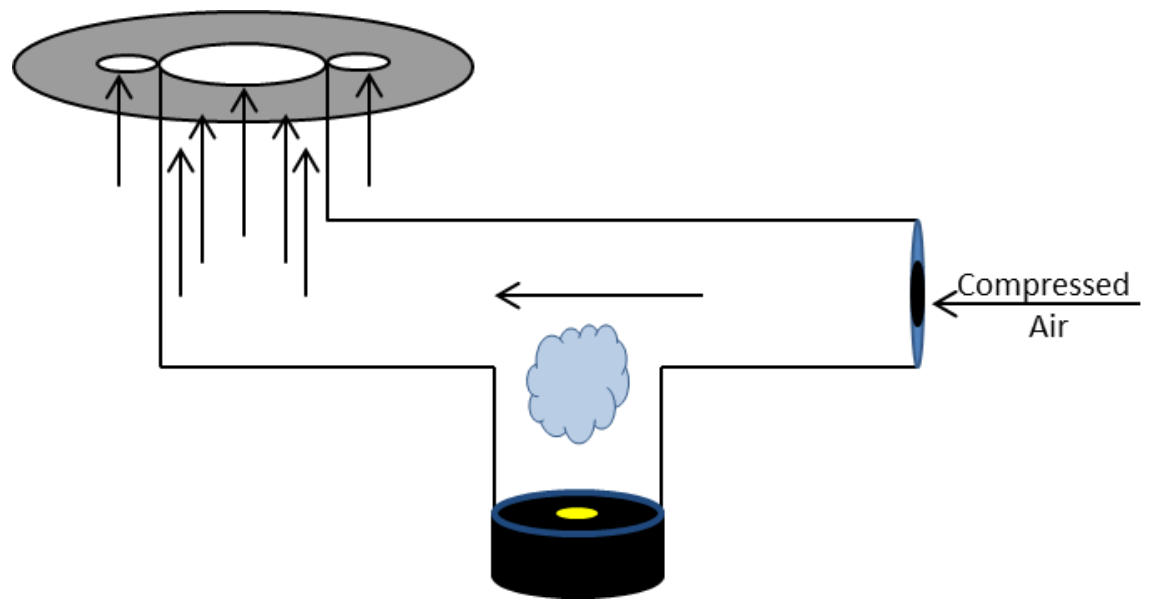

Figure 5.2.1.3: Cross flow nebulizer assembly

In order to ensure the particles generated by the nebulizer entered the reactor, a direct connection from the atomizer to the reactor was implemented as illustrated by Figure 5.2.1.4. The reactor was tested using nominal conditions and a nickel-Pechini precursor solution at a 0.09 molar concentration. Although the particles were observed entering the reactor, the flow profile of the carrier gas caused the particles to coat the bottom of the reactor tube, and negligible sample was collected. Splattering of the precursor solution out of the nebulizing vessel and onto the reactor tube was also observed. Based upon these observations and other considerations, it was concluded that additional modification of the system was required.

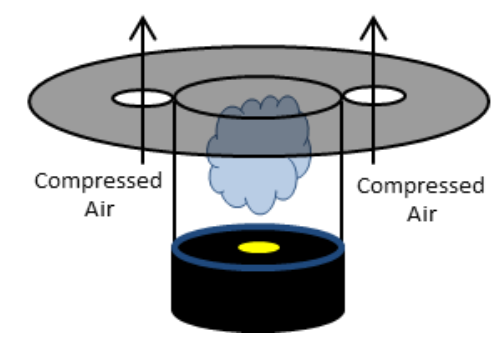

Figure 5.2.1.4: Direct flow nebulizer assembly 
To that end, additional tubing length was added to the nebulizer-reactor interface. This prevented spillover of large droplets to the bottom of the reactor. To assist in the movement of particles into the reactor, compressed air was introduced just above the liquid level in the nebulizer. Experimentation with distilled water indicated that an air flow rate of approximately 3 SCFM effectively carried the particles into the reactor. At greater gas flow rates droplets were pushed to the side of the nebulizing chamber and flowed back into the precursor reservoir. This configuration, illustrated by Figure 5.2.1.5, successfully produced a quantity of sample sufficient for XRD and SEM analysis, and was used for all five experiments reported. All other experimental methods followed the procedures discussed in Chapter 2.

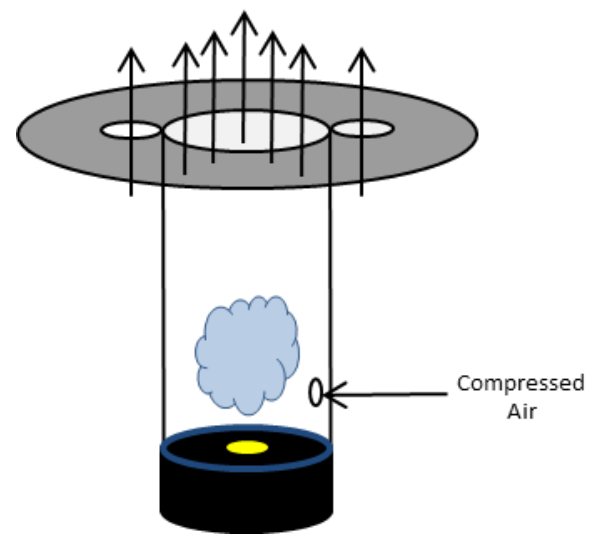

Figure 5.2.1.5: Lengthened direct-flow nebulizer assembly

\subsection{Results}

Initial experiments were performed using the Pechini precursor solution. The Pechini precursor solution was required to be diluted to a concentration of $0.09 \mathrm{M}$ to facilitate atomization. However evaporation inside the nebulizer resulted in higher concentrations during operation and caused very low atomization rates. The XRD spectra in Figure 5.3.1 indicate the 
formation of an amorphous pyrochlore phase for both experiments conducted with the $0.09 \mathrm{M}$ Pechini solution. The background signal varies between the two patterns and was attributed to carbon contamination of the sample. Figure 5.3.2 represents SEM of the particles obtained from the water bath of the Pechini precursor solution. The particle morphology is clearly spherical, with a particle size ranging from a few hundred nanometers to a few microns.

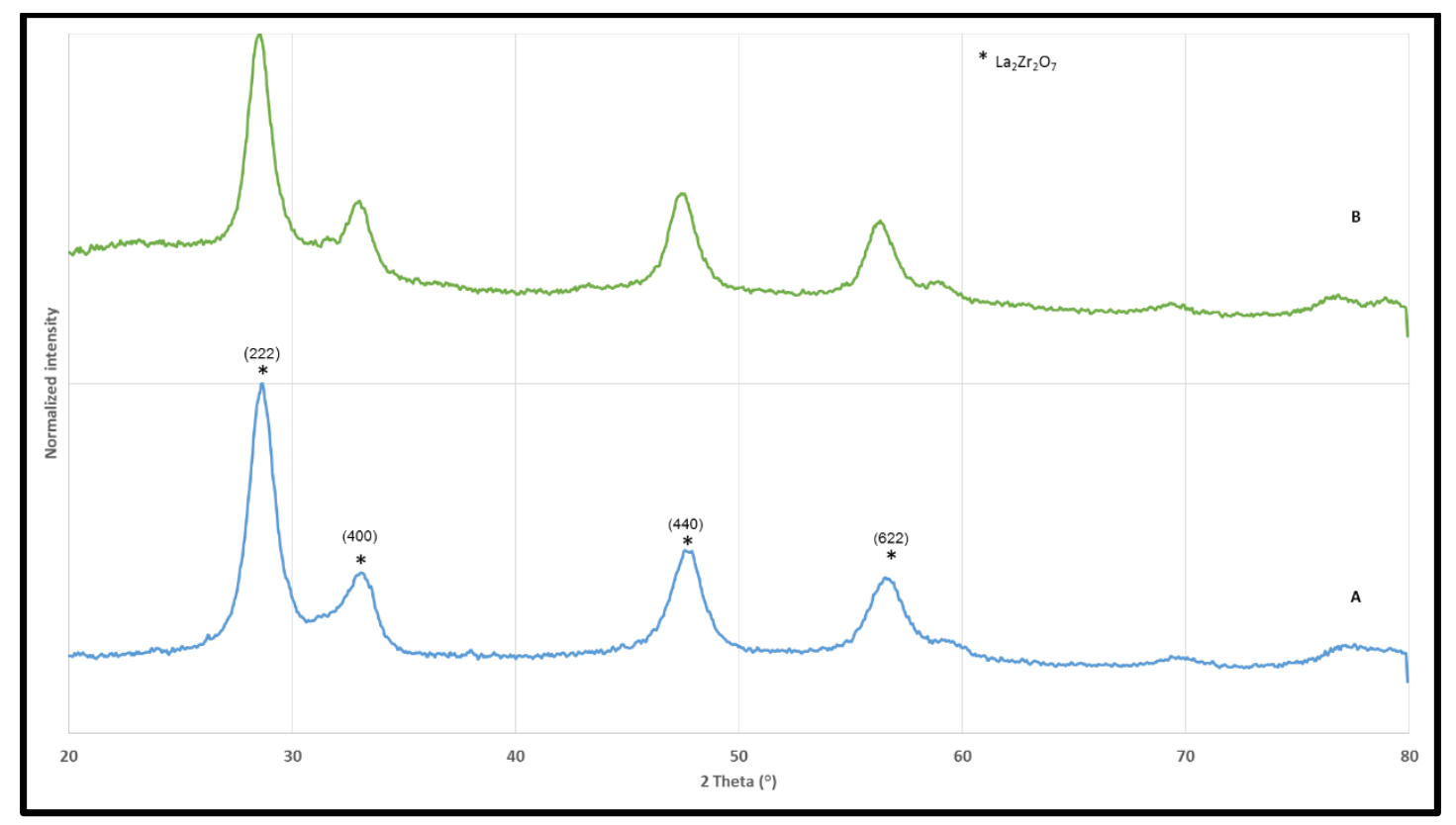

Figure 5.3.1: XRD patterns of particles synthesized from Pechini precursor at 2.4 MHz (A and B represent 0.9 Molar concentration $(\mu=1.45 \mathrm{cp}))$ 


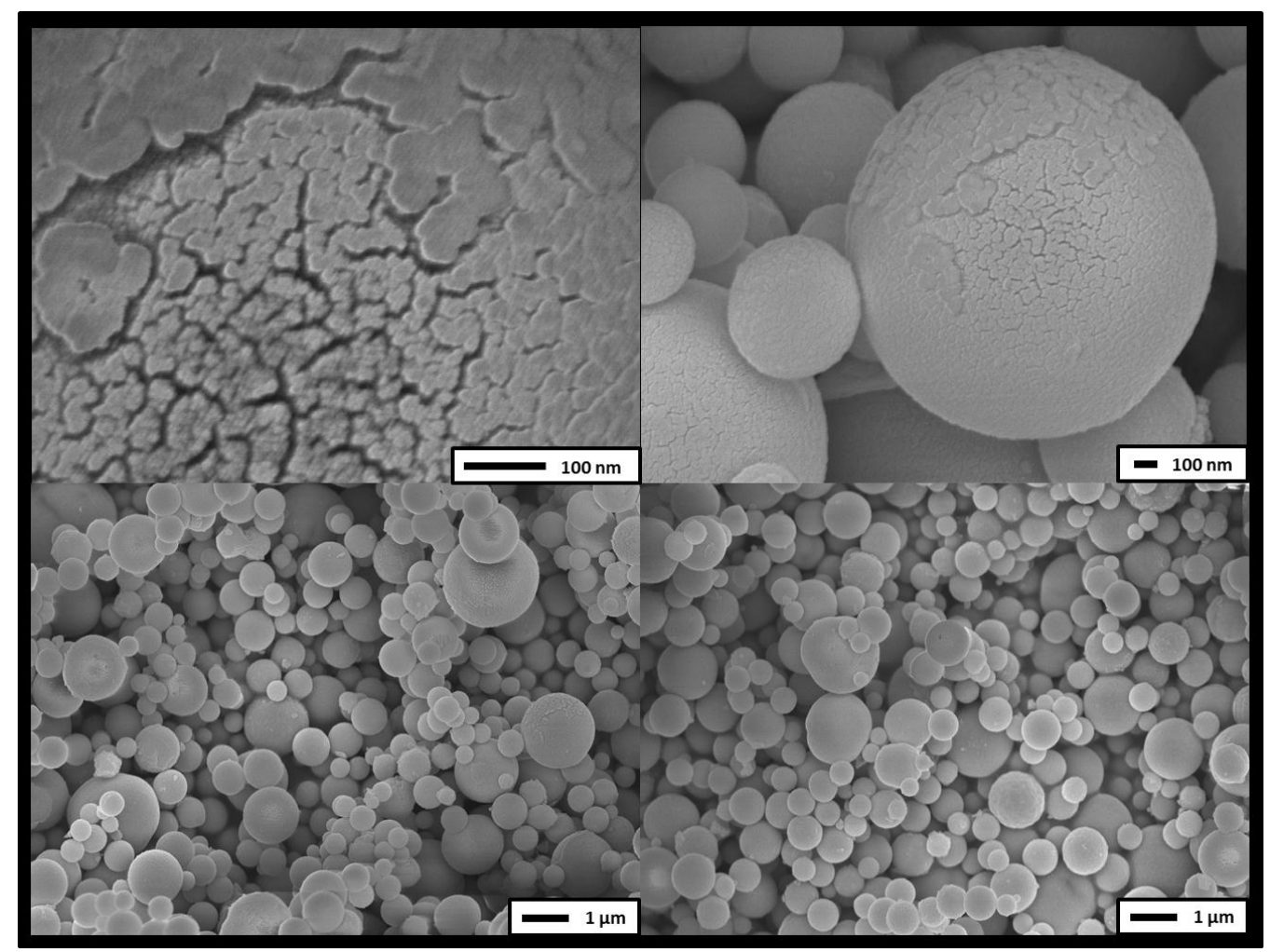

Figure 5.3.2: SEM images of 2.4 MHz, 0.09 Molar Pechini particles

The glycine samples XRD spectra, presented in order of concentration, are represented by Figure 5.3.3. Significant secondary phases are present in the XRD pattern, and have been labeled with asterisks and identified as $\mathrm{La}_{2} \mathrm{O}_{3},{ }^{\mathrm{c}} \mathrm{ZrO}_{2},{ }^{\mathrm{d}}$ nano-crystalline $\mathrm{ZrO}_{2},{ }^{\mathrm{e}}$ and $\mathrm{La}_{2} \mathrm{Zr}_{2} \mathrm{O}_{7}{ }^{\mathrm{f}}$. The pyrochlore phase is present, but the ratio of pyrochlore phase to secondary phases decreases as the solution concentration increases. It is also noted that the nanocrystalline phase has a weaker signal relative to the bulk when using the higher concentration precursor solution. This is explained by the lanthanum and zirconium forming oxides rather than $\mathrm{La}_{2} \mathrm{Zr}_{2} \mathrm{O}_{7}$.

\footnotetext{
CJCPDS\#: 01-073-2141

d JCPDS\#:97-000-9993

e JCPDS\#:97-009-2093

f JCPDS\#:00-050-0837
} 


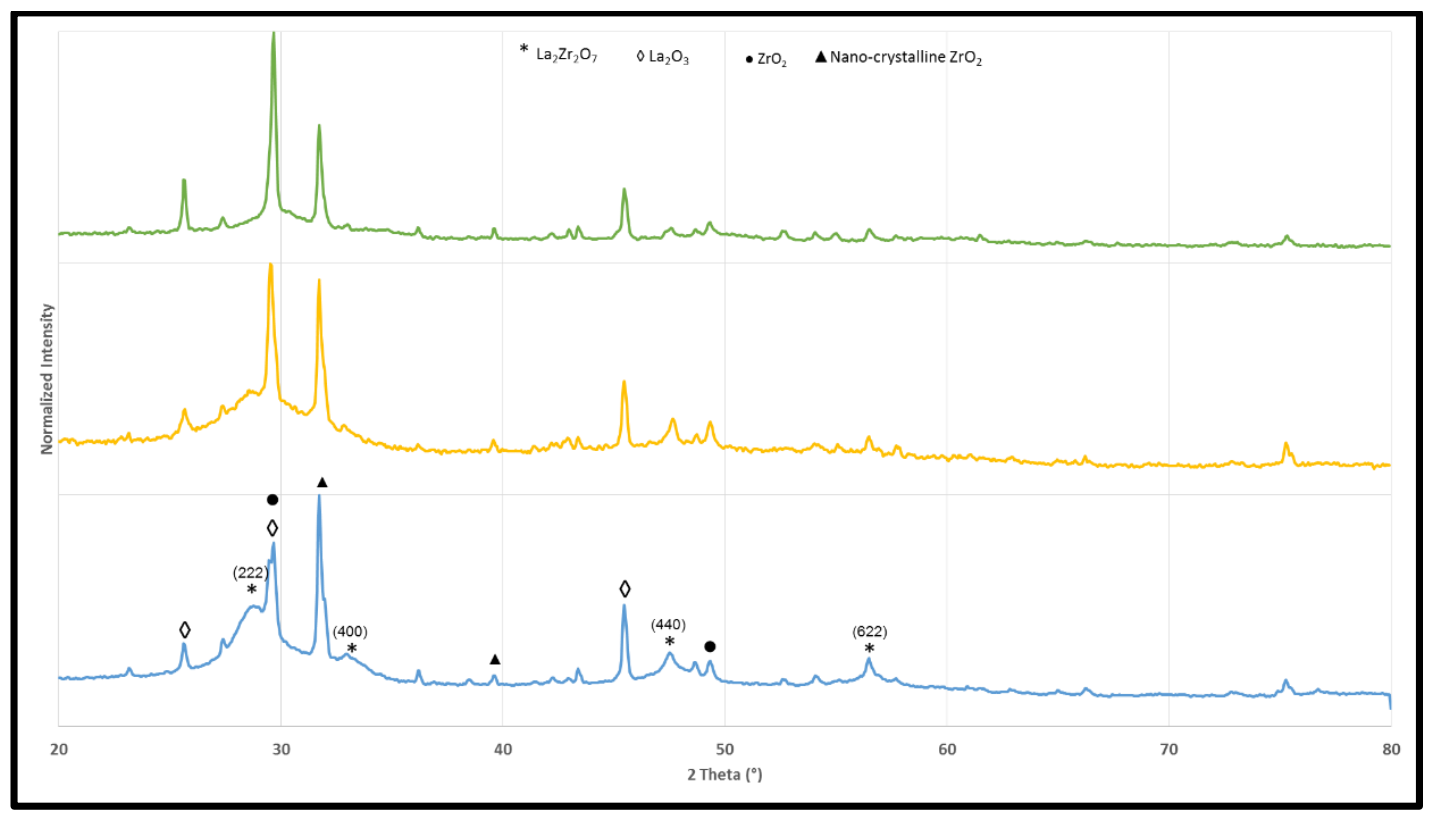

Figure 5.3.3: XRD patterns of particles synthesized from Glycine-nitrate precursor at 2.4 MHz (A:0.9 Molar $(\mu=1.25 \mathrm{cp}), \mathrm{B}: 0.18$ Molar $(\mu=2.11 \mathrm{cp}), \mathrm{C}: 0.36$ Molar $\left(\mu=2.26 \mathrm{cp}\right.$ ). (Green: $\mathrm{La}_{2} \mathrm{O}_{3}$, Blue: $\mathrm{La}_{2} \mathrm{Zr}_{2} \mathrm{O}_{7}$, Orange: $\mathrm{ZrO}_{2}$, Black: Nano-crystalline $\mathrm{ZrO} \mathrm{O}_{2}$ )

The underlying cause of the secondary phase formation was not directly observed, but due to the higher $\mathrm{pH}$ of the glycine solution and the evaporation rate particles it is likely that precipitation of precursor metals contributes. Due to the smaller droplet size, the amount of heat present for combustion in each particle is insufficient to for crystalline LZ. This result is in agreement with the results from the 60 and $130 \mathrm{kHz}$ studies which also found that higher frequency atomization resulted in less crystalline material. As concentration increases the droplet size decreases, further reducing the temperature observed by the particles. SEM images of the GN samples are shown in Figures 5.3.4-5.3.6, in order of increasing concentration. Although some spherical particles are observed, the majority of particles are agglomerates or thin flakes of material. As the concentration is increased, the trend of morphology shifts to fractured spherical particles. Debris and large grains are clearly visible in the SEM micrographs for all concentrations, however chemical identification of particles at this size is not possible with sufficient resolution for this purpose. 


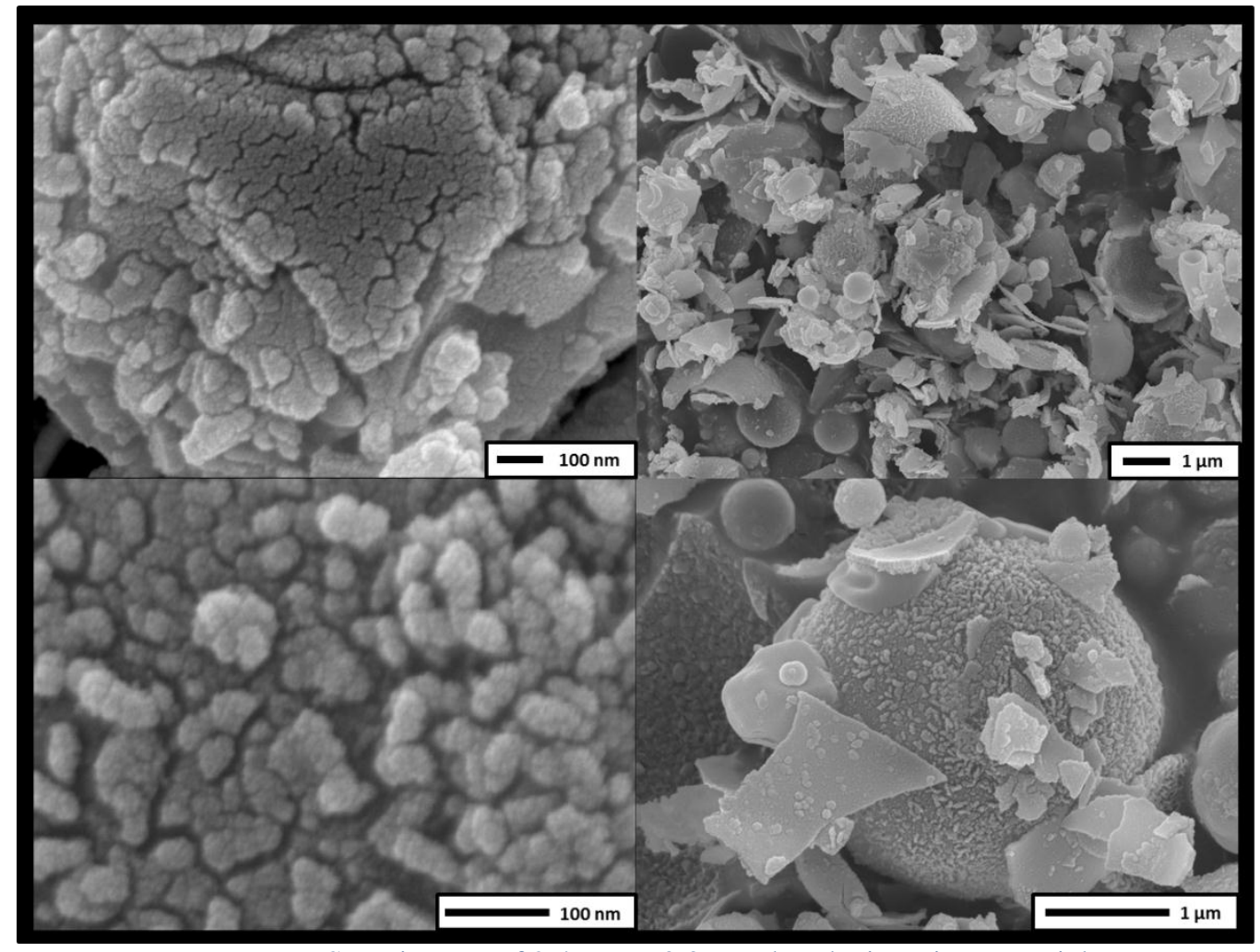

Figure 5.3.4: SEM images of $2.4 \mathrm{MHz}, 0.09$ Molar glycine-nitrate particles

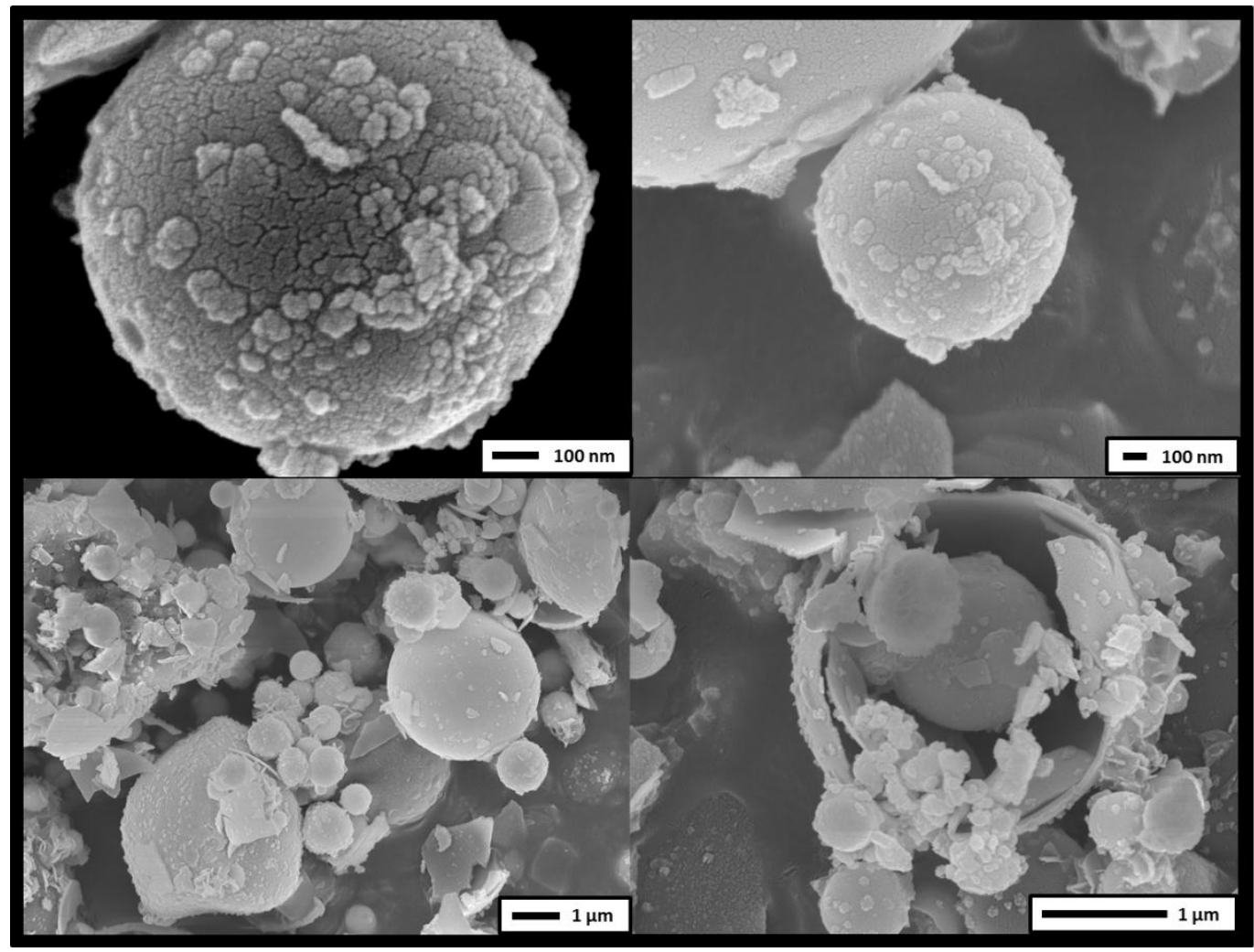

Figure 5.3.5: SEM images of $2.4 \mathrm{MHz}, 0.18$ Molar glycine-nitrate particles 


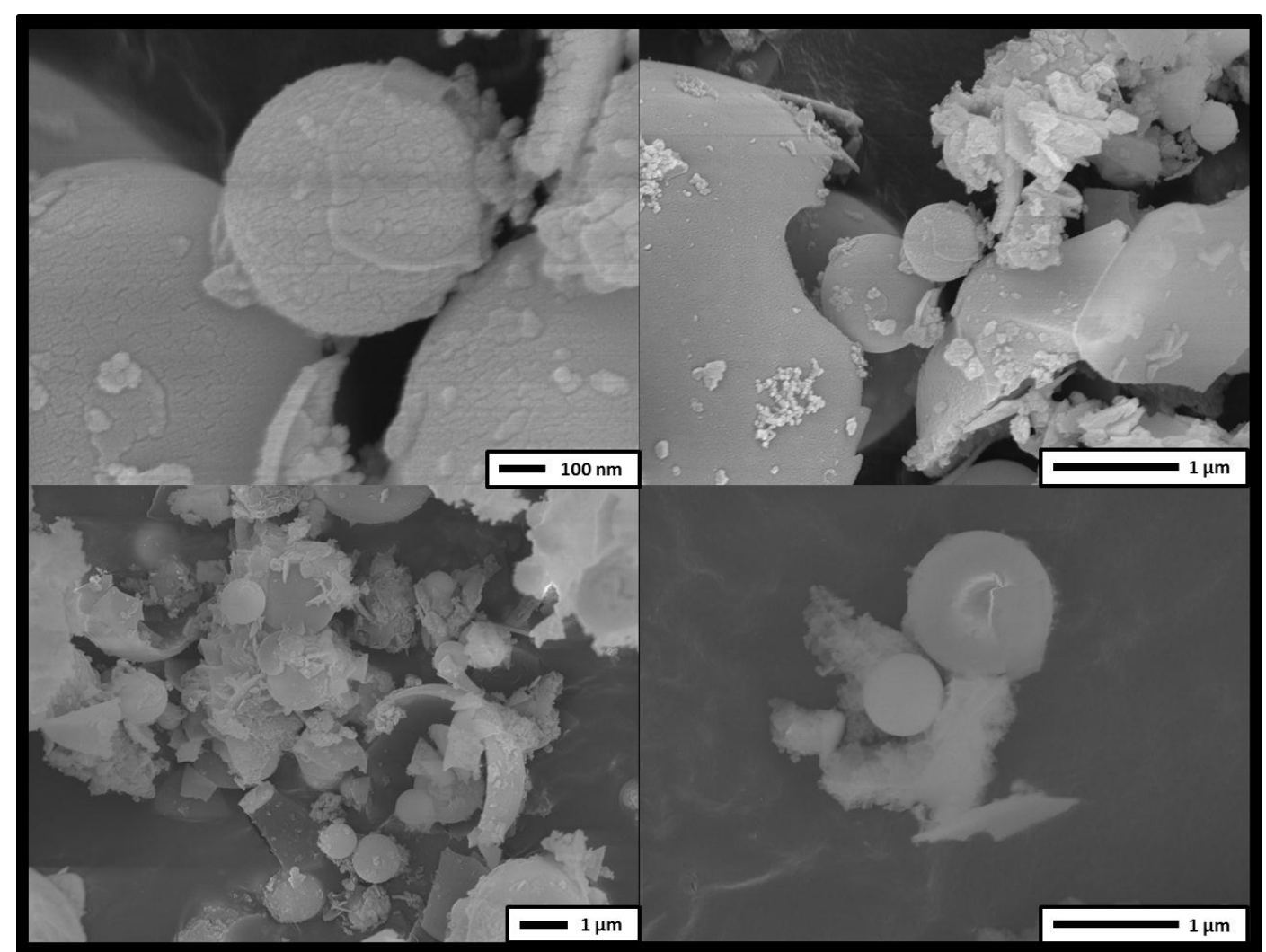

Figure 5.3.6 SEM images of 2.4 MHz, 0.36 Molar glycine-nitrate particles

Pechini and glycine samples were calcined to $1000^{\circ} \mathrm{C}$ for 2 hours with a $3^{\circ} \mathrm{C} / \mathrm{min}$ ramp rate. The samples were analyzed by SEM to observe changes in morphology. The micrographs are pictured in Figure 5.3.1.6 below. The spherical nano-particles observed in the amorphous samples are still present in the calcined samples. Although the particles retain their original morphology, after the heat treatment, it was observed that the spheres fused to form agglomerates. Although the 2.4 atomizer was able to produce Ni-doped $\mathrm{La}_{2} \mathrm{Zr}_{2} \mathrm{O}_{7}$, but the atomization rate was insufficient to produce enough catalyst for comprehensive characterization. Further study will be required to determine the feasibility and the properties of catalysts produced by this method. However, it is likely that the trend observed between the 60 and 130 $\mathrm{kHz}$ materials will apply to the $2.4 \mathrm{MHz}$ materials. 


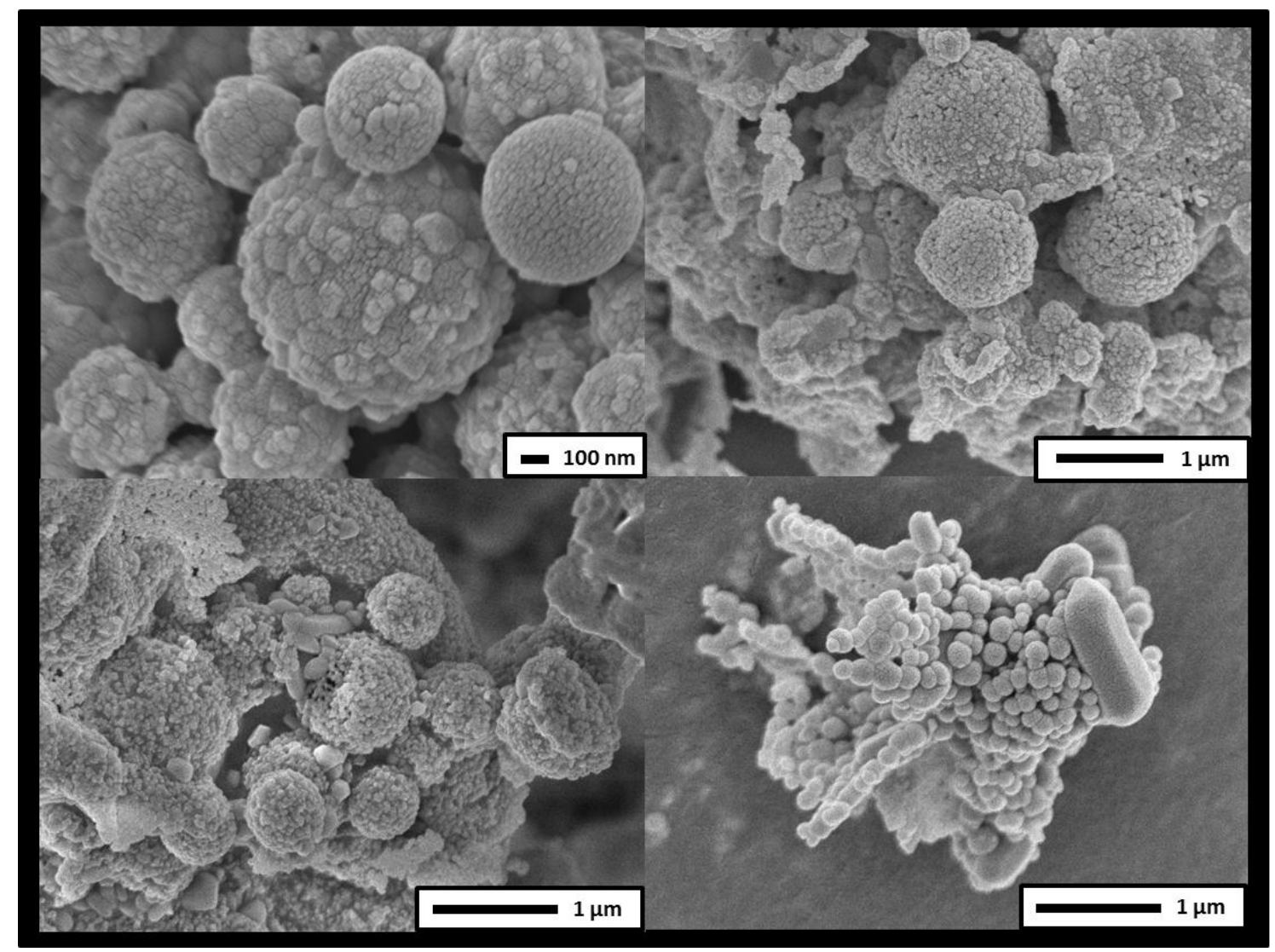

Figure 5.3.7: SEM images of calcined Pechini and glycine samples atomized at $2.4 \mathrm{MHz}$. In descending order (from left to right) : 0.09 M Pechini, 0.09 M glycine, 0.18 M glycine, 0.36 M glycine.

\subsection{Conclusions}

Ni-doped LZ nano-particles were successfully synthesized using a $2.4 \mathrm{MHz}$ atomizer from Pechini precursor solution. The atomizer required very dilute solutions with viscosities $<1.5 \mathrm{cp}$. Nano-particles synthesized from glycine-nitrate precursors formed the pyrochlore phase, however significant secondary phases identified as $\mathrm{LaO}_{2}$ and $\mathrm{ZrO}_{2}$ were present in the XRD 
spectra. Increasing GN solution concentration resulted in more secondary phases formation as seen in the XRD spectra. 


\section{Chapter 6: Conclusions and Recommendations for Future Study}

Ni- and Rh-doped LZ by from Pechini and glycine-nitrate precursor solutions using ultrasonic atomizers operating at multiple frequencies were successfully synthesized by spray pyrolysis. Pechini Ni- and Rh-doped LZ samples formed fully-crystalline, stable catatlysts after heat treatment to $1000{ }^{\circ} \mathrm{C}$ for 2 hours. Glycine-nitrate Ni-doped LZ samples were crystalline with 222 peak FWHM values ranging from 1.630 to 0.368 and were stable as synthesized. This process can reduce the time and temperature required to produce this material from $1000{ }^{\circ} \mathrm{C}$ and 36 hours by the batch method to $500{ }^{\circ} \mathrm{C}$ and approximately 30 minutes by spray-pyrolysis. However, Rh-doped LZ synthesized from the glycine-nitrate precursor was found to be coated with carbon that caused rapid deactivation of the catalyst after 8 hours of rapid aging testing. The carbon was removed by both heat treatment and template methods, resulting in $90 \% \mathrm{H}_{2}$ yield for the duration of the rapid aging testing. To eliminate the need for the heat treatment step that would increase the energy and time required for synthesis, a novel template-spray-pyrolysis method was developed. The template method reduced activation energy of nucleation and enhanced combustion of precursor solution during spray pyrolysis. This method resulted in higher crystallinity and improved performance testing, and holds promise for enhancing catalyst properties.

The effects of chemical and system variables upon material properties on the catalysts were investigated. Solution concentration was found to strongly affect catalyst properties. Increasing precursor solution resulted in more crystalline pyrochlore materials with higher valence states of $\mathrm{Ni}$ and $\mathrm{Rh}$ incorporated into the pyrochlore lattice. Atomizer frequency was found to relate inversely to crystallinity, and increased frequency resulted in lower valence states of $\mathrm{Ni}$ and $\mathrm{Rh}$ comprising a majority of the active sites. The relations found in this study provide 
evidence that low frequency atomization and high solution concentrations should be used when preparing LZ by spray pyrolysis.

It is recommended that future work investigate longer term reforming studies to confirm the RAT results reflect the long-term stability of the Rh catalyst materials. For this study the glycine:nitrate ratio was held constant, but determination of the optimum ratio for the precursor composition in this study could result in a catalyst with more desired properties. Further experimentation using novel template method is recommended to assess its advantages in forming active catalyst materials by spray pyrolysis. 


\section{Bibliography}

1. Van, C. \& Dettling, J. Rhodium-Support Interactions in Automotive Exhaust Catalysts. (1987).

2. $\quad$ Maeda, K. Rhodium-Doped Barium Titanate Perovskite as a Stable p-Type Semiconductor Photocatalyst for Hydrogen Evolution under Visible Light. (2014). doi:10.1021/am405293e

3. Padeste, C., Cant, N. \& Trimm, D. Reactions of ceria supported rhodium with hydrogen and nitric oxide studied with TPR/TPO and XPS techniques. Catalysis Letters (1994). doi:10.1007/BF00806060

4. Haynes, D., Berry, D., Shekhawat, D. \& Spivey, J. Catalytic partial oxidation of $<$ i $>$ $\mathrm{n}</ \mathrm{i}>$-tetradecane using pyrochlores: Effect of $\mathrm{Rh}$ and $\mathrm{Sr}$ substitution. (2008).

5. Gaur, S., Haynes, D. \& Spivey, J. Rh, Ni, and Ca substituted pyrochlore catalysts for dry reforming of methane. (2011).

6. ....., Shaw, C., Haynes, D., Shekhawat, D. \& Spivey, J. Effect of reaction temperature on activity of Pt-and Ru-substituted lanthanum zirconate pyrochlores ( $\mathrm{La}<\mathrm{sub}>2</ \mathrm{sub}>\mathrm{Zr}<\mathrm{sub}>$ $2</$ sub $>\mathrm{O}<$ sub $>7</$ sub $>$ ) for dry $(\mathrm{CO} \ldots . .(2013)$.

7. Cao, X. et al. Thermal Stability of Lanthanum Zirconate Plasma- Sprayed Coating. Journal of the American Ceramic Society (2001). doi:10.1111/j.1151-2916.2001.tb00962.x

8. Cao, X., Vassen, R. \& Stoever, D. Ceramic materials for thermal barrier coatings. (2004).

9. Kilner, J. Fast oxygen transport in acceptor doped oxides. (2000).

10. Kramer, S. \& Tuller, H. A novel titanate-based oxygen ion conductor: Gd 2 Ti 2 O 7. Solid State Ionics 82, 15-23 (1995).

11. Dijk, V., Vries, D. \& Burggraaf, A. Oxygen ion and mixed conductivity in compounds with the fluorite and pyrochlore structure. (1983).

12. Mandal, B. \& Deshpande, S. Ionic conductivity enhancement in $\mathrm{Gd} 2 \mathrm{Zr} 2 \mathrm{O} 7$ pyrochlore by Nd doping. (2008).

13. Díaz-Guillén, J., Fuentes, A. \& Díaz-Guillén, M. The effect of homovalent A-site substitutions on the ionic conductivity of pyrochlore-type $\mathrm{Gd} 2 \mathrm{Zr} 2$ O 7. (2009).

14. Díaz-Guillén, J., Díaz-Guillén, M. \& Padmasree, K. High ionic conductivity in the pyrochlore-type Gd 2- y La y Zr 2 O 7 solid solution $(0 \leq \mathrm{y} \leq 1)$. (2008).

15. Yamamura, H., Nishino, H., Kakinuma, K. \& Nomura, K. Electrical conductivity anomaly around fluorite-pyrochlore phase boundary. (2003).

16. Holtappels, P., Poulsen, F. \& Mogensen, M. Electrical conductivities and chemical stabilities of mixed conducting pyrochlores for SOFC applications. (2000).

17. Dijk, V., Vries, D. \& Burggraaf, A. Electrical conductivity of fluorite and pyrochlore LnxZr1-xO2-x/2 (Ln= Gd, Nd) Solid Solutions. (1980). doi:10.1002/pssa.2210580114

18. Stanek, C. \& Minervini, L. Nonstoichiometry in A2B2O7 pyrochlores. (2002). doi:10.1111/j.1151-2916.2002.tb00530.x

19. Vassen, R., Cao, X., Tietz, F. \& Basu, D. Zirconates as new materials for thermal barrier coatings. (2000). doi:10.1111/j.1151-2916.2000.tb01506.x

20. Kintaka, Y. et al. Abnormal Partial Dispersion in Pyrochlore Lanthanum Zirconate

Transparent Ceramics. Journal of the American Ceramic Society 95, 28992905 (2012).

21. Jarligo, M., Kang, Y.-S. \& Kawasaki, A. Physicochemical Properties of Single Phase La2Zr2O7 Powder. MATERIALS TRANSACTIONS 46, 189-192 (2005). 
22. Azad, AM \& Subramaniam, S. Synthesis of BaZrO 3 by a solid-state reaction technique using nitrate precursors. Materials research bulletin (2002). at

<http://www.sciencedirect.com/science/article/pii/S0025540801008017>

23. Sathyamurthy, S. \& Paranthaman, M. Lanthanum zirconate: A single buffer layer processed by solution deposition for coated conductor fabrication. (2002).

24. Ion, E.-D. et al. Characterization of lanthanum zirconate prepared by a nitrate-modified alkoxide synthesis route: From sol to crystalline powder. Journal of the European Ceramic Society 30, 569-575 (2010).

25. Wang, C. et al. Nanocomposite Lanthanum Zirconate Thermal Barrier Coating Deposited by Suspension Plasma Spray Process. J Therm Spray Tech (2014). doi:10.1007/s11666-0140068-3

26. Weber, S., Lein, H., Grande, T. \& Einarsrud, M. Deposition Mechanisms of Thick Lanthanum Zirconate Coatings by Spray Pyrolysis. J. Am. Ceram. Soc. 94, 42564262 (2011). 27. Kitaoka, K., Kozuka, H. \& Yoko, T. Preparation of Lead Lanthanum Zirconate Titanate (PLZT, (Pb,La)(Zr,Ti)O3) Fibers by Sol- Gel Method. Journal of the American Ceramic Society 81, 11891196 (1998).

28. Razpotnik, T. \& Maček, J. Synthesis of nickel oxide/zirconia powders via a modified Pechini method. Journal of the European Ceramic Society 27, 14051410 (2007).

29. Douy, A. Polyacrylamide gel: an efficient tool for easy synthesis of multicomponent oxide precursors of ceramics and glasses. International Journal of Inorganic Materials $\mathbf{3}$, 699707 (2001).

30. Qiu, S. et al. $\mathrm{Pb}(\mathrm{Zr} 0.95 \mathrm{Ti} 0.05) \mathrm{O} 3$ powders and porous ceramics prepared by one-step pyrolysis process using non-aqueous Pechini method. Ceramics International 35, 733740 (2009). 31. Nair, J. et al. Sintering of Lanthanum Zirconate. Journal of the American Ceramic Society 82, 20662072 (1999).

32. Thangaraju, D., Babu, S., Samuel, P., Durairajan, A. \& Hayakawa, Y. Influence of pH and microwave calcination on the morphology of KGd(WO4)2 particles derived by Pechini SolGel method. Journal of Sol-Gel Science and Technology 58, 419426 (2011).

33. Chen, X., Li, Z., Bao, S. \& Ji, P. Porous MA12O4:Eu2+ (Eu3+), Dy3+ (M=Sr, Ca, Ba) phosphors prepared by Pechini-type sol-gel method: The effect of solvents. Optical Materials 34, 4855 (2011).

34. Wang, C. et al. Hydrothermal assisted synthesis and hot-corrosion resistance of nano lanthanum zirconate particles. (2014).

35. Sardar, K. et al. Nanocrystalline Cerium-Bismuth Oxides: Synthesis, Structural Characterization, and Redox Properties. Chemistry of Materials 22, 61916201 (2010).

36. Zeng, J., Wang, H., Zhang, Y., Zhu, M. \& Yan, H. Hydrothermal synthesis and photocatalytic properties of pyrochlore La2Sn2O7 nanocubes. The Journal of Physical Chemistry C 111, 11879-11887 (2007).

37. Weng, X. et al. Synthesis and characterization of doped nano-sized ceria-zirconia solid solutions. Applied Catalysis B: Environmental 90, 405415 (2009).

38. Messing, G., Zhang, S. \& Jayanthi, G. Ceramic Powder Synthesis by Spray Pyrolysis. J American Ceramic Society (1993). doi:10.1111/j.1151-2916.1993.tb04007.x

39. Tohge, N, Tatsumisago, M \& Minami, T. Direct Preparation of Uniformly-Distributed YBa2Cu3O7-x Powders by Spray-Pyrolysis. Japanese journal of ... (1988).

doi:10.1143/JJAP.27.L1086 
40. Jang, H. et al. Characteristics of samaria-doped ceria nanoparticles prepared by spray pyrolysis. Ceramics International 36, 465471 (2010).

41. Mädler, L., Kammler, H., Mueller, R. \& Pratsinis, S. Controlled synthesis of nanostructured particles by flame spray pyrolysis. Journal of Aerosol Science 33, 369389 (2002).

42. Height, M., Mädler, L. \& Pratsinis, S. Nanorods of ZnO made by flame spray pyrolysis. (2006). doi:10.1021/cm052163y

43. Mädler, L. \& Pratsinis, S. Bismuth Oxide Nanoparticles by Flame Spray Pyrolysis. Journal of the American Ceramic Society (2002). doi:10.1111/j.1151-2916.2002.tb00340.x 44. Bickmore, C., Waldner, K. \& Baranwal, R. Ultrafine titania by flame spray pyrolysis of a titanatrane complex. (1998).

45. Lee, J. et al. Mn-Doped Zn2SiO4 Phosphors Synthesis Using Flame Spray Pyrolysis. Journal of Thermal Spray Technology 20, 10011008 (2011).

46. Lee, G.-Y. et al. Properties of $\mathrm{Cu}, \mathrm{Ni}$, and $\mathrm{V}$ doped-LaCrO 3 interconnect materials prepared by pechini, ultrasonic spray pyrolysis and glycine nitrate processes for SOFC. Journal of Electroceramics 17, 723727 (2006).

47. Jiang, K., Liu, S. \& Li, C. Nano-Nano Composite Powders of Lanthanum Zirconate and Yttria-Stabilized Zirconia by Spray Pyrolysis. Journal of the American Ceramic Society n/an/a (2013). doi:10.1111/jace.12470

48. Faber, H. et al. Indium oxide thin-film transistors processed at low temperature via ultrasonic spray pyrolysis. ACS applied materials \& interfaces 7, 782-90 (2015).

49. Oh, S., Bang, H., Bae, Y. \& Sun, Y... on morphology, crystallinity and electrochemical properties of nano-crystalline metal oxides ( $\mathrm{Co} 3 \mathrm{O} 4, \mathrm{CuO}$, and $\mathrm{NiO}$ ) prepared via ultrasonic spray pyrolysis. (2007).

50. Skrabalak, S. \& Suslick*, K. Porous MoS2 Synthesized by Ultrasonic Spray Pyrolysis. J. Am. Chem. Soc. (2005). doi:10.1021/ja051654g

51. Sahay, P. \& Nath, R. Al-doped ZnO thin films as methanol sensors. (2008).

52. Korotcenkov, G. \& Han, D. (Cu, Fe, Co, or Ni)-doped tin dioxide films deposited by spray pyrolysis: Doping influence on thermal stability of the film structure. (2009).

53. Ramírez-Cabrera, E., Atkinson, A. \& Chadwick, D. Reactivity of ceria, Gd- and Nbdoped ceria to methane. Applied Catalysis B: Environmental 36, 193206 (2002).

54. Haynes, D, Shekhawat, D, Berry, D \& Spivey, J. Characterization and activity study of the Rh-substituted pyrochlores for CO2 (dry) reforming of CH4. Applied Petrochemical ... (2013). at <http://link.springer.com/article/10.1007/s13203-013-0042-x>

55. Haynes, D., Campos, A., Smith, M. \& Berry, D. Reducing the deactivation of Ni-metal during the catalytic partial oxidation of a surrogate diesel fuel mixture. (2010).

56. Aruna, S. \& Mukasyan, A. Combustion synthesis and nanomaterials. Current Opinion in Solid State and Materials Science 12, 4450 (2008).

57. Shih, S., Tzeng, W. \& Kuo, W. Fabrication of ceria particles using glycine nitrate spray pyrolysis. (2014).

58. Hwang, CC, Tsai, JS \& Huang, TH. Combustion synthesis of Ni-Zn ferrite by using glycine and metal nitrates - investigations of precursor homogeneity, product reproducibility, and reaction mechanism. Materials Chemistry and Physics (2005). at <http://www.sciencedirect.com/science/article/pii/S025405840500180X>

59. Hwang, CC \& Wu, TY. Combustion synthesis of nanocrystalline $\mathrm{ZnO}$ powders using zinc nitrate and glycine as reactants-influence of reactant composition. Journal of materials science (2004). at <http://www.springerlink.com/index/t56w565533144257.pdf> 
60. Abdelsayed, V., Shekhawat, D., Poston, J. \& Spivey, J. Synthesis, characterization, and catalytic activity of Rh-based lanthanum zirconate pyrochlores for higher alcohol synthesis. (2013).

61. Cabana, J, Valdés-Solís, T \& Palacin, MR. Enhanced high rate performance of LiMn 2 O 4 spinel nanoparticles synthesized by a hard-template route. Journal of Power ... (2007). at <http://www.sciencedirect.com/science/article/pii/S0378775307002340>

62. Yu, M, Lin, J \& Fang, J. Silica spheres coated with YVO4: Eu3+ layers via sol-gel process: A simple method to obtain spherical core-shell phosphors. Chemistry of materials (2005). doi:10.1021/cm0479537

63. Mackenzie, JD \& Bescher, EP. Chemical routes in the synthesis of nanomaterials using the sol-gel process. Accounts of chemical research (2007). doi:10.1021/ar7000149 


\section{Appendix}

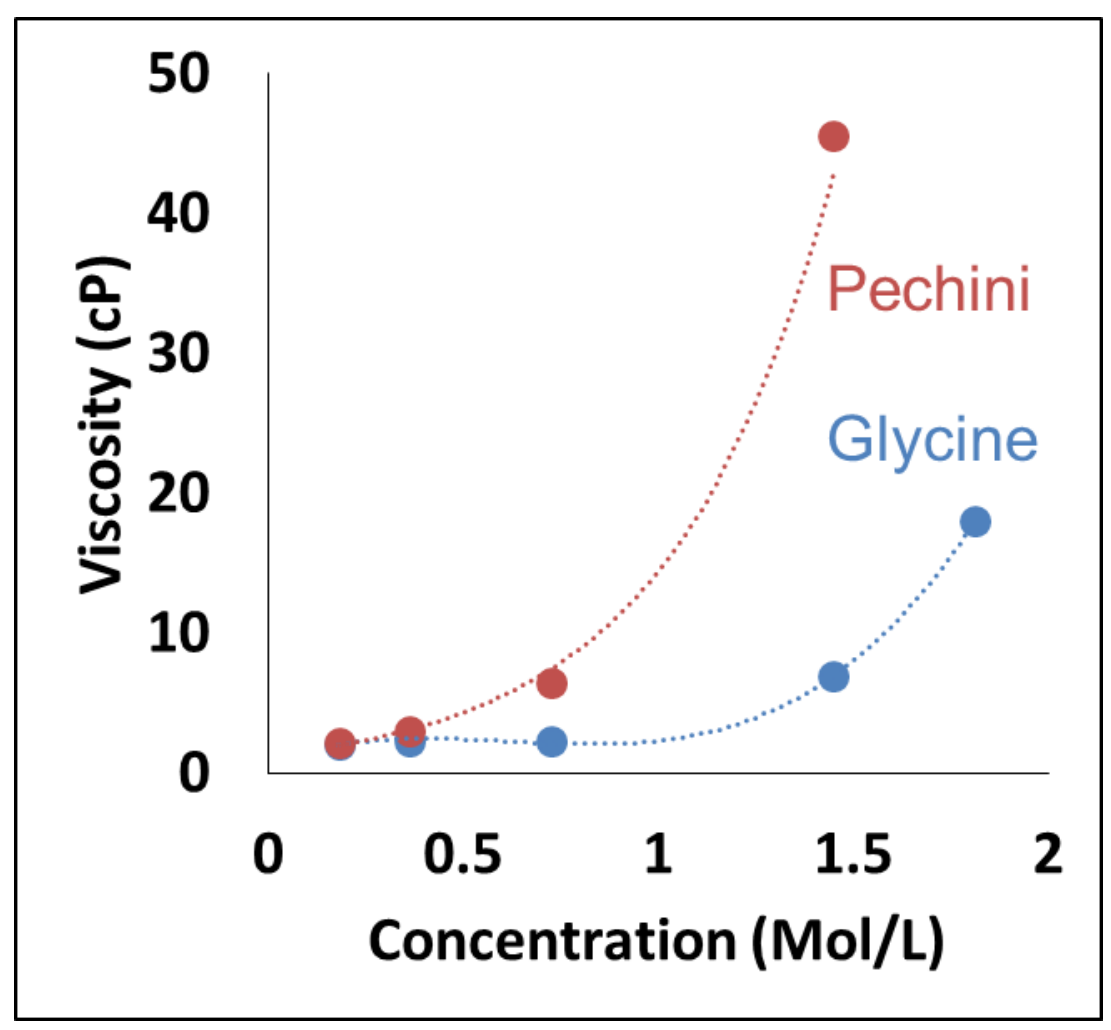

Figure A1: Viscosity of Pechini and GN precursors as a function of concentration 


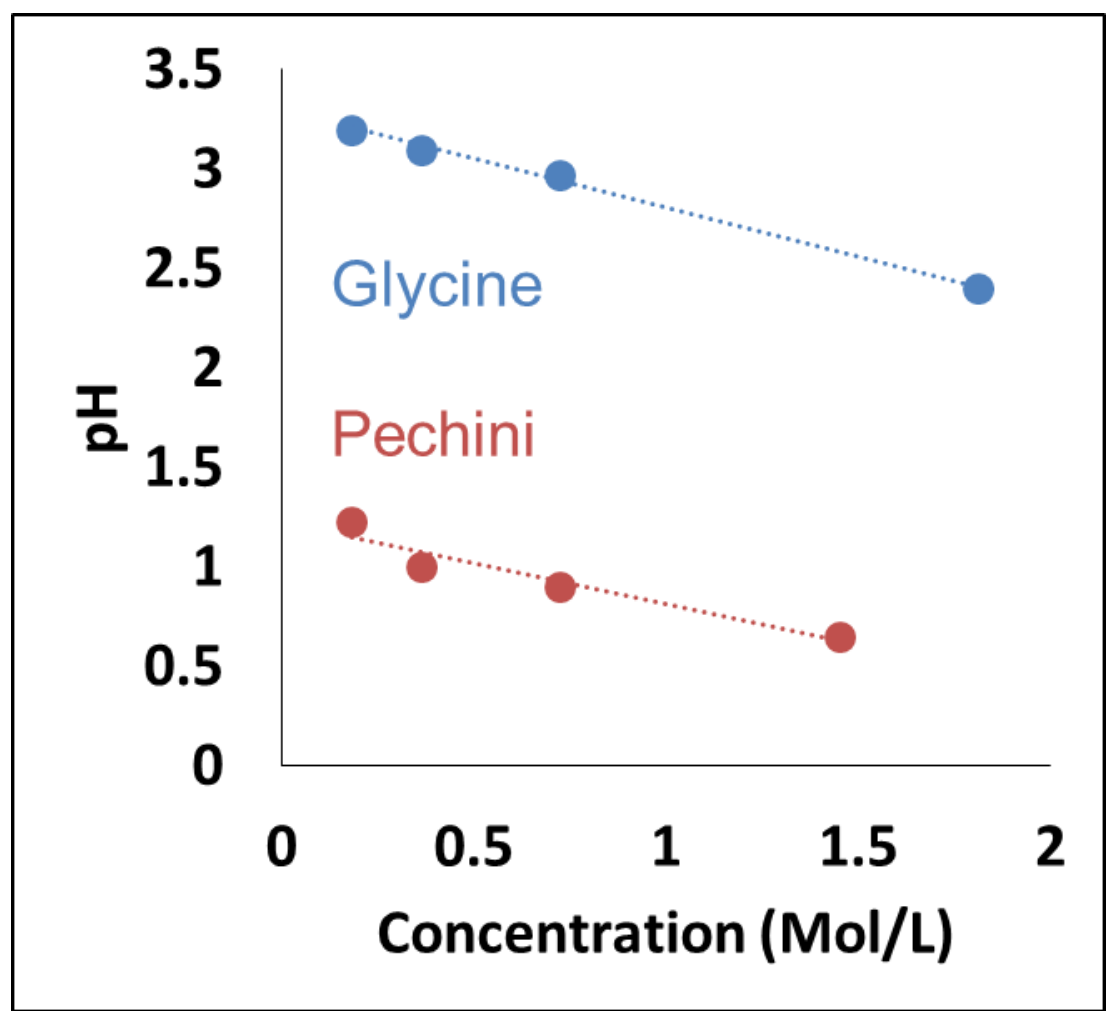

Figure A2: pH of Pechini and GN precursors as a function of concentration 


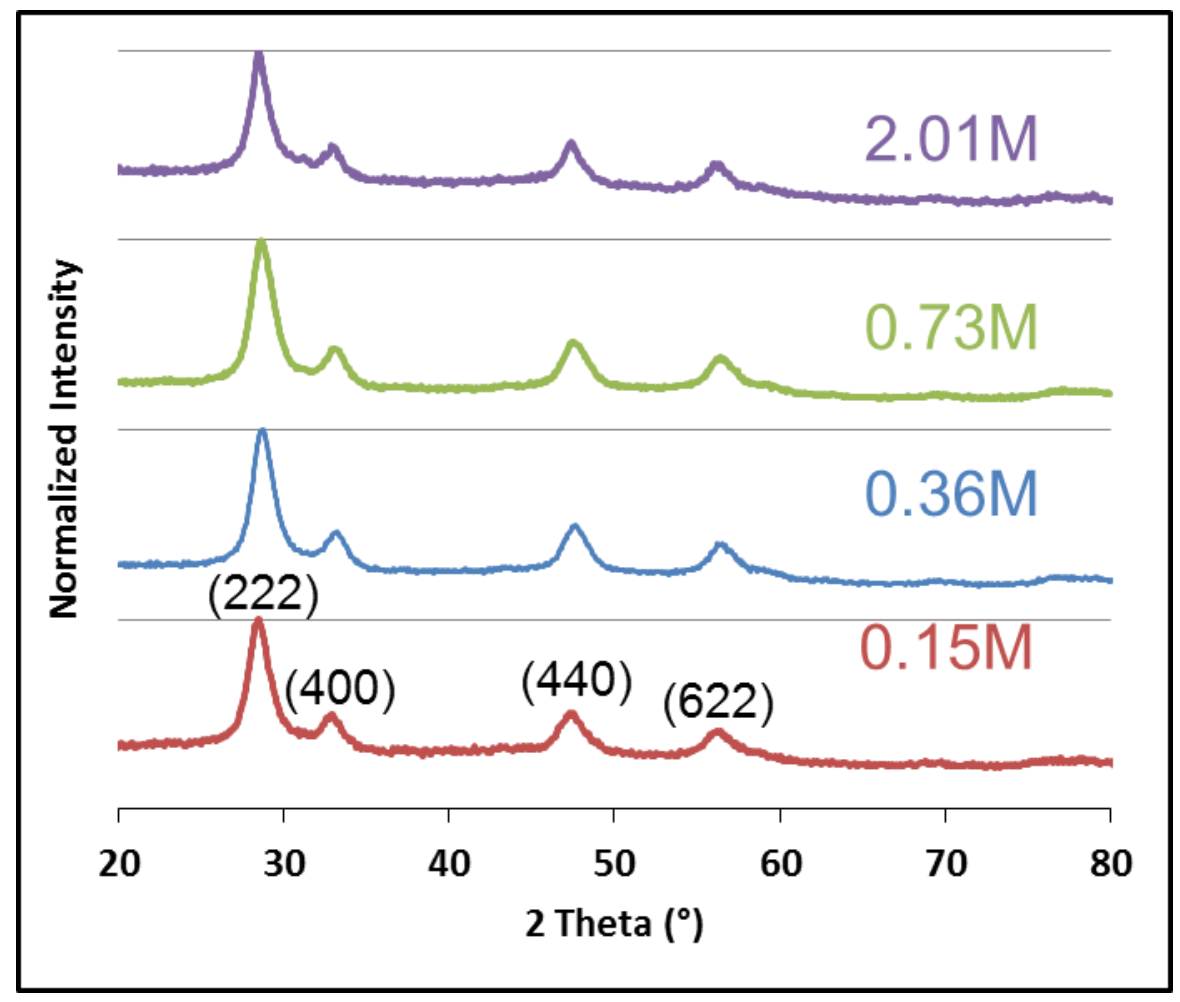

Figure A3: XRD spectra of $60 \mathrm{kHz}$ Pechini samples prepared at different concentrations, a 20 SCFH carrier gas flow rate, and without heat treatment. 

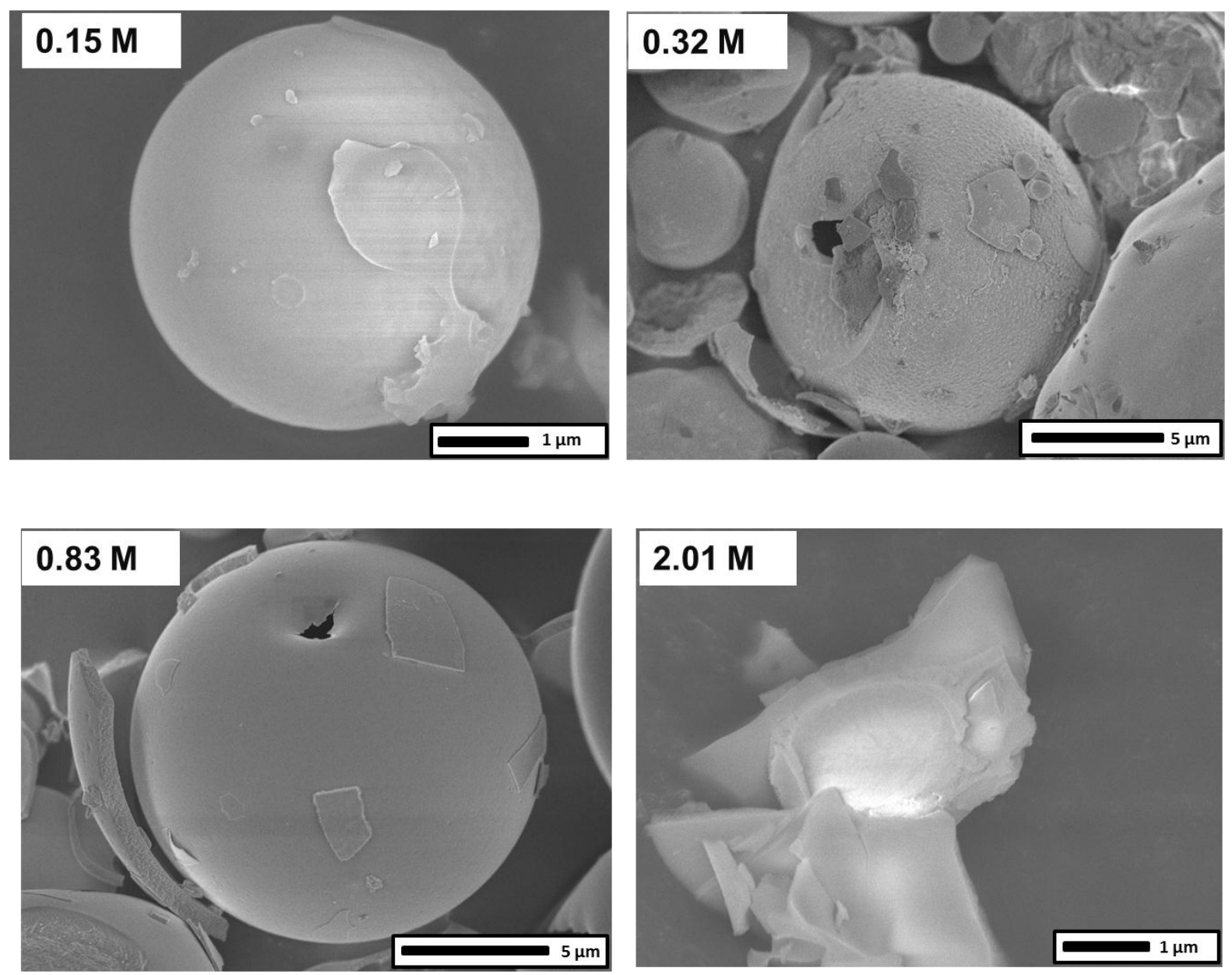

Figure A4: SEM images of Pechini samples prepared at $60 \mathrm{kHz}$ 